\title{
Evaluation of the Commercial FBR Introduction Date
}

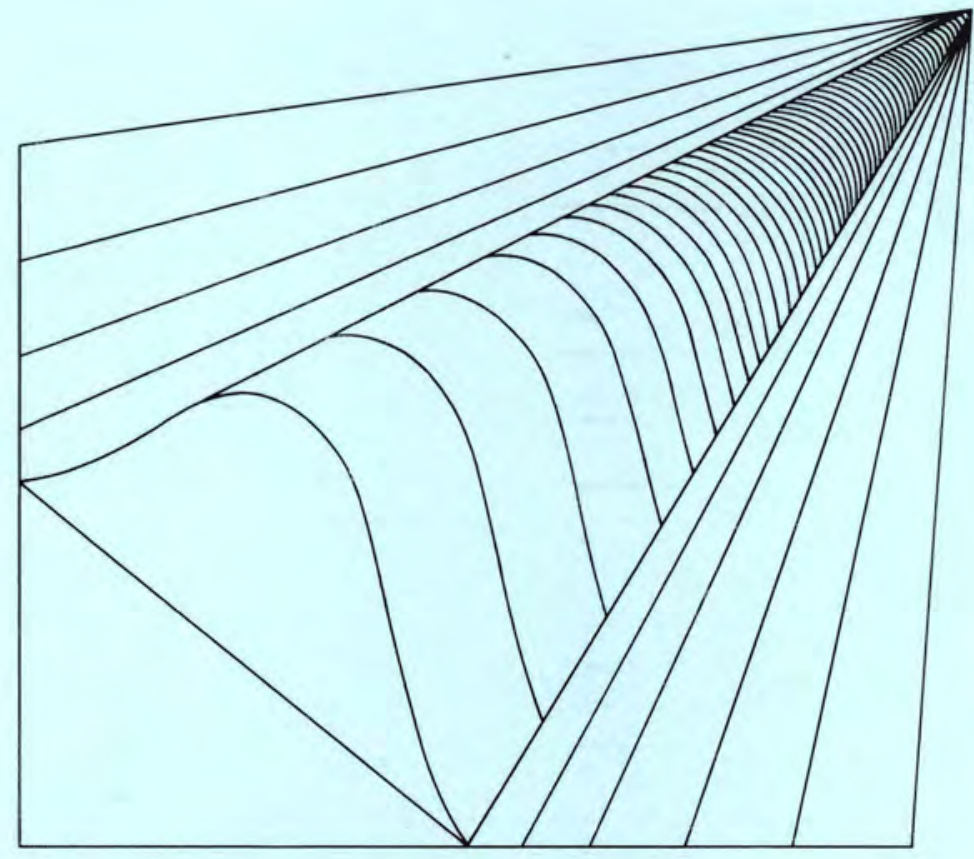

Prepared for the U.S. Department of Energy under Contract DE-AC06-76RLO 1830

Pacific Northwest Laboratory

Operated for the U.S. Department of Energy by Battelle Memorial Institute 
This report was prepared as an account of work sponsored by the United States Government. Neither the United States nor the Department of Energy, nor any of their employees, nor any of their contractors, subcontractors, or their employees. makes any warranty, express or implied, or assumes any legal liability or responsibility for the accuracy. completeness or usefulness of any information. apparatus. product or process disclosed, or represents that its use would not infringe privately owned rights.

The views. opinions and conclusions contained in this report are those of the contractor and do not necessarily represent those of the United States Government or the United States Department of Energy.

\author{
PACIFIC NORTHWEST LABORATORY \\ operated by \\ BATTELLE \\ for the \\ UNITED STATES DEPARTMENT OF ENERGY \\ Under Contract DE-AC06-76RLO 1830
}

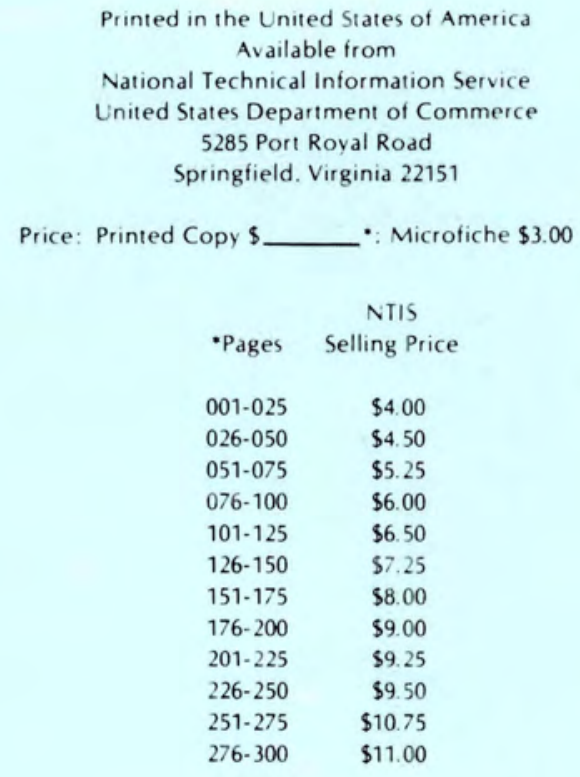


EVALUATION OF THE COMMERCIAL

FBR INTRODUCTION DATE

M. K. White

E. T. Merrill

September 1981

Prepared for

the U.S. Department of Energy under Contract DE-AC06-76RLO 1830

Pacific Northwest Laboratory

Richland, Washington 99352 



\section{SUMMARY}

There is considerable uncertainty in the major factors that influence the selection of an approach and the timing for developing Fast Breeder Reactor (FBR) technology. Because a reactor development program involves the construction of a sequence of large power plants over many years, the duration and cost of the program are highly uncertain. There is also considerable uncertainty in estimates of when FBR technology will be economically competitive with other central station power plant options. Because of these planning uncertainties, it is not possible to structure, with complete confidence, a development program that provides a mature technology exactly when economic forces establish market demand.

Despite these uncertainties, near-term decisions regarding the nature and pace of the FBR development program must be made. This report is part of a larger program which is designed to provide DOE with information that can be used to make strategic programmatic decisions. This report examines one criterion for introducing a commercial FBR: that is, economic competitiveness with a Light Water Reactor (LWR). For this analysis, the commercial FBR is assumed to be the fifth-of-a kind replicate resulting from one of the development strategies discussed in Characterization of Alternative FBR Development Strategies (Boegel and Clausen 1981). This reactor represents an economically mature plant, since many of the first-of-a-kind costs will have been incurred by earlier replicate plants. This FBR is deemed economically competitive when its life-cycle energy cost is less than or equal to that of an LWR. The FBR introduction date refers to the date that a fifth-of-a-kind replicate coming on-line meets this criterion.

The results of this analysis are used in a comparative analysis of alternative FBR development stategies in A Method of Selecting Fast Breeder Reactor Development Strategies in the Presence of Uncertainties (Fraley and Burnham 1981). The strategies evaluated in these studies assume both 1000and 1457-MWe FBRs. Since the capital costs per kilowatt, and therefore the energy costs, for these two FBR sizes are different, they will become economically competitive at different times. Key data for this analysis are probabilistic representations of nuclear growth capacity, uranium supply, and 
reactor capital cost. Other data have significantly less impact on the results. Nuclear capacity growth projections are developed in this report. Uranium supply and reactor captial cost data are documented in companion reports (Piepel et al. 1981; Boegel and Clausen 1981).

The key results of this analysis and much of the input data are expressed in terms of probability. The probability density function of FBR introduction dates expresses the probability that this criterion is first met in a specific year or interval. Figure 1 shows the probability density functions for the dates that the 1000- and 1457-MWe FBRs will become economically competitive with LWRs. The probability density function for the 1457-MWe FBR has an expected value date or weighted average date of 2030, compared with 2033 for the probability density function for the 1000-MWe FBR. This difference is due to the lower capital cost per kilowatt for the larger FBR. This figure illustrates the magnitude of uncertainty associated with the FBR's economically competitive date. Dates between 2022 and 2041 for the 1457-MWe FBR and dates between 2025 and 2047 for the 1000-MWe FBR are within the $90 \%$ confidence interval. This uncertainty confirms the desirability of using a probabilistic approach to describe the date that the FBR will become economically competitive. No single date adequately characterizes these results.

Intermediate results for calculating the probability density function for the FBR becoming commercially competitive are probabilistic projections of uranium's cost, LWR's energy cost, and FBR's energy cost. These results are reported. In addition, the sensitivity of the results to introduction of advanced isotope separation technology and advanced converter reactors is examined. Introduction of these technologies delays the date the FBR becomes economically competitive by 1 to 4 years. 


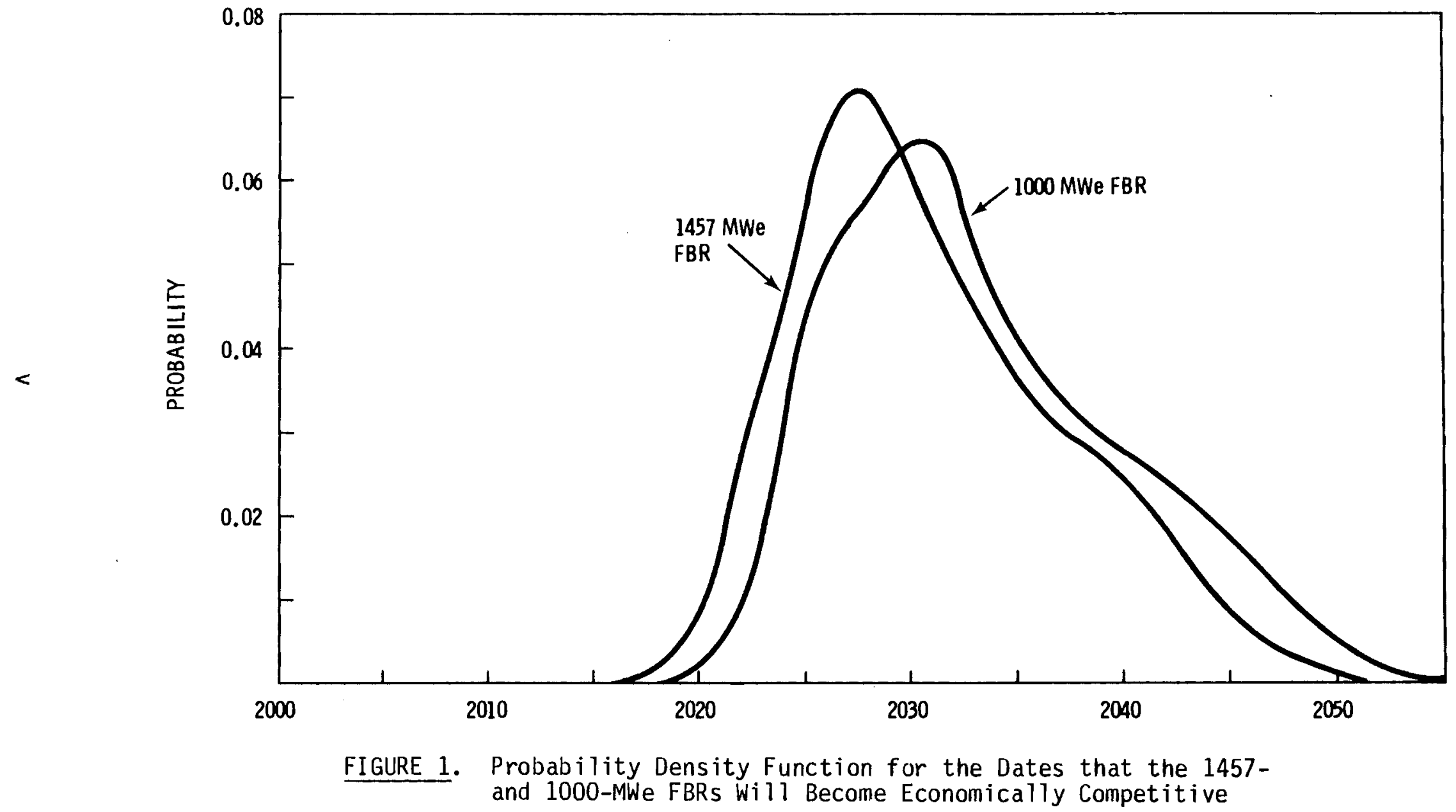



SUMMARY

1.0 INTRODUCTION

2.0 APPROACH .

3.0 INPUT DATA

3.1 URANIUM CONSUMPTION FOR A SPECIFIC URANIUM SUPPLY FUNCTION • 3.1

3.1.1 Nuclear Power Capacity Projections . • • • 3.1

3.1.2 Nuclear Reactor Uranium Requirements . • • • 3.3

3.1.3 Enrichment Tails Assay • • • • • • • • 3.5

3.2 PROBABILITY THAT FBR ENERGY IS LESS EXPENSIVE THAN
LWR ENERGY FOR A SELECTED URANIUM SUPPLY FUNCTION . . . $\quad 3.7$

3.2.1 Cost Data for Assumed Uranium Supplies • • • 3.7

3.2.2 Reactor Capital, Operating, and Fuel Cycle Cost Data . 3.8

3.3 DATA FOR COMBINING INTERIM RESULTS FOR THE THREE

URANIUM SUPPLY FUNCTIONS • $•$ •

4.0 RESULTS

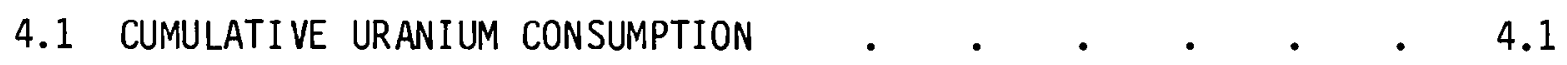

4.2 URANIUM COST

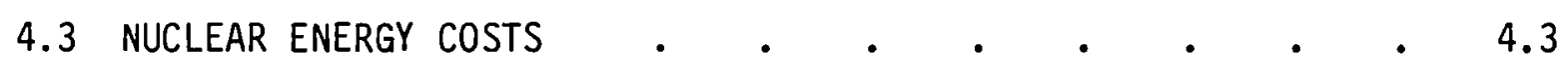

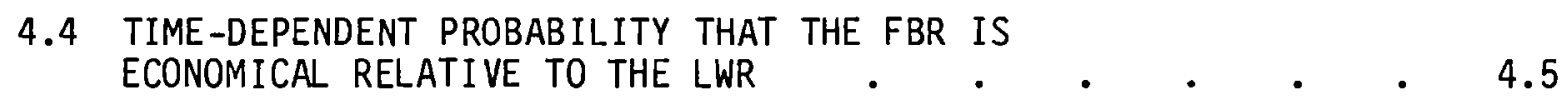

4.5 IMPACT OF ALTERNATIVE ASSUMPTIONS .

4.5.1 Synergistic Impact of FBR Introduction . • . 4.9

4.5.2 Impact of Advanced Converter Reactors and
Advanced Isotope Separation Technology . . . 4.11

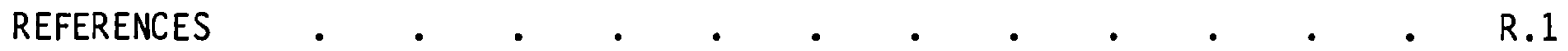




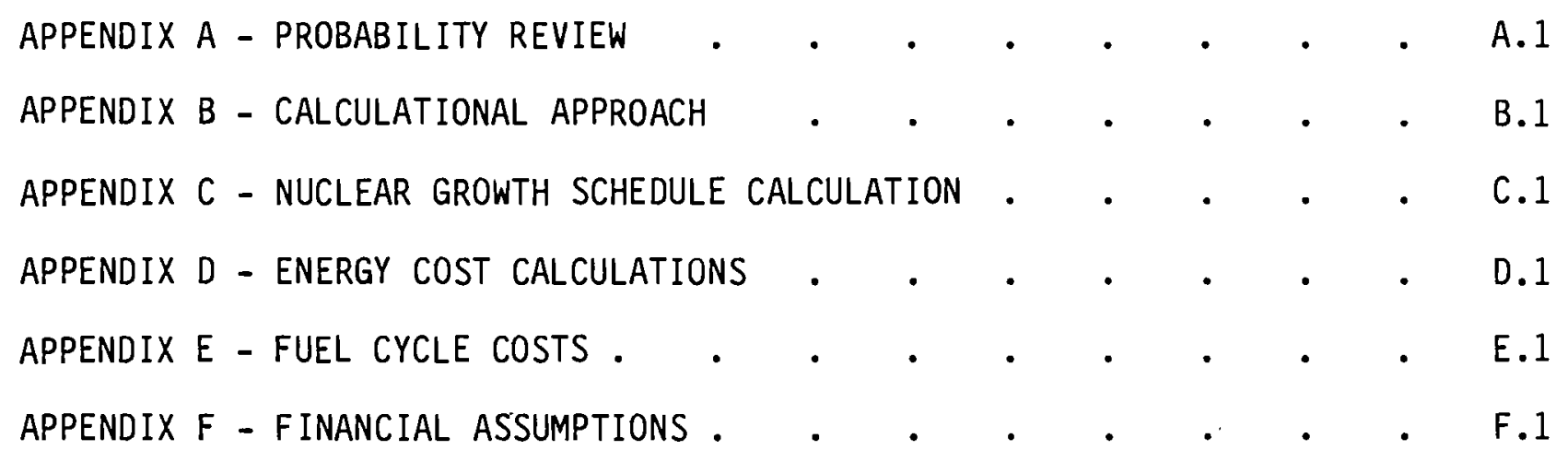


FIGURES

1 Probability Density Function for the Dates that the 1457 and 1000 MWe FBRs Will Become Economically Competitive . • v

2.1 Calculation of the Uranium Use Probability Data Base . . . 2.3

2.2 Calculation of the Time-Dependent Probability that the FBR Is Economic for the Assumed Uranium Supply . $\quad . \quad$. $\quad . \quad 2.4$

2.3 Combination of the Results for Individual Uranium Supply Functions into the Time-Dependent Probability of Meeting the FBR Introduction Criterion . • • • • • • 2.6

3.1 Uranium Supply Probability Density Function . . . . . . 3.2

3.2 Nuclear Power Capacity Projections for the Uranium Supply Function Representing the Low Quartile of the Domestic Uranium Supply Probability Density Function

3.3 Nuclear Power Capacity Projections for the Uranium Supply Function Representing the Middle Quartiles of the Domestic Uranium Supply Probability Density Function . . . • . 3.4

3.4 Nuclear Power Capacity Projections for the Uranium Supply Function Representing the Upper Quartile of the Domestic Uranium Supply Probability Density Function . . . . . 3.5

3.5 Uranium Supply and Cost Probability Data for the Lower Quartile of the Probability Density Function for the

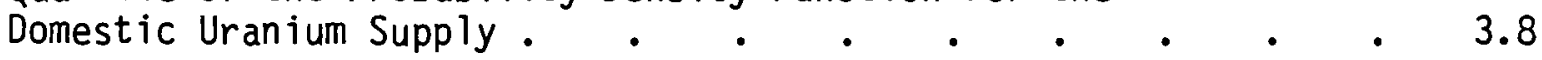

3.6 Uranium Supply and Cost Probability Data for the Middle Quartiles of the Probability Density Function for the Domestic Uranium Supply. . . . . . . . . 3.9

3.7 Uranium Supply and Cost Probability Data for the Upper Quartile of the Probability Density Function for the Domestic Uranium Supply.

3.8 Capital Cost Probability Density Functions for 1000-MWe and 1457-MWe FBRs and an LWR

4.1 Median and 90\% Confidence Interval for Projected Uranium Consumption (No FBR) .

4.2 Median and 90\% Confidence Interval for Projected Uranium Cost (No FBR) 
4.3 Energy Cost Probability Density Functions for LWR and

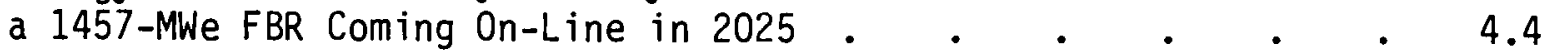

4.4 Energy Cost Probability Density Functions for LWR and

a 1457-MWe FBR Coming On-Line in 2035 .

4.5 Median and 90\% Confidence Interval for Life-Cycle Cost

that FBR Must Achieve To Be Economically Competitive

with an LWR

4.6 Median and 90\% Confidence Interval for FBR's

Life-Cycle Cost

4.7 Cumulative Probability that a 1000-MWe or a 1457-MWe FBR

Is Economically Competitive with an LWR

4.8 Probability Density Function for a 1000-MWe or a 1457-MWe

FBR Becoming Economically Competitive with an LWR

4.9 Probability that the Cost Penalty for an FBR Introduced at

Selected Dates Exceeds a Specified Cost

4.10 Impact of Synergisms Between FBR Deployment and LWR

Energy Cost on the Cumulative Probability that the

FBR Is Economically Competitive

4.11 Comparison of the Cumulative Probability that the FBR

Is Economically Competitive With an ACR and Without

an $A C R$

4.12 Comparison of the Cumulative Probability that the FBR

Is Economic With and Without AIST ..$\quad$. . . . 4.16

A.1 Frequency Histograms of Activity Completion for 50 Trials • • A.2

A.2 Probability Density Function for Activity Completion • • • • A.3

A.3 Cumulative Distribution Function for Completion Times . . . A.4

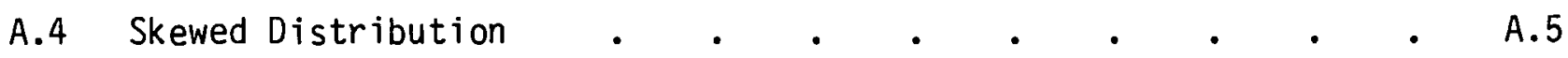

A.5 Confidence Interval 5 . 5 .

A.6 "One-Sided" Confidence Interval 6 .

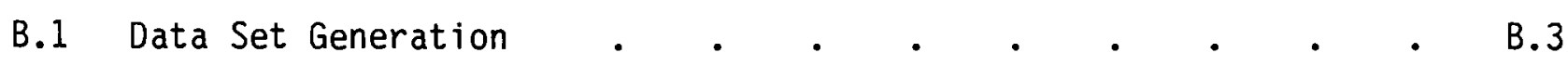

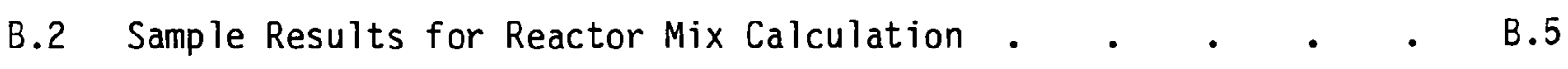

B.3 Cumulative Uranium Consumption Results . 
B.4 Transition From Initial to Lower Tails Assay . . . . . B.7

B.5 Initial Probability Calculation . . . . . . . . . . B.10

B.6 Criteria 1 Evaluation . . . . . . . . . . . . B.13

B.7 Criterial 2 and 3 Evaluation . . . . . . . . . B.15

C.1 Cumulative Probability that Elasticity of Substitution Is Greater Than e . • • . . . . . . . . C.4

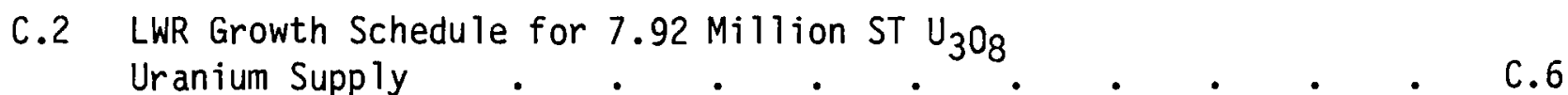

C.3 LWR Growth Schedule for 7.05 Million ST $U_{3} 0_{8}$

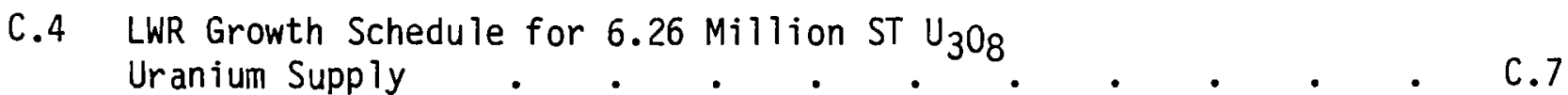

E.1 Probability Density Function for LWR Reprocessing . . . . E.6

E.2 Probability Density Function for FBR Reprocessing . . • . E.7 


\section{TABLES}

3.1 Uranium Supply Function Representing Selected Portions of the Total Domestic Uranium Supply Probability Density Function.

3.2 Reduction in $\mathrm{U}_{3} \mathrm{O}_{8}$ Requirement for Potential Retrofit Options in PWRs . . . . . . . . . . . . 3.6

3.3 Uranium Requirement ( $\mathrm{ST} \mathrm{U}_{308}$ ) per GW for the Reference and Improved PWR, 65\% Capacity Factor . . . . 3.6

3.4 Operation and Maintenance and Fuel Cycle cost Assumptions . . . . . . . . . . . . . 3.11

C.1 Comparison of Nuclear Growth Schedules . . . . . . . C.3

C.2 Supply of Uranium at Selected Costs for Assumed

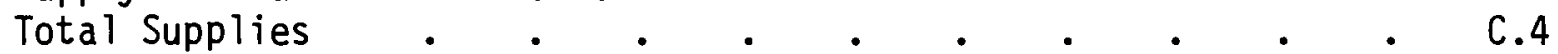

C.3 Summary of Results of ETA-MACRO Calculations . . . . . C.5

D.1 Parameters for Reactor Capital Cost Levelization

Calculation . . • • • • . . . . . D.3

D.2 Fixed Charge Rate . . . . . . . . . . . . . 0.3

D.3 PWR Fuel Management Parameters . . . . . . . . . 0.6

D.4 Expenses and Depreciation Per MW for the First PWR Core • • D.7

D.5 Expenses and Depreciation Per MW for PWR Equilibrium Reload N . • . . . . . . . . . . . 0.8

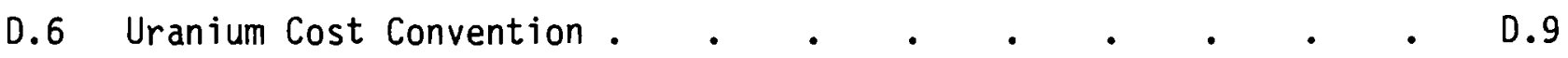

D.7 FBR Fuel Mass Flows . . . . . . . . . . . . D.10

D.8 Plutonium Isotopic Composition . . . . . . . . . D.11

D.9 Expenses, Credits, and Depreciation Per MW for Initial FBR Core and Blankets. . . . . . . . . . D.12

D.10 Expenses, Credits, and Depreciation Per MW for the FBR's
Equilibrium Reload $\mathrm{N}$. . . . . . . . . D.13

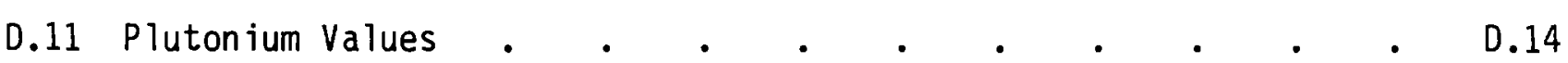

D.12 Composition of LWR Spent Fuel Discharge from the Improved
LWR Per kg Heavy Metal Charged . . . . . D.15 


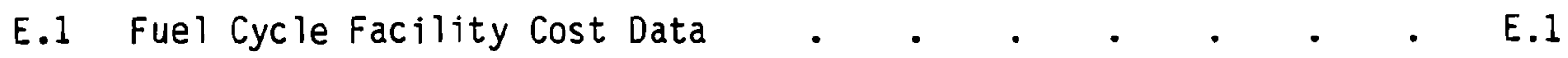

E.2 Fuel Transportation Costs . . . . . . . . . E.2

E.3 Parameters Used to Calculate Fuel Cycle Unit Costs . . . E.3

E.4 Commercial Fuel Cycle Service Unit Costs . . . . . . E.6

E.5 AFCEP Repository Data . . . . . . . . . . . . . . E.8

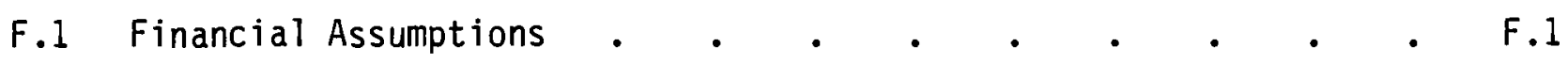

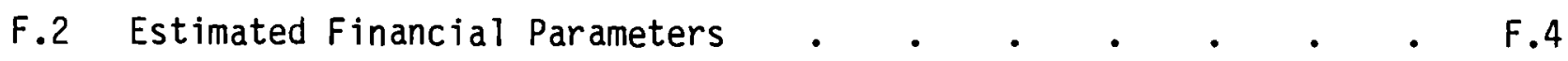

F.3 Utility Financial Parameters Used in Other Analyses . . . F F.5

F.4 NASAP Financial Parameters .

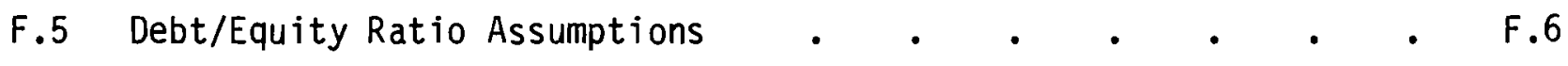





\subsection{INTRODUCTION}

This report is part of a series of analyses evaluating alternative strategies for developing the fast breeder reactor (FBR). These analyses are summarized in Analyses of Alternative FBR Development Strategies (Burnham et al. 1981). Two other reports in that series provide additional details about data used in this report. Probabilistic Estimates of U.S. Uranium Supply (Piepe) et al. 1981) describes the derivation of the probabilistic uranium supply and cost data used in this report. Characterization of Alternative FBR Development Strategies (Boegel and Clausen 1981) is the source of LWR and FBR reactor cost data for this analysis. The results of this report are used as input for developing decision information in A Method for Selecting FBR Development Strategies in the Presence of Uncertainties (Fraley and Burnham 1981).

The commercial introduction date is of fundamental importance in the selection of a strategy to develop an FBR. For purposes of this study, it is assumed that the FBR will be commercially introduced in the U.S. when it is economically competitive with the light water reactor (LWR). A relatively early introduction date could dictate a development strategy that proceeds rapidly through the developmental and prototypical plant stages. Later introduction would allow for a more deliberate developmental program, with little or no overlap between successive stages. Determining economic competitiveness is a complex process and requires the prediction of such factors as nuclear capacity growth, uranium cost, implementation of technology improvements, and ultimate FBR cost. This report analyzes the relationship between these factors and the commercial introduction date.

Because all the factors have a broad range of potential values, it is misleading to predict a single date when the FBR will be economically competitive. Therefore, both the critical factors and the date that an FBR will be commercially competitive are expressed in terms of time-dependent probabilities rather than as single values. By expressing the analytical results in probabilistic terms, the relative likelihood of various FBR introduction dates can be estimated. To decision-makers, this approach is more useful than the 
traditional approach of selecting individual values for key variables to calculate a single introduction date. In the traditional approach, even if the values are selected parametrically to generate a matrix of FBR introduction dates, no insight is provided into the relative merit of one date versus another. Therefore, the individual decision-maker may select, with some justification, the combination of factors that supports his point of view. The treatment of input data and expression of resulting dates in terms of probabilities tends to overcome this limitation of parametric analyses. Appendix A reviews the use of probability functions and the terminology used to characterize probability functions.

The report is organized into three major sections. It first (Chapter 2) describes the criterion of economic competitiveness used to determine the commercial introduction date for the FBR, and the methodology used to calculate the time-dependent probability of satisfying that criterion. It then (Chapter 3) describes the data used in that calculation, and the results (Chapter 4) of the calculations. Details of the input data and calculations are found in Appendices B through $F$. 


\subsection{APPROACH}

The criterion for introducing a commercial FBR is assumed to be economic competitiveness with the LWR. For the purpose of this report, and for consistency with the companion reports, the FBR introduction date refers to the date the reactor achieves full power. Therefore, the criterion for FBR introduction is energy cost less than or equal to that of an LWR coming on-line the same year. Economic competitiveness with the LWR is not the only possible criterion for introducing the FBR; for example, uranium limitations and societal benefit are other possible criteria. The former criterion suggests that the FBR should be introduced as a last resort, only when uranium limitations allow no more LWRs to be fueled. The latter, societal benefit, is usually expressed in terms of discounted (present worth) savings or cost of introducing the FBR into the energy economy at various future dates. In such an analysis, the FBR displaces the most expensive energy sources (coal, oil, solar, etc.) used for generating electricity. Since the FBR generates excess fuel, which allows additional FBRs to be fueled later, and displaces future expensive sources of energy, early FBR introduction may be beneficial even if its energy cost at the time it is introduced exceeds that of energy from the sources it displaces.

Satisfying the uranium limitation criterion implies that individual utilities would delay introducing an economically competitive FBR. This means voluntarily incurring an energy cost penalty for their rate payers. The societal benefit criterion can be satisfied only if some utilities introduce the FBR before it is economically advantageous to their current rate payers in order to decrease the future energy cost. Again, a voluntary cost penalty is incurred by a utility to the detriment of its current rate payers. Neither of these alternatives to the selected criterion reflects utilities' current decision-making practices.

The acquisition of any type of nuclear generating capacity entails unique regulatory and institutional constraints. Therefore, a utility generally will order a nuclear unit only if the nuclear option shows economic advantages relative to other power generating options. The decision to order an FBR will 
thus be based on a comparison with other nuclear options rather than on a comparison with all available power generation options. The criterion that the FBR be economically competitive with an LWR is an appropriate model of the utilities' decision-making process.

Comparing the future cost of energy from LWRs and FBRs requires projecting the capital, operating, fuel, and fuel cycle costs for these reactors. The capital, operating, and fuel cycle costs are reasonably well known for an LWR. However, the future cost of uranium is not so well known because of uncertainty in both the supply of uranium and the interaction between supply and demand. Uncertainties exist for the FBR's capital, fuel, and fuel cycle costs because neither a large commercial FBR nor commercial sized fuel cycle facilities have ever been constructed or operated in the U.S. These uncertainties are expressed probabilistically in our analysis.

Determining when the FBR will be competitive is a three step process. The first step requires projecting the future rate of uranium consumption for each of three estimates of the total domestic uranium supply. The steps of this calculation are depicted in Figure 2.1. A set of nuclear power capacity projections and their relative probabilities are calculated for each uranium supply estimate using an econometric simulation model, ETA MACRO. This model is described in detail by Manne (1977). Important factors in the calculation of nuclear power capacity projections include the relative costs of LWR energy and energy from other sources, economic growth, and the relationship between economic growth and energy demand. This calculation is described in Appendix $C$. The alternative nuclear power capacity projections are then combined with assumptions about LWR uranium use, introduction of advanced (non-FBR) reactors, and reduction of the enrichment tails assay. These assumptions are also expressed probabilistically. Probabilities for alternative assumptions for these factors are combined to yield probability density functions for future uranium consumption. These calculations are shown in Appendix $B$.

The second step in the process is to compare life-cycle energy costs of future LWRs and FBRs for each selected uranium supply estimate (Figure 2.2). The uranium consumption probability functions from the first step are combined 


\section{CALCULATION OF THE URANIUM USE PROBABILITY DATA BASE}

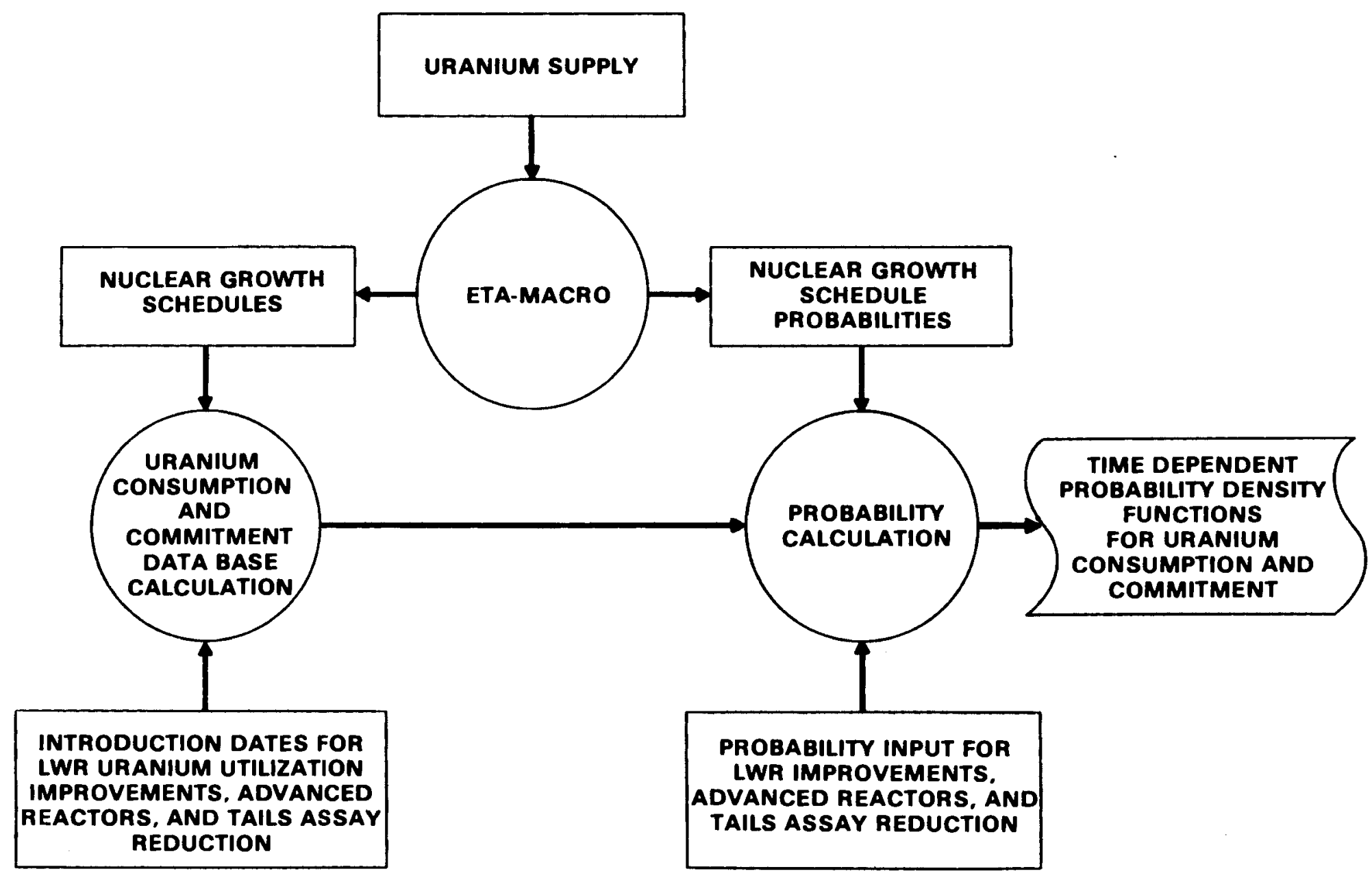

FIGURE 2.1. Calculation of the Uranium Use Probability Data Base 


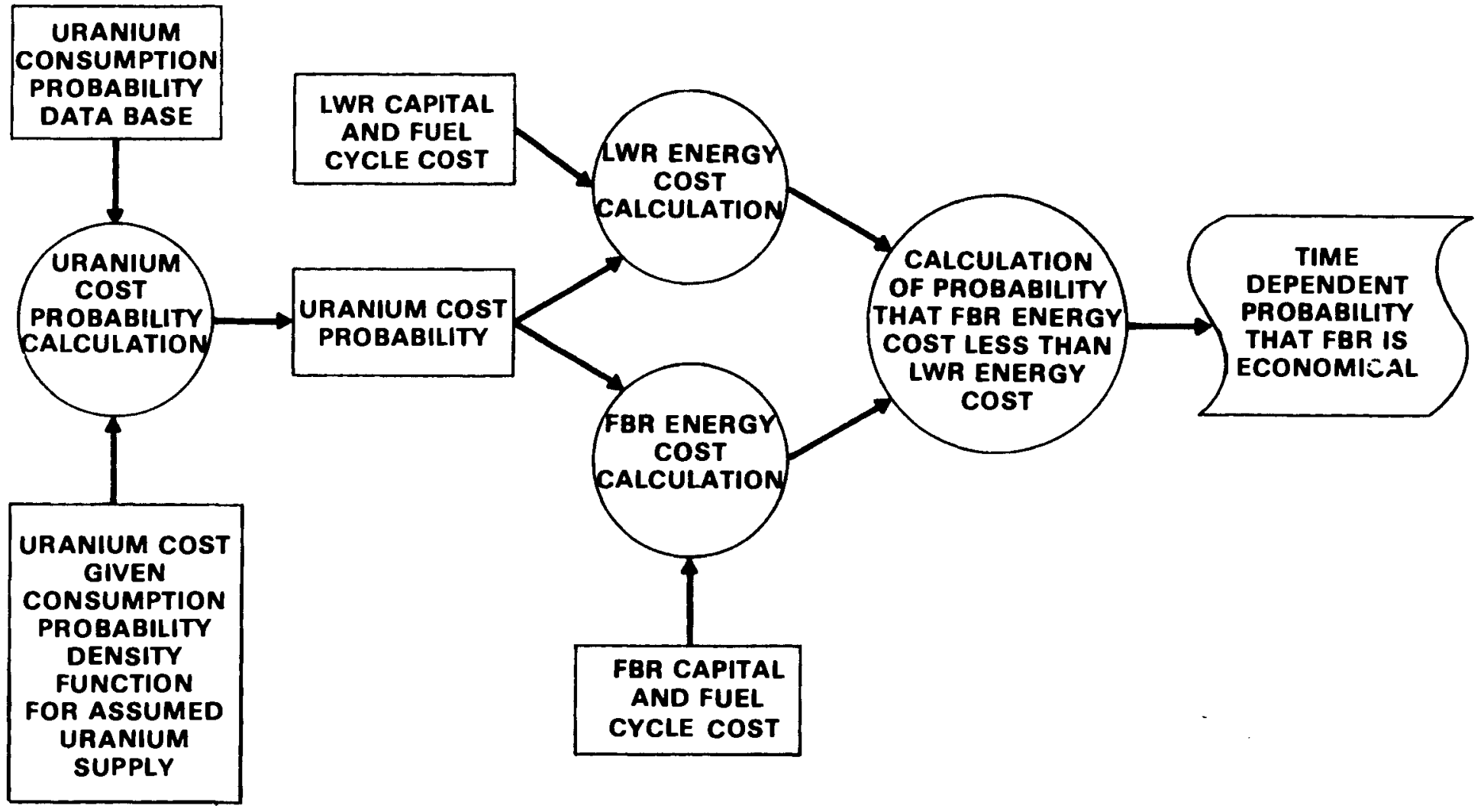

FIGURE 2.2. Calculation of the Time-Dependent Probability that the FBR is Economic for the Assumed Uranium Supply 
with data reflecting the probable cost of uranium as a function of consumption to yield time-dependent uranium cost probabilities. The uranium cost probability functions are also a factor in FBR energy cost, since plutonium value is related to uranium cost. The future uranium cost probability functions are combined with estimates of capital, operating, and fuel cycle costs for LWRs and FBRs. The capital costs of the LWR and FBR and the FBR's fuel cycle costs are expressed in terms of probability. The resulting time dependent LWR and FBR energy costs are then compared to determine the probability that the FBR has a lower life-cycle energy cost. Repeating this calculation for various future dates results in the time-dependent cumulative probability of meeting the criterion for FBR introduction for the assumed uranium supply. This calculation is discussed in detail in Appendix B.

The first two steps of the process are repeated for each assumed uranium supply estimate. The third step of the process is to combine these results. They are combined, or weighted, based on the relative probabilities of the assumed uranium supplies to yield the time-dependent probability that the FBR will become economically competitive. The results depend on which uranium supply function was used in steps 1 and 2. This part of the calculation is illustrated in Figure 2.3. The resultant time-dependent probability is discussed in Chapter 4.

This output is used in a probabilistic analysis for selecting an FBR development strategy (Fraley and Burnham 1981). That analysis compares strategy completion dates with the date the FBR is commercially competitive. Thus, the commercial introduction date described above corresponds to the required completion date for the FBR development strategies.

The methodology and data used for this calculation may also be used to determine the relative impact of other nuclear energy development programs. For example, the impact on the analysis' results of introducing an advanced converter reactor or improved isotope separation technology is evaluated (Appendix F). The potential impact of these technologies on the date the FBR becomes competitive is a factor in evaluating those technologies' development schedules and costs. 


\section{COMBINATION OF THE URANIUM SUPPLY DEPENDENT RESULTS INTO THE TIME DEPENDENT PROBABILITY OF MEETING THE FBR INTRODUCTION CRITERION}

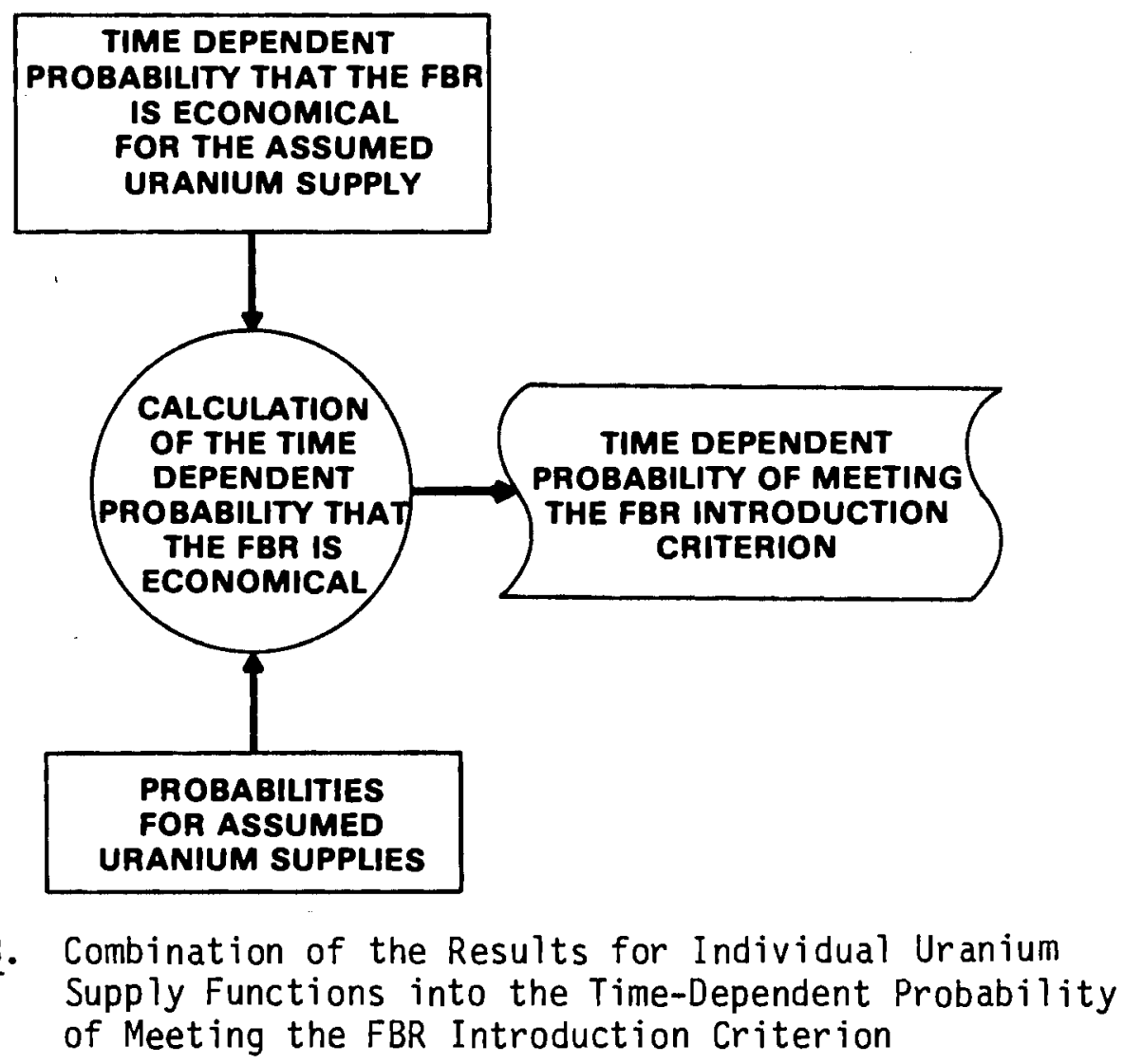




\subsection{INPUT DATA}

This section summarizes and presents the analys is' important data in terms of the three steps of the calculation described in Chapter 2. Additional information and derivations are contained in Appendices $C$ through $F$.

\subsection{URANIUM CONSUMPTION FOR A SPECIFIC URANIUM SUPPLY FUNCTION}

The conceptual flow of information for this calculation is shown in Figure 2.1. The required data are divisible into major categories of nuclear power capacity projections, reactor uranium requirements, and enrichment tails assay. These are discussed individually below.

\subsubsection{Nuclear Power Capacity Projections}

Nuclear power capacity projections for three uranium supply functions were calculated using the econometric simulation model, ETA-MACRO. The three uranium supply functions are shown in Table 3.1. These supply functions represent the lower quartile, middle two quartiles, and upper quartile of the probability density function for the total domestic uranium supply, as shown on Figure 3.1. The three uranium supply functions correspond to the weighted average or expected values of the respective ranges of the uranium supply probability density functions. The uranium data are developed in a companion report (Piepel et al. 1981). It is important to note that this analys is bases future uranium cost on the domestic rate of consumption of the domestic

TABLE 3.1. Uranium Supply Function Representing Selected Portions of the

Total Domestic Uranium Supply Probability Density Function

Portion

of Total Supply

(Million ST $\left.\mathrm{U}_{3} \mathrm{O}_{8}\right)$

Lower Quartile

Middle Quartiles

Upper Quartile

Cost $(\$ / 1 \mathrm{~b}, \$ 1980)$

\begin{tabular}{|c|c|c|c|c|c|c|c|}
\hline$\$ 50$ & $\$ 70$ & $\$ 100$ & $\$ 150$ & $\$ 200$ & $\$ 250$ & $\$ 350$ & $\$ 500$ \\
\hline 89 & 3.09 & 4.37 & 5.41 & 5.73 & 5.88 & 6.05 & 6.2 \\
\hline 16 & 3.49 & 4.91 & 6.11 & 6.49 & 6.66 & 6.84 & 7.05 \\
\hline & 3.82 & 5.47 & .86 & 7.31 & 7.53 & 7.71 & \\
\hline
\end{tabular}




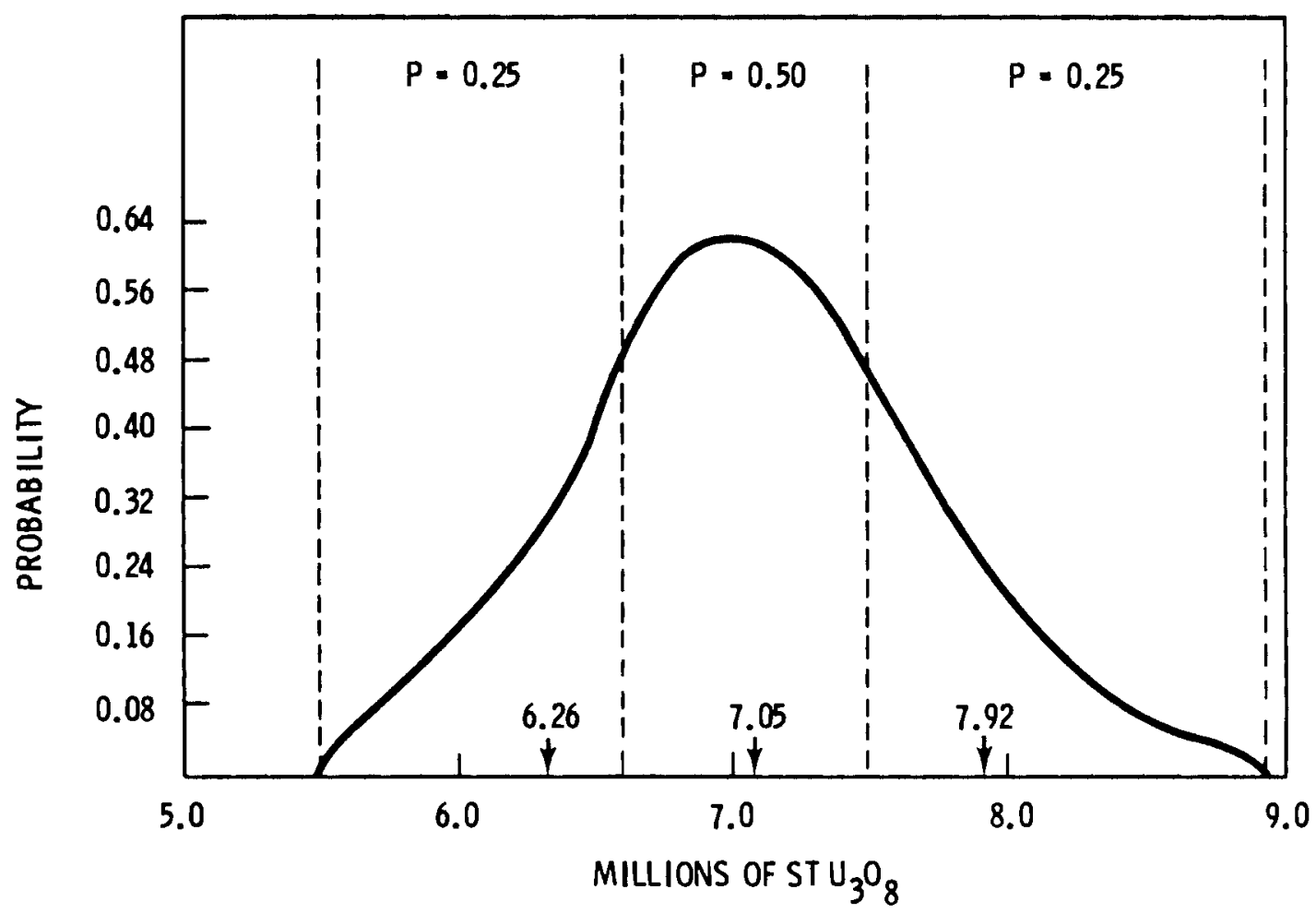

FIGURE 3.1. Uranium Supply Probability Density Function

uranium supply. This corresponds to no net import or export of uranium. Import of inexpensive uranium would delay the date that FBR would become competitive with the LWR. Export of domestic uranium would make the FBR competitive sooner.

Two types of data were input to ETA-MACRO to project future nuclear power generation capacity: 1) cost data for nuclear energy and alternative energy sources (coal, oil, etc), and 2) the econometric relationship between economic growth and the impacts of energy, labor, and capital on the economy. The relationship between economic growth and these three factors is expressed as the elasticity of substitution ( ), which specifies how well energy can be substituted for other inputs to the economy. This is defined as the change in total energy demand with a change in the cost of energy relative to capital and labor. Four equally probable elasticities of substitution were used to calculate four projections of nuclear power capacity for each uranium supply function. The elasticity of substitution data were derived from data collected by a survey of members of the Energy Modeling Forum (EMF), an organization created by the Electric Power Research Institute (EPRI) to 
improve practical applications of energy models to policy issues and planning. The growth projections and the elasticities of substitution are discussed in more detail in Appendix $C$. The calculated nuclear power capacity projections are shown on Figures 3.2, 3.3, and 3.4. The four projections on each figure have equal probability.

\subsubsection{Nuclear Reactor Uranium Requirements}

A current design for a PWR with a once-through (OT) fuel cycle was selected as the reference LWR. These reactors are typically refueled annually and achieve a fuel exposure of about 30,000 MWd/MT. Several retrofit options for these reactors are currently being investigated to decrease uranium requirements. Table 3.2 lists some of these improvements and the range of uranium savings that may be achieved. The data in the table are from the Report of the Nonproliferation Alternative Systems Assessment Program (DOE 1980).

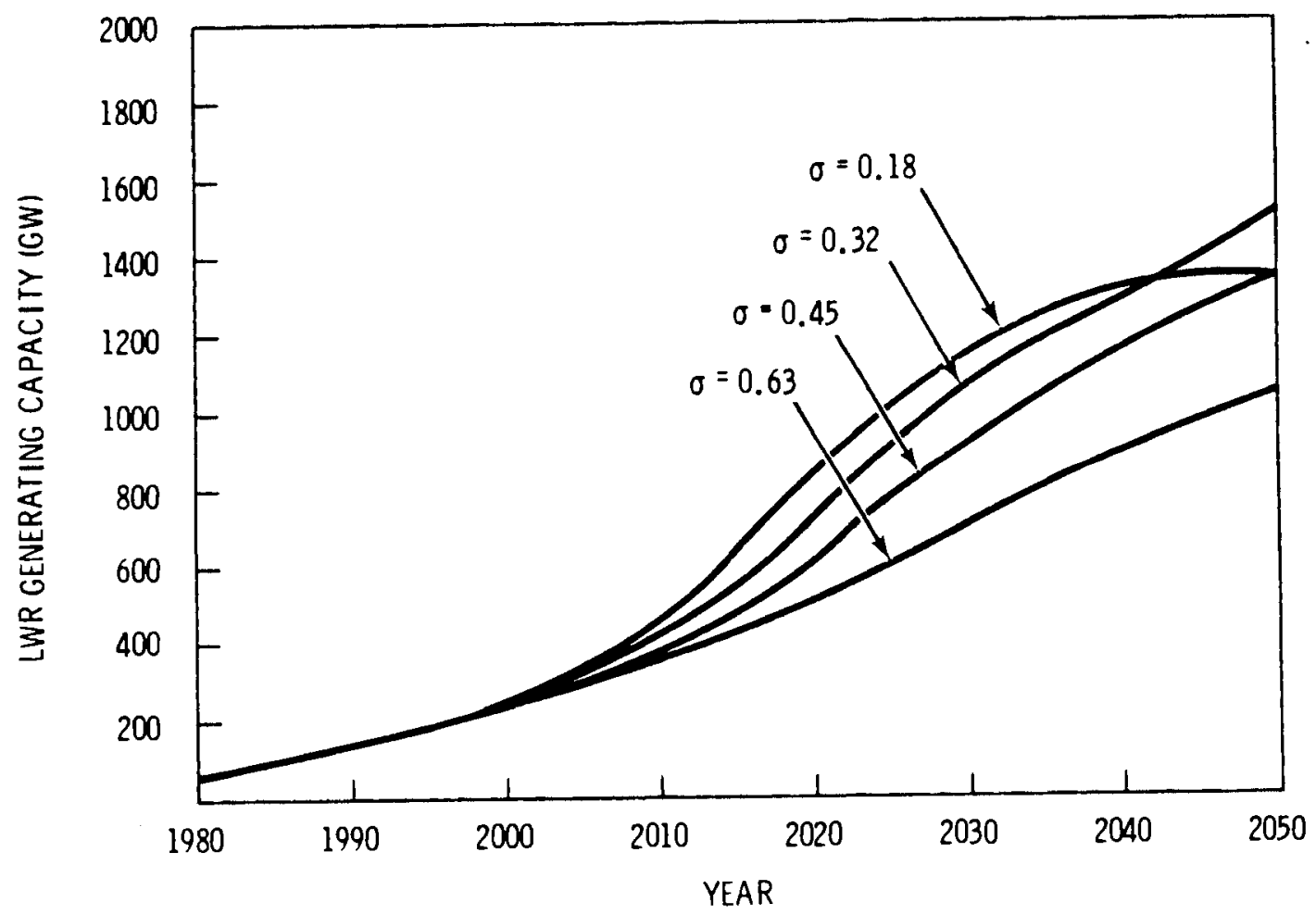

FIGURE 3.2. Nuclear Power Capacity Projections for the Uranium Supply Function Representing the Low Quartile of the Domestic Uranium Supply Probability Density Function 


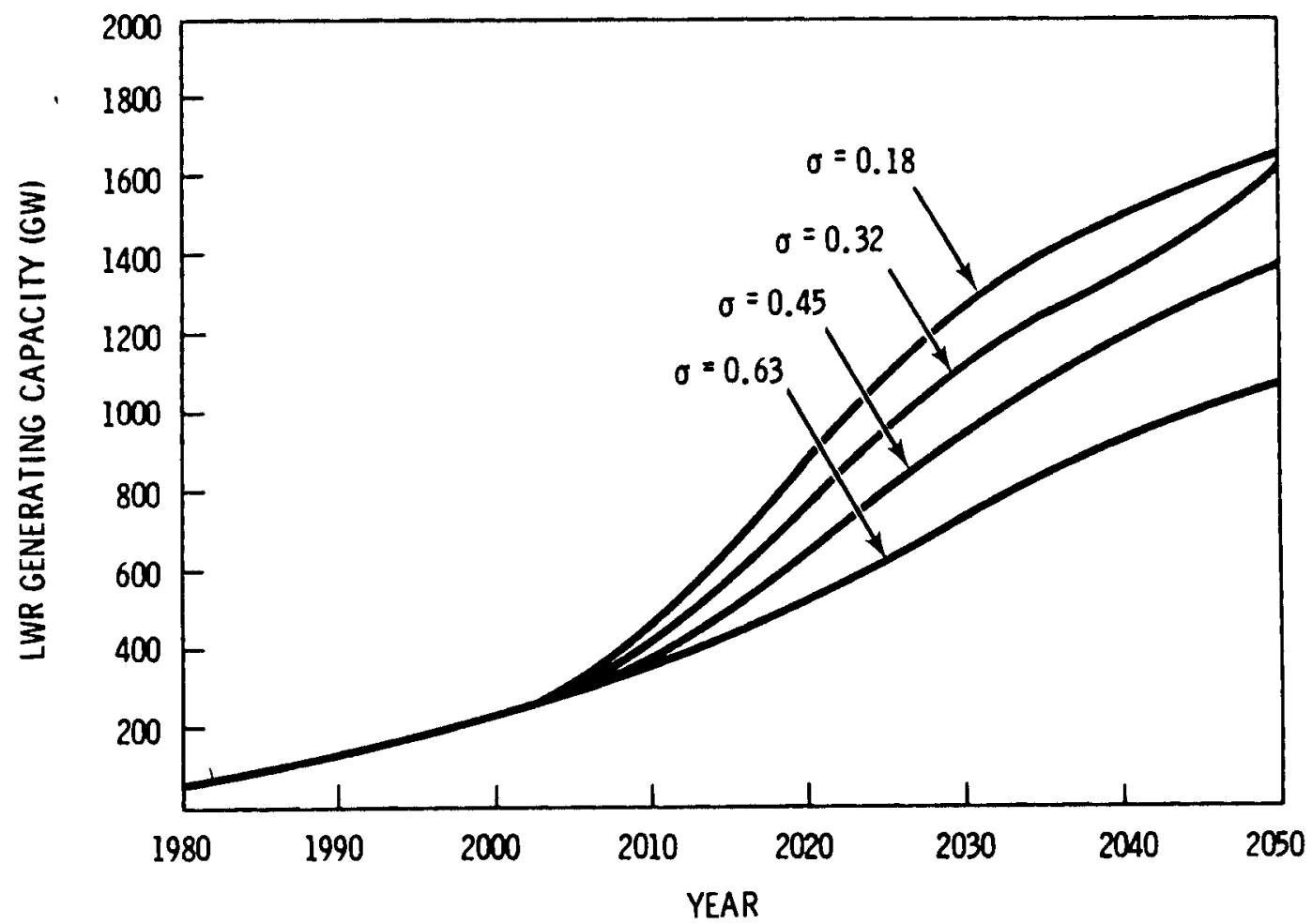

FIGURE 3.3. Nuclear Power Capacity Projections for the Uranium Supply Function Representing the Miadle Quartiles of the Domestic Uranium Supply Probability Density Function

The reference and improved PWR description in Uranium Resource

Utilization Improvements in the Once-Through PWR Fuel Cycle (Matzie 1980) was used for this analysis. The Matzie report describes uranium requirements for a reference PWR and a PWR incorporating extended burnup, low leakage fuel management, modified lattice design, and end-of-cycle coastdown. Uranium requirements for both PWRs were based on a $75 \%$ capacity factor, $0.2 \%$ enrichment tails assay, and annual refueling. These were modified for this report to reflect a $65 \%$ capacity factor for both $0.1 \%$ and $0.2 \%$ enrichment tails assay. Fuel requirements for refueling every 18-months rather than annually were estimated based on the fuel savings shown in Table 3.2. The calculated uranium requirements for the reference and improved PWR are shown in Table 3.3.

Transition from the current PWR fuel cycle to an improved fuel cycle was assumed to occur at a uniform rate between 1988 and 2000. The 12-month and 18 -month fuel cycles were assigned equal probabilities (50\%), since the 


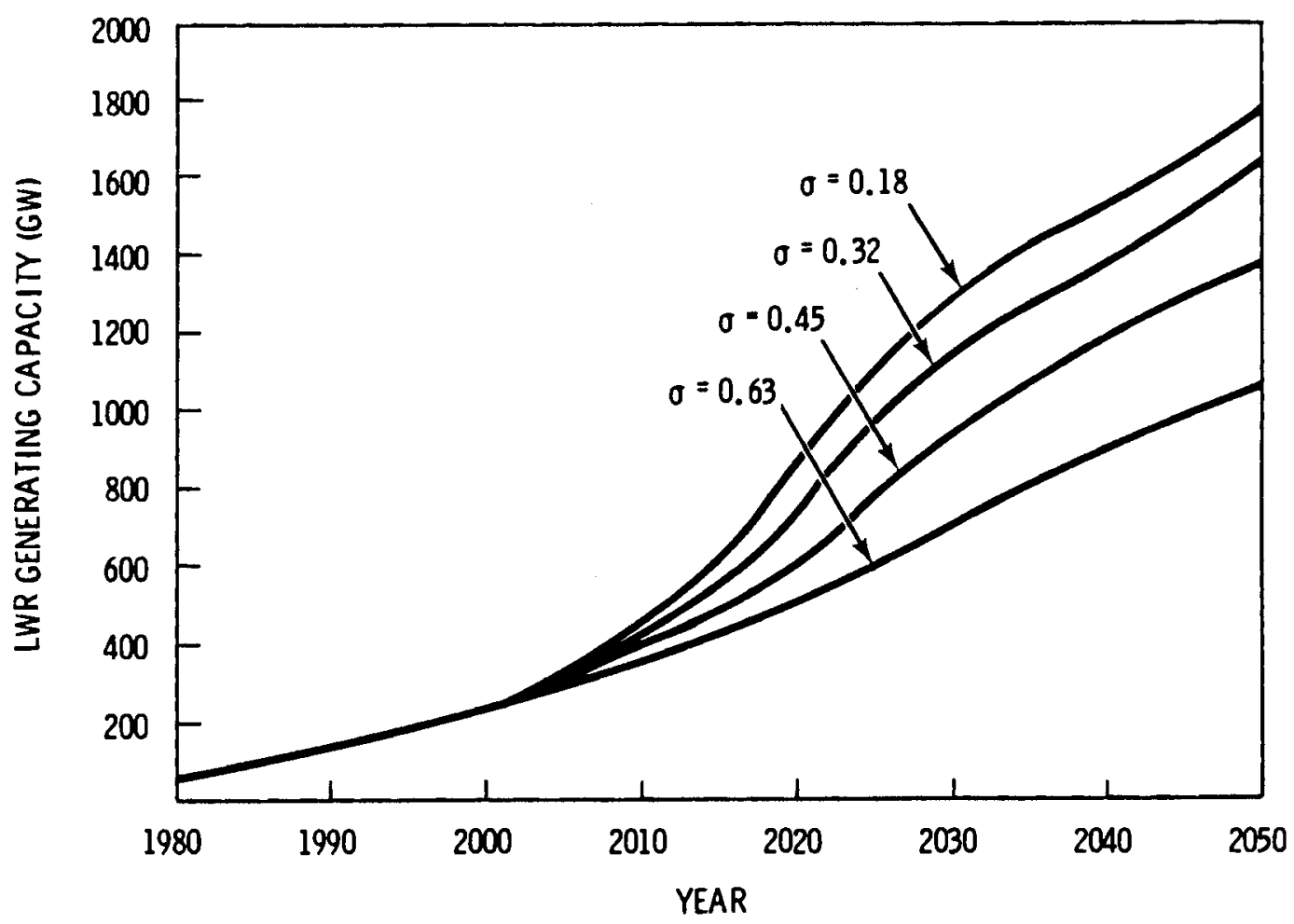

FIGURE 3.4. Nuclear Power Capacity Projections for the Uranium Supply Function Representing the Upper Quartile of the Domestic Uranium Supply Probability Density Function

greater uranium savings possible with the 12-month fuel cycle are offset by the less frequent outage times for the 18-month cycle. At this time the two fuel cycles appear equaliy likely to be accepted by utilities.

No other advanced reactor systems were assumed implemented before the FBR. Even if these systems were available early in the next century, they afford only a small cumulative uranium savings before the FBR will be available. Therefore, implementation of these systems would have little impact on the date that the FBR becomes economically competitive. Sensitivity of the analysis' results to the assumed availability of an advanced reactor is shown in Chapter 4.

\subsubsection{Enrichment Tails Assay}

The current enrichment tails assay is $0.2 \%$. When uranium costs increase, there will be an incentive to decrease the tails assay, trading increased enrichment costs for decreased uranium costs. A detailed analysis of the 
TABLE 3.2. Reduction in $\mathrm{U}_{3} \mathrm{O}_{8}$ Requirement for Potential Retrofit Options in PWRS

Reduction in 30-year

Retrofit

$\mathrm{U}_{3} \mathrm{O}_{8}$ Requirement (\%)

Increased burnup

$50,000 \mathrm{MWd} / \mathrm{MT}$, 12-month refueling

$50,000 \mathrm{MWd} / \mathrm{MT}, 18$-month refueling

11

5

Lattice changes

Annular pellets; reduced fuel-rod diameter 2-3

Variable-lattice fuel assembly design $1-4$

Improved fuel management and control design

Low-leakage fuel management

Other

1

Enrichment zoning/fertile blankets

Pinwise enrichment zoning within assembly 0.1

Axial blanket

$2-4$

End-of-cycle coastdown 3

Ful1 use of batches in startup core $\quad 0.5$

TABLE 3.3. Uranium Requirement (short tons $\mathrm{U}_{3} \mathrm{O}_{8}$ ) per $\mathrm{GW}$ for the Reference and Improved PWR, 65\% Capacity Factor

First Core Equilibrium Reload

Reference PWR, 12-month cycle

$0.2 \%$ Tails

$0.1 \%$ Tails

394

346

168

146

Improved PWR 12-month cycle

$0.2 \%$ Tails

376

130

$0.1 \%$ Tails

330

111

Improved PWR, 18-month cycle

$0.2 \%$ Tails

376

330

$0.1 \%$ Tails

120 
increases in future enrichment capacity required to meet additional demand for separative work while decreasing the tails assay is beyond the scope of this study. It was assumed that the tails assay would decrease from $0.2 \%$ to $0.1 \%$, beginning in 1995. The time required to complete the transition depends on the assumed nuclear growth schedule. Details of how this transition is assumed to occur are discussed in Appendix B.

The 1995 date for beginning the reduction in tails assay corresponds to the scheduled completion of demonstration of one or more of the advanced isotope separation technologies currently being evaluated by the Department of Energy (DOE). However, reducing the tails assay to $0.1 \%$ does not depend on the success of that program. The $0.1 \%$ tails assay was chosen because it is technically feasible using existing gaseous diffusion or centrifuge enrichment technology and will become economical as uranium costs increase. The impact of introducing advanced isotope separation technology to further reduce the tails to $0.05 \%$ is discussed in Section 4.5.2. Modifying these assumptions have a minimal impact on the results of the analysis.

\subsection{PROBABILITY THAT FBR ENERGY IS LESS EXPENSIVE THAN LWR ENERGY FOR A SELECTED URANIUM SUPPLY FUNCTION}

This part of the calculation compares the costs of energy from FBRs and LWRs. Data are required to translate the uranium consumption probability functions from the first step of the calculation into uranium cost probability functions. The uranium cost probability function is then combined with non-uranium cost data for the LWR and FBR to calculate energy cost, as is illustrated in Figure 2.2. Uranium cost data and LWR and FBR energy cost data are discussed below.

\subsubsection{Cost Data for Assumed Uranium Supplies}

Each uranium supply function shown in Table 3.1 represents a range of the total domestic uranium supply. The supply function for the lower quartile represents the range of potential uranium endowment of 6.62 million short tons (ST) or less. The supply function for the middle quartiles represents the range between 6.62 and 7.49 million ST $U_{3} 0_{8}$. The supply function for the upper quartile represents the range from 7.49 million ST $U_{3} 0_{8}$ and up. 
Figures $3.5,3.6$ and 3.7 show the uranium cost probabilities as a function of cumulative uranium consumption. These data are from Piepel et al. (1981). The probability that uranium costs a selected amount $(\$ / 1 b)$ or less when some quantity of uranium has been consumed is represented by the probability that that quantity, or more, of uranium exists at the selected cost. This is illustrated in Figure 3.5. On that figure, the probability that uranium costs $\$ 130 / 1 \mathrm{~b}$ or less when 5.0 million ST have been consumed is 0.76 . Similarly, the probability that uranium costs less than $\$ 150 / 1 \mathrm{~b}$ is 0.93 . These data are required to translate uranium consumption probability functions into uranium cost probability functions.

\subsubsection{Reactor Capital, Operating, and Fuel Cycle Cost Data}

The capital cost data used in this report were developed in another report in this series (Boegel and Clausen 1981). These estimates were developed from historical data and consultation with reactor vendors and architect-engineers.

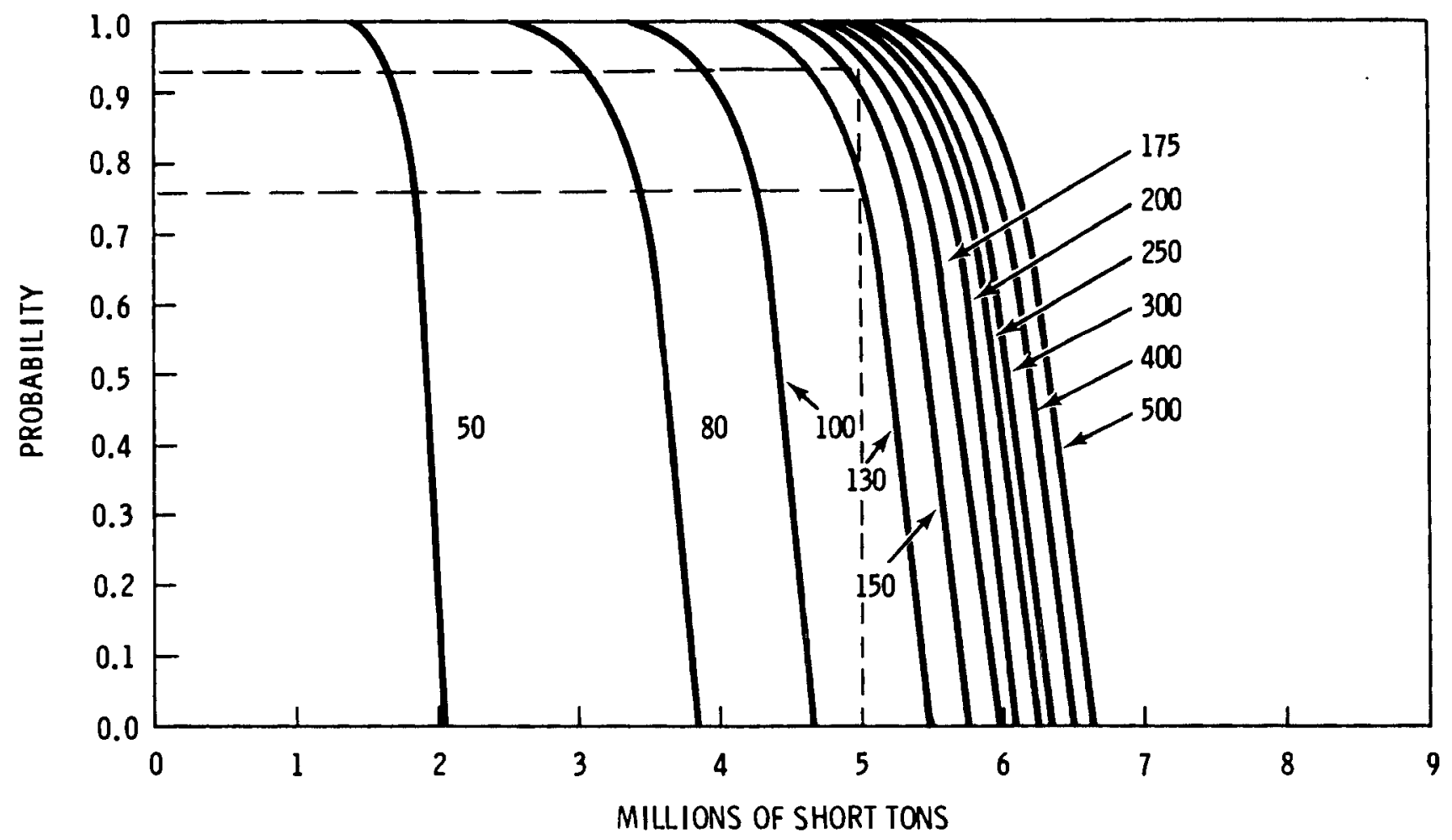

FIGURE 3.5. Uranium Supply and Cost Probability Data for the Lower Quartile of the Probability Density Function for the Domestic Uranium Supply 


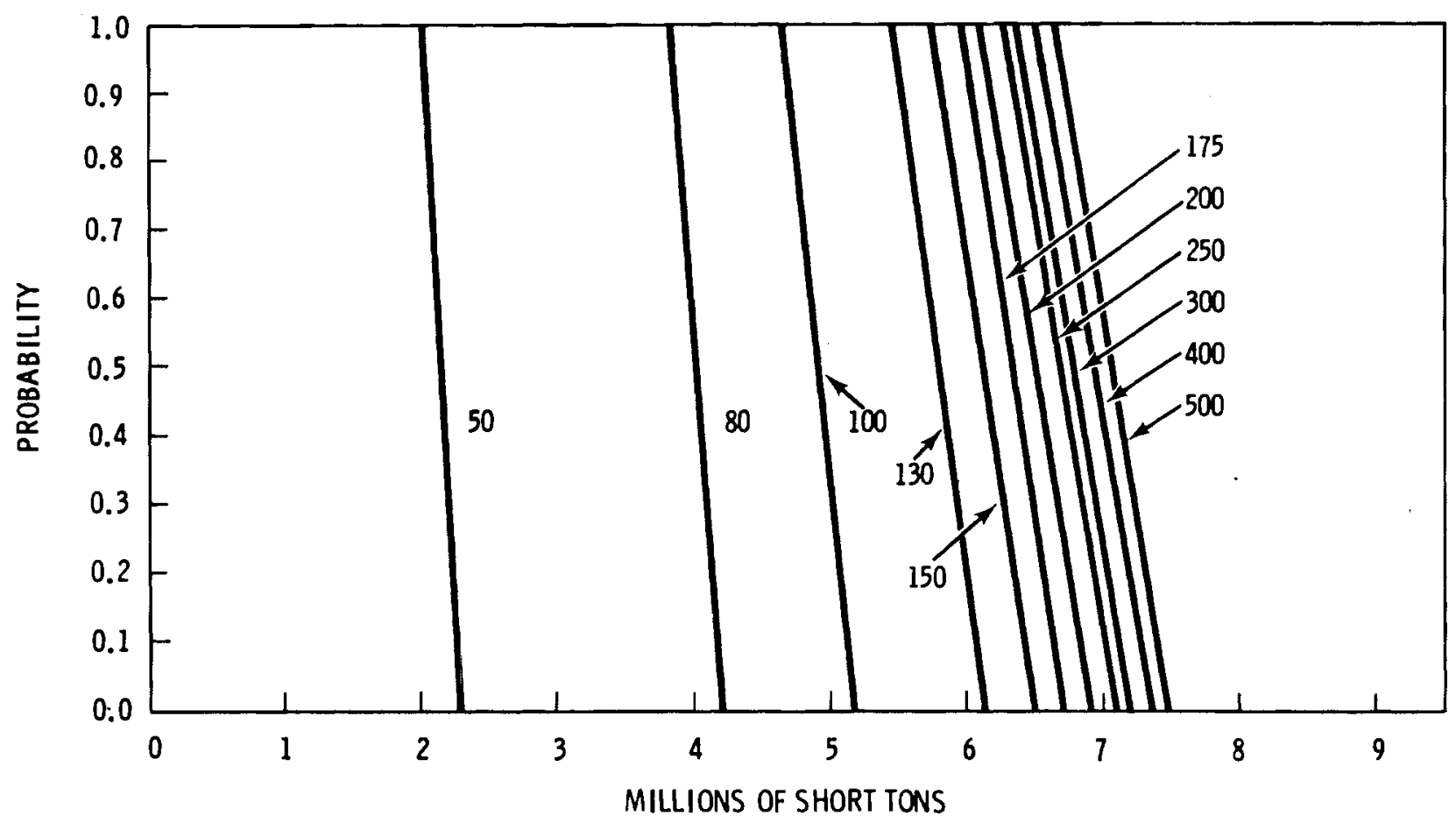

FIGURE 3.6. Uranium Supply and Cost Probability Data for the Middle Quartiles of the Probability Density Function for the Domestic Uranium Supply

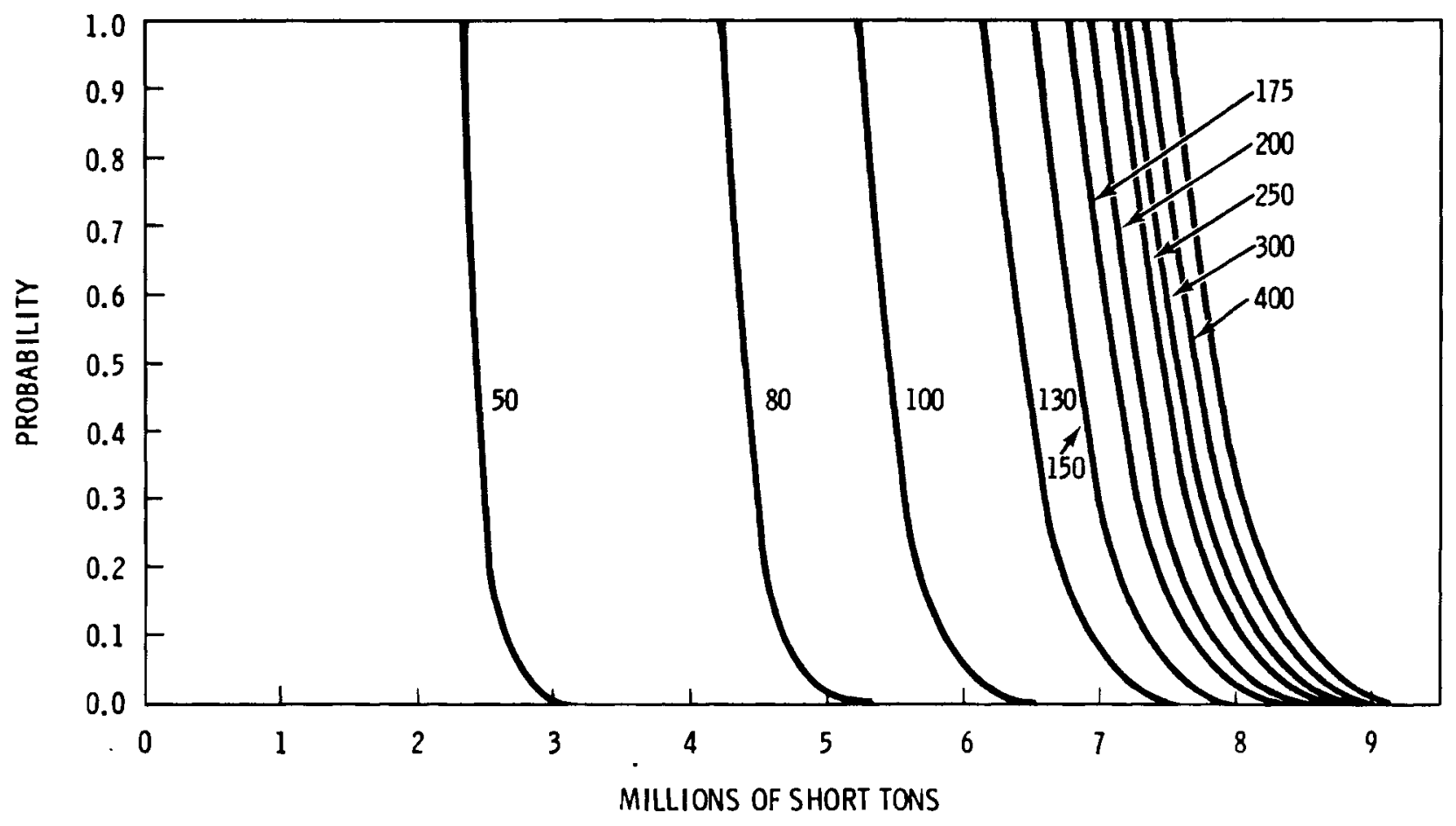

FIGURE 3.7. Uranium Supply and Cost Probability Data for the Upper Quartile of the Probability Density Function for the Domestic Uranium Suppiy 
Figure 3.8 surmarizes the data. The capital costs for 1000-MWe and 1457-MWe FBRs and for the LWR are shown as probability density functions in terms of $\$ / \mathrm{kW}$. These estimates do not include interest during construction, which is a major cost component. Interest during construction is accounted for separately in the energy cost calculation.

Operation and maintenance (O\&M) costs and fuel cycle costs are derived from data prepared for NASAP (DOE 1980; HEDL 1979) and translated from 1978 dollars to 1980 do 11 ars for this report. Unit fuel cycle costs were calculated from NASAP estimates of construction and operating costs for various facilities. Details of these calculations are found in Appendix E. Table 3.4 summarizes the O\&M and fuel cycle costs used in the analysis.

The reference LWR fuel cycle for this analysis assumes the storage of spent fuel until the contained plutonium is required for fueling an FBR. LWR energy costs are calculated by levelizing capital, 0\&M, and fuel cycle costs over the life of the reactor. This results in a probability density function

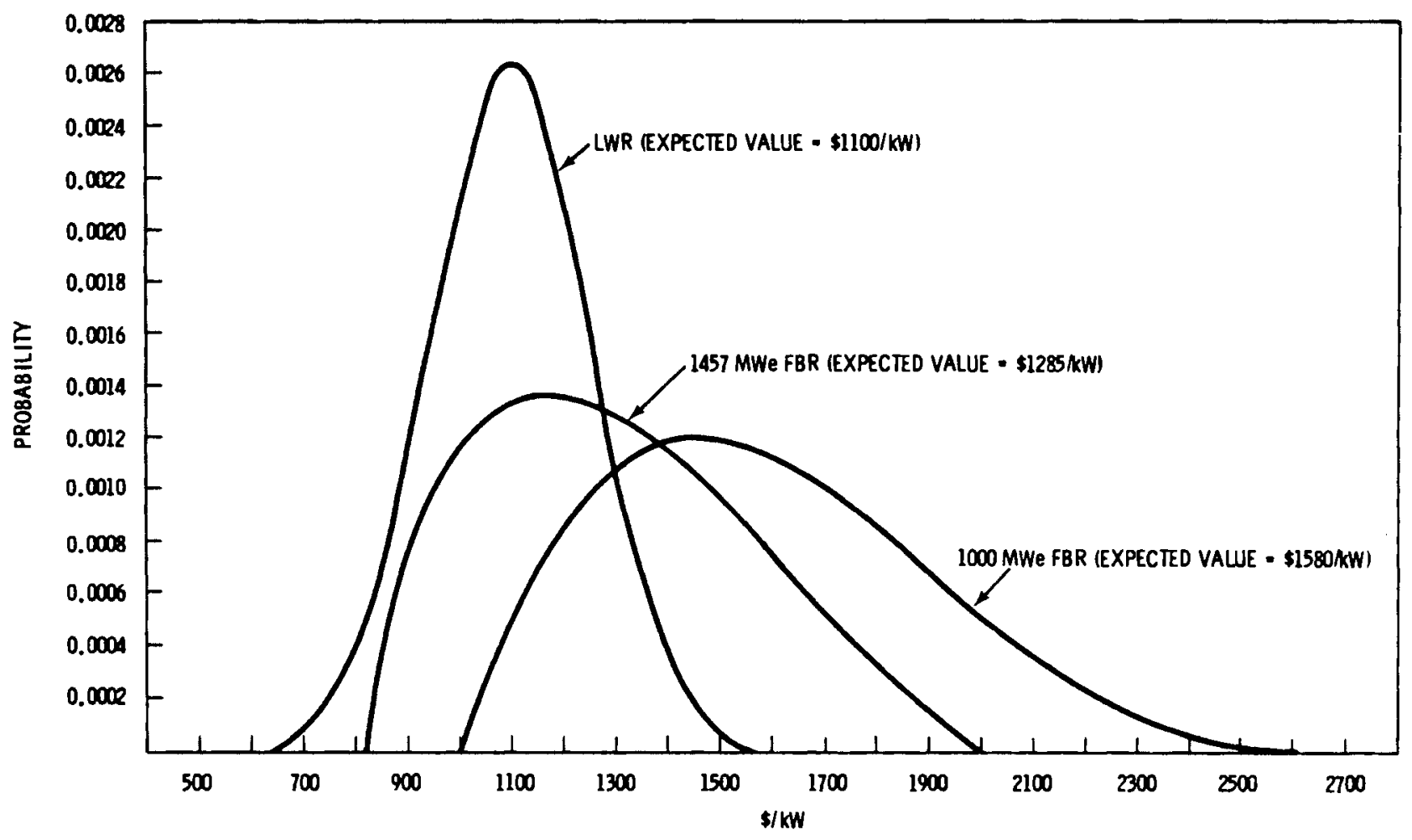

FIGURE 3.8. Capital Cost Probability Density Functions for 1000-MWe and 1457-MWe FBRs and an LWR 
TABLE 3.4. Operation and Maintenance and Fuel Cycle Cost Assumptions

\begin{tabular}{ll}
\multicolumn{1}{c}{ Operation } & $\frac{\text { Costs }(\$ 1980)}{\text { LWR 0\&M }}$ \\
FBR 0\&M & $\$ 17 / \mathrm{kW} / \mathrm{yr}$ \\
Enrichment & $\$ 22 / \mathrm{kW} / \mathrm{yr}$ \\
LWR fabrication & $\$ 100 / \mathrm{SWU}$ \\
FBR core + axial blanket & $\$ 145 / \mathrm{kg}$ \\
FBR radial blanket & $\$ 599 / \mathrm{kg}$ \\
LWR spent fuel transportation & $\$ 145 / \mathrm{kg}$ \\
FBR spent fuel transportation & $\$ 26 / \mathrm{kg}$ \\
(Pu,U) 02 transportation & $\$ 95 / \mathrm{kg}$ \\
LWR fuel reprocessing + waste management & $\$ 224-\$ 349 / \mathrm{kg}$ \\
FBR fuel reprocessing + waste management & $\$ 324-\$ 431 / \mathrm{kg}$
\end{tabular}

for LWR energy cost, since uranium costs and LWR capital costs are both expressed in terms of probability density functions.

FBR energy costs are calculated in a similar manner. The FBR energy cost calculation also results in a probability density function, since reactor capital cost, some fuel cycle costs, and uranium costs input to that calculation are represented by probabilistic data.

The methodology for calculating levelized life-cycle costs from capital, 0\&M, fuel and fuel cycle costs is described in Appendix D. Parametric equations for LWR and FBR energy costs as a function of those variables are deve 1oped in that appendix.

\subsection{DATA FOR COMBINING INTERIM RESULTS FOR THE THREE URANIUM SUPPLY FUNCTIONS}

As was illustrated in Figure 2.3 , the interim results for three uranium supply functions are combined based on the relative probabilities. Figure 3.1 
shows that the uranium supply functions have relative probabilities of 0.25 , 0.50 , and 0.25 , respectively. These probabilities were used to weight the results of the calculations for each of the three uranium supply functions and complete the calculation of the time dependent probability that the FBR is economically competitive with the LWR. The results of this calculation are discussed in Chapter 4. Additional calculational details and data are contained in Appendices $B$ through $F$. 


\subsection{RESULTS}

This chapter presents the results of the analysis. Interim results are presented for cumulative uranium consumption, uranium cost, LWR energy cost, and FBR energy cost. These interim results are required to calculate the timedependent probability that the FBR is economically competitive with the LWR. The last section briefly examines the results when selected assumptions are modified relative to the reference case.

\subsection{CUMULATIVE URANIUM CONSUMPTION}

The range of projected uranium consumption reflects two major sources of uncertainties. The first, future nuclear capacity, is characterized in the analysis by four equally probable nuclear capacity projections for each of three uranium supply functions. The second source of uncertainties is the annual uranium requirement for future LWRs. The analysis considered the annual uranium requirements for 12 -month and 18-month fuel cycles with 50,000 MWD/MT burnup equally probable for the post-2000 time period.

The cumulative uranium consumption shown in Figure 4.1 assumes that the FBR is not yet on-line. Figure 4.1 shows the the median and $90 \%$ confidence interval of projected cumulative uranium consumption for the base case assumptions and data discussed in Chapter 3. The figure shows that there is a 0.95 probability that cumulative uranium consumption will exceed 2.19 million ST by 2030, a 0.50 probability that it will exceed 2.80 million ST, and a 0.05 probability that it will exceed 3.44 million ST.

\subsection{URANIUM COST}

Probability functions calculated for future uranium costs reflect the uncertainties in both future uranium consumption and future uranium supply. Figure 4.2 shows the median and the $90 \%$ confidence interval for projected uranium costs. The projected median uranium cost rises from $\$ 45 / 1 \mathrm{~b}$ in 2020 to $\$ 150 / 1 \mathrm{~b}$ in 2050. The uranium costs are expressed in 1980 dollars, so the increases projected are in addition to inflation. 


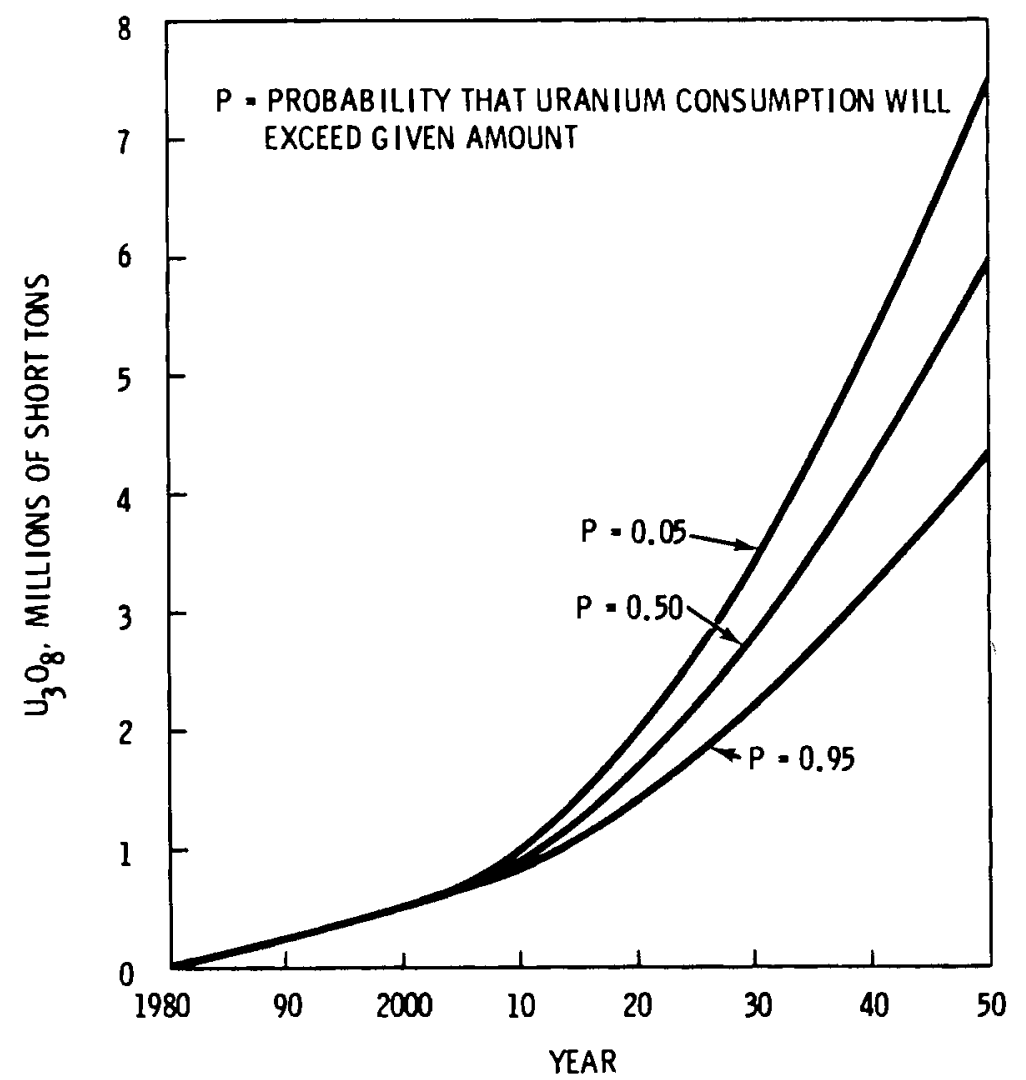

FIGURE 4.1. Median and 90\% Confidence Interval for Projected Uranium Consumption (No FBR)

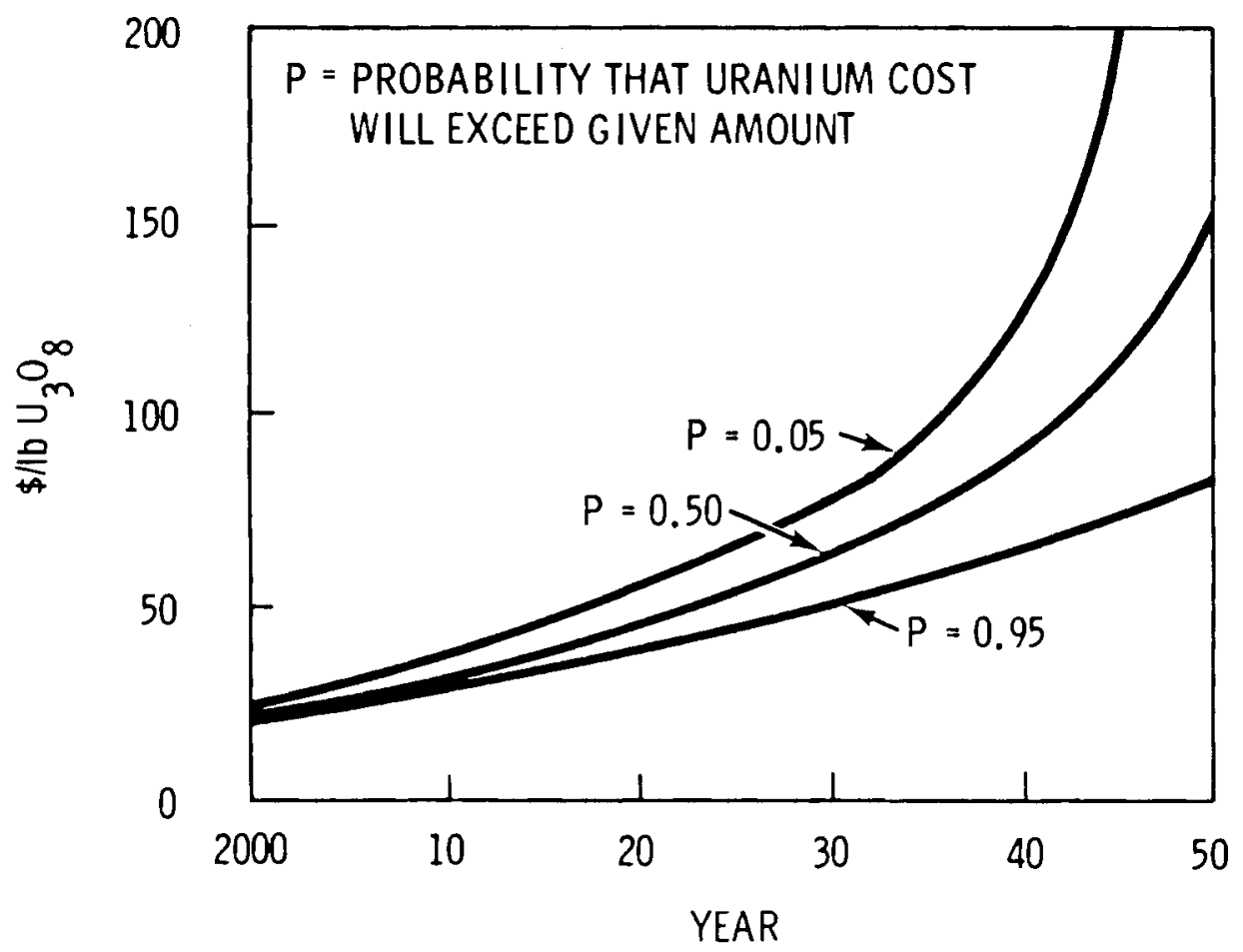

FIGURE 4.2. Median and 90\% Confidence Interval for Projected Uranium Cost (No FBR) 
The domestic uranium supply data used in the calculation were developed on the basis of uranium cost equaling the levelized life-cycle cost, which included a return on mining and milling investment (Piepel 1981). The increase in the projected uranium cost reflects the gradual transition to using lower grade uranium resources as uranium becomes more scarce; no attempt was made to simulate short-term market fluctuations. Implicit in the cost data are the simplifying assumptions that the domestic uranium resource base is developed in a timely fashion, and that the lowest cost uranium is produced first. This would require rapid expansion of domestic uranium mining and milling capacity.

Market-place realities such as difficulties of capital formation, availability of miners, uncertainty in future uranium demand, and the cost of other energy producing resources will cause the actual price of uranium to vary from the projected cost of it. Another factor that could affect the cost of uranium is the import or export of uranium. This analysis assumes no net import or export of uranium. Although this assumption is a reasonable basis for evaluating a domestic energy program such as FBR development, the factors that affect the development of the domestic resource base also affect the desirability of importing or exporting uranium.

\subsection{NUCLEAR ENERGY COSTS}

Projected life-cycle costs (mills/kWh) for LWRs and FBRs are calculated for reactors coming on-line between 2000 and 2050. The energy cost calculation is described in detail in Appendix D. Figures 4.3 and 4.4 illustrate these energy costs. Those figures show the probability density functions for life-cycle costs for the LWR and a 1457-MWe FBR coming on-line in 2025 and 2035. In 2025, the expected value for the LWR's life-cycle cost is $30 \mathrm{mills} /$ $\mathrm{kWh}$, compared with $32.6 \mathrm{mills} / \mathrm{kWh}$ for the $1457-$ MWe FBR. Using the methodology described in Appendix $B$ to compare these two probability density functions results in a probability of .17 that the FBR's life-cycle cost is less than the LWR's life-cycle cost for a reactor coming on-line in 2025. In 2035 (Figure 4.4), the expected value for the LWR life-cycle cost is $34.8 \mathrm{mills} / \mathrm{kWh}$, compared with $27.4 \mathrm{mills} / \mathrm{kWh}$ for the FBR. Comparing these two probability 


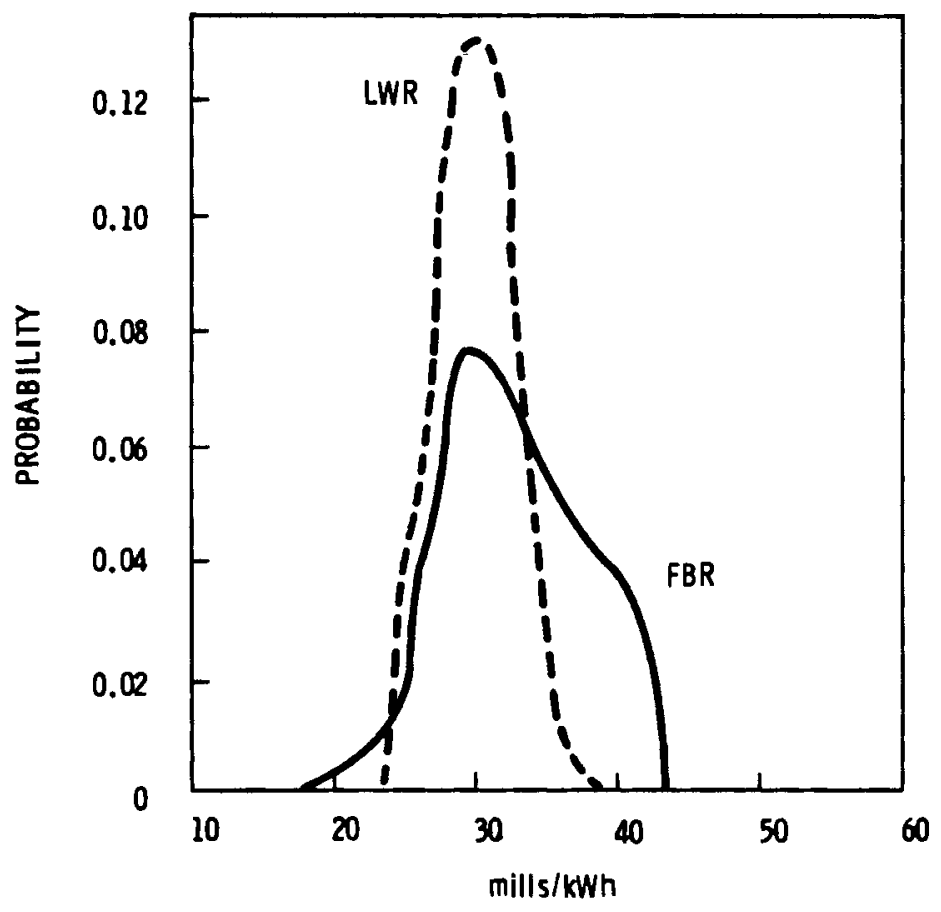

FIGURE 4.3. Energy Cost Probability Density Functions for LWR and a 1457-MWe FBR Coming On-Line in 2025

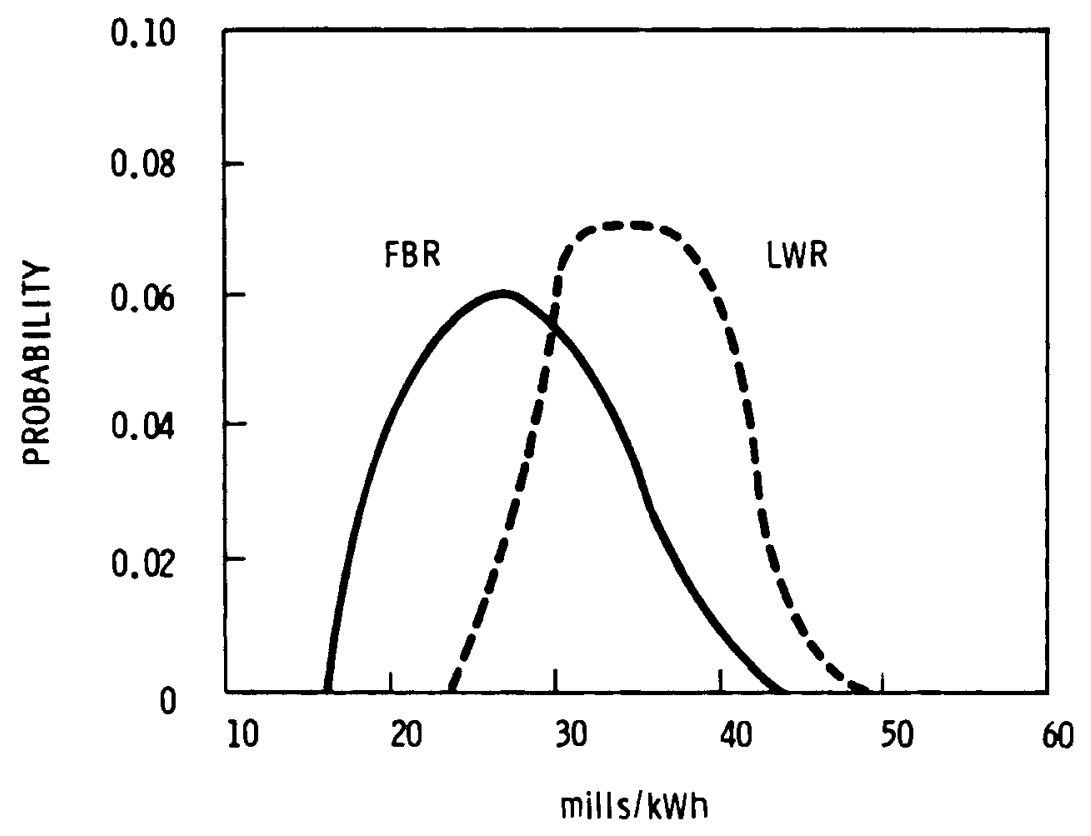

FIGURE 4.4. Energy Cost Probability Density Functions for LWR and a 1457-MWe FBR Coming On-Line in 2035 
density functions yields a .73 probability that an FBR coming on- 1 ine in 2035 will have a lower life-cycle cost than an LWR coming on-line in that year.

Figure 4.5 shows the calculated median and $90 \%$ confidence interval for life-cycle cost that an FBR coming on- 1 ine between 2000 and 2050 would have to achieve to be competitive with an LWR. The median life-cycle cost rises from $27 \mathrm{mills} / \mathrm{kWh}$ in 2000 to $45 \mathrm{mills} / \mathrm{kWh}$ in 2050. This target cost corresponds to the life-cycle cost for LWRs coming on-line the same year as the first FBR. The target energy cost increases with time because uranium costs increase. The LWR energy costs shown in the figure should not be confused with the cost of LWR energy if the FBR does not come on-line. Commercial introduction of the FBR reduces uranium costs, and therefore LWR life-cycle energy costs; this is implicit in the data shown in the figure. The details of this calculation are found in Appendix $B$.

Figure 4.6 shows the calculated median and $90 \%$ confidence interval for the life-cycle cost of a 1457-MWe FBR coming on-line between 2000 and 2050. The median is $35 \mathrm{mills} / \mathrm{kWh}$ in 2000 and $20 \mathrm{mills} / \mathrm{kWh}$ in 2050 . The energy costs decrease because the value of uranium recovered in reprocessing LWR fuel for the initial FBR plutonium inventory increases and because the value of bred plutonium increases as uranium costs increase. The results illustrated in Figures 4.5 and 4.6 are included to indicate both the projected trend and uncertainty in LWR and FBR life-cycle costs. Any actual comparison between life-cycle costs for particular dates should be performed using the complete energy cost probability density functions illustrated in Figures 4.3 and 4.4. The results of comparing these costs are discussed in the next section.

\subsection{TIME-DEPENDENT PROBABILITY THAT THE FBR IS ECONOMICAL RELATIVE TO THE LWR \\ Performing the calculation illustrated in Figures 4.3 and 4.4 for dates between 2000 and 2050 yields the time-dependent cumulative probability that the FBR has a lower life-cycle cost than the LWR. Figure 4.7 shows the cumu- lative probability distribution for both the 1457-MWe and 1000-MWe FBRs being economically competitive with an LWR. There is a .50 probability that the 1457-MWe FBR is economically competitive by 2030 and that the 1000-MWe FBR is economically competitive by 2033.}




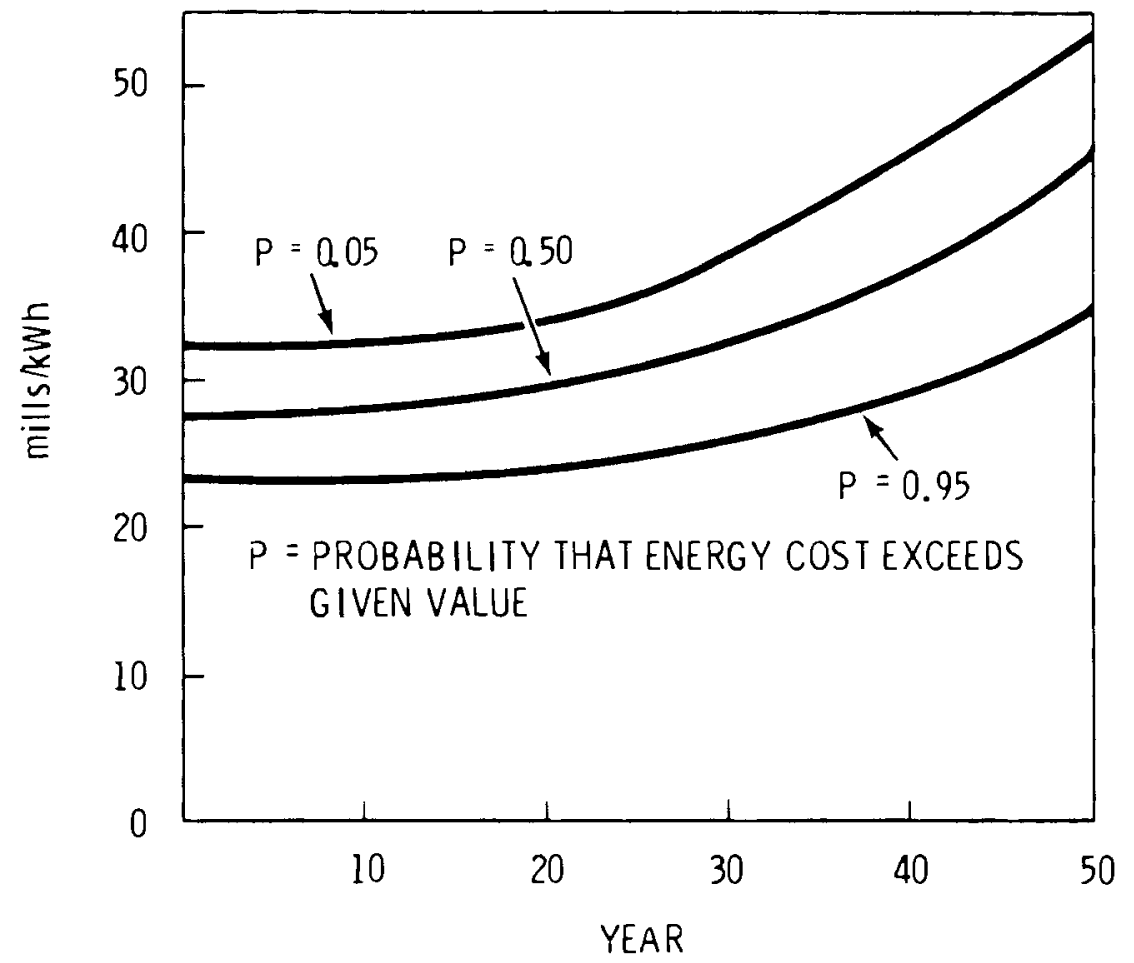

FIGURE 4.5. Median and 90\% Confidence Interval for Life-Cycle Cost that FBR Must Achieve To Be Economically Competitive with LWR

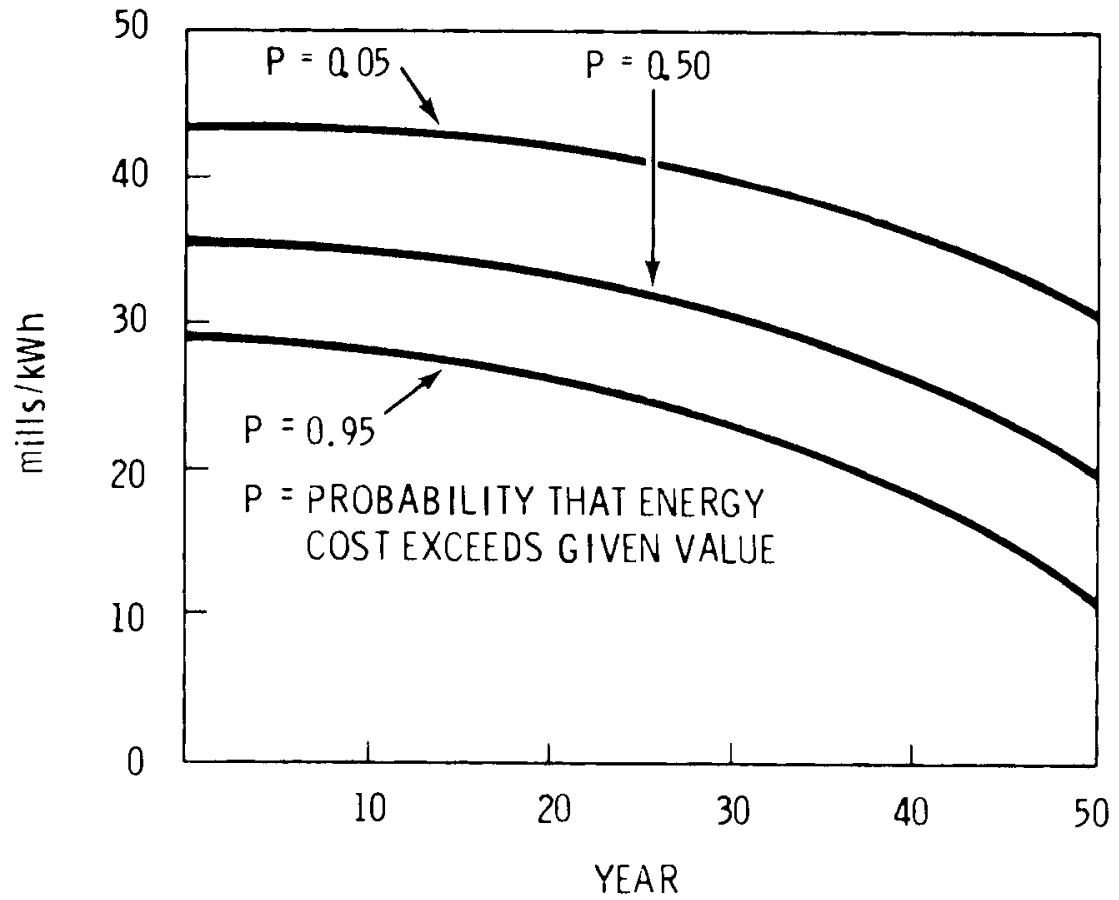

FIGURE 4.6. Median and 90\% Confidence Interval for FBR's Life-Cycle Cost 


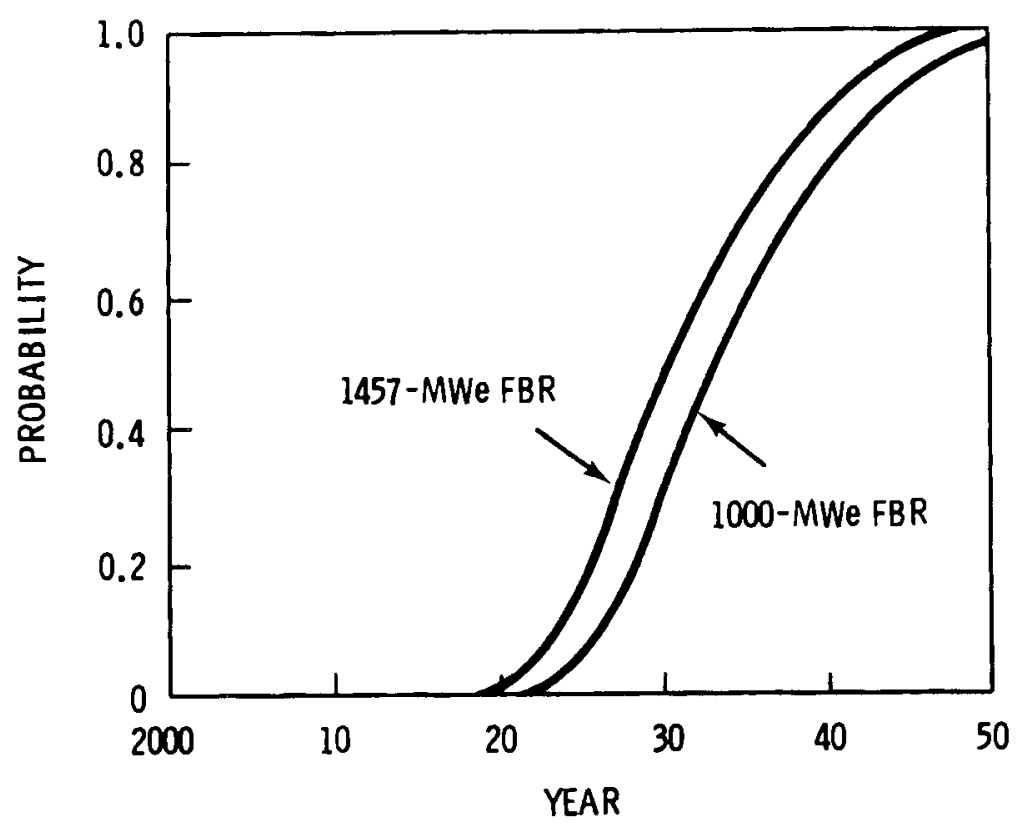

FIGURE 4.7. Cumulative Probability that a 1000-MWe or a 1457-MWe FBR Is Economically Competitive with an LWR

Figure 4.8 displays the same information in its differential form. These probability density functions allow comparison of the relative likelihood that FBRs coming on-line at various dates would be economically competitive with an LWR. This figure also indicates the $90 \%$ confidence interval for completion of development strategies for the two FBRs sizes. In Boegel and Clausen (1981), completion of the development strategy is defined consistently as the date the FBR is ready to enter the commercial market. Therefore, these dates on Figure 4.8 are comparable to those reported in Boegel and Clausen (1981). The significance of the relationship between the dates the development strategies are complete and the date that the FBR becomes economically competitive is discussed in Fraley and Burnham (1981). In that analysis it is assumed that the commercial FBR does not come on-line until it is economically competitive and the development strategy is complete. The cost penalty for completing the development strategy before or after the date the FBR would be economically competitive is also calculated. The type of data shown in Figures 4.3 and 4.4 can also be used to develop the probability function for the difference in FBR and LWR life-cycle costs. This is of interest because it illustrates the range and likelihood of cost penalties that would be incurred if an FBR were 


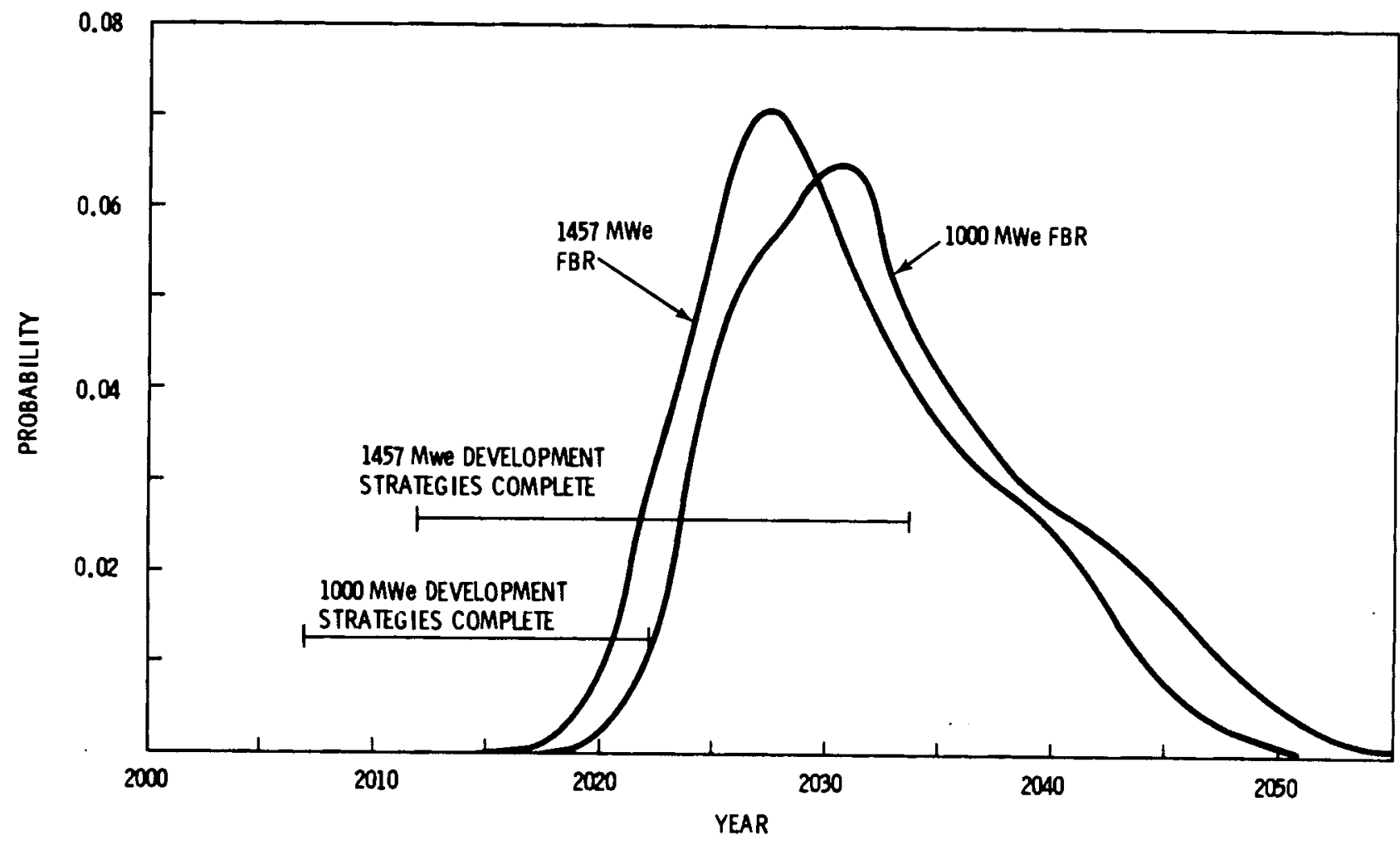

FIGURE 4.8. Probability Density Function for a 1000-MWe or a 1457-MWe FBR Becoming Economically Competitive with an LWR

introduced before it is economically competitive. This differs from the cost penalty calculated in Fraley and Burnham (1981), since in that report the FBR comes on-line only if it is economic. Figure 4.9 shows the cost penalty probability density functions for introducing the FBR at a variety of dates at which it is not economically competitive. The probability that the life-cycle cost difference (cost penalty) exceeds various costs is plotted. For example, the figure shows that an FBR coming on-line in 2025 has a .83 probability of incurring a cost penalty. This .83 is the complement of the .17 probability (discussed earlier) that the FBR is economically competitive. The figure also shows a .50 probability that the cost penalty will exceed $3.4 \mathrm{mills} / \mathrm{kWh}$ and a .10 probability that the penalty will exceed $6.7 \mathrm{mills} / \mathrm{kWh}$. The upper limit cost penalty is approximately $12 \mathrm{mills} / \mathrm{kWh}$, which is less than the difference between the cost of nuclear energy and fossil energy for some regions of the U.S. 


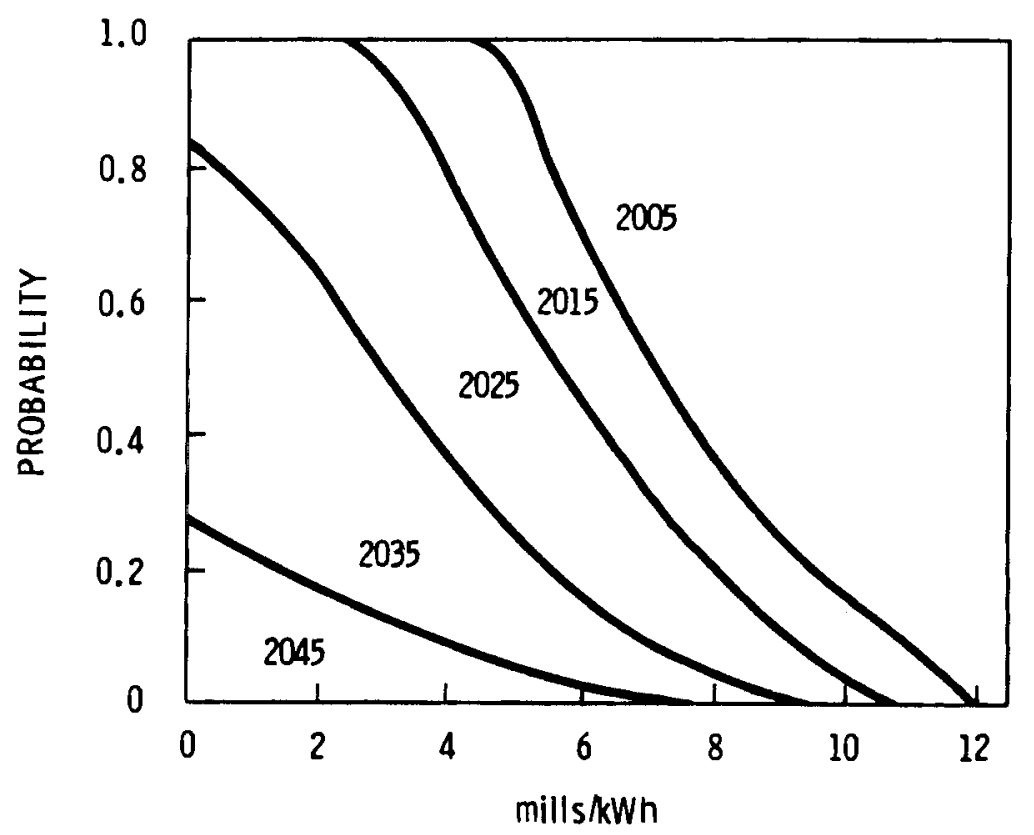

FIGURE 4.9. Probability That the Cost Penalty for an FBR Introduced at Selected Dates Exceeds a Specified Cost

\subsection{IMPACT OF ALTERNATIVE ASSUMPTIONS}

This section describes the impact of alternative assumptions on the results of the reference case. Specifically, we examine the impact of the impending introduction of the FBR on the date that the FBR becomes economically competitive, and the impact of alternative assumptions for the introduction of advanced reactor or enrichment technology.

\subsubsection{Synergistic Impact Of FBR Introduction}

The results of the analysis refer to when an FBR should be introduced, not whether it should be introduced. Implicit in the analys is is the assumption that the FBR will eventually be introduced. Because of synergistic effects between FBR deployment and LWR life-cycle cost, the cost of LWR energy is decreased if an FBR is introduced. Decreased LWR energy costs delay the date that FBR becomes economically competitive. In a sense, the FBR competes against itself. Knowledge that there will be an FBR deployed delays the dates when it will be economical to introduce the FBR. 
Assuming that the FBR will be deployed requires two major decisions in the analysis: 1) selection of an appropriate LWR fuel cycle, and 2) selection of the basis for projecting uranium costs. The reference fuel cycle for calculating LWR energy costs in this analysis is a stowaway fuel cycle. In the stowaway fuel cycle, LWR spent fuel is stored at the reactor until it is reprocessed for plutonium for FBRs. No cost or credit is assumed for management of LWR spent fuel. The cost of plutonium for initial FBR inventory is assumed to be the cost of reprocessing LWR spent fuel minus a credit for recovered uranium. This is consistent with the assumption that LWR spent fuel has no net salvage value. These are reasonable assumptions for determining when the FBR will become economically competitive. A utility comparing the energy costs of an LWR and an FBR to decide which to purchase would be aware that spent fuel from the LWR would eventually be reprocessed. The utility could not be sure whether LWR spent fuel would be a net asset or liability, but would know that the maximum liability would be less than for disposing of the spent fuel.

If eventual FBR deployment is not assumed, then the throwaway fuel cycle is more appropriate for calculating LWR life-cycle costs. In the throwaway fuel cycle, spent fuel is a liability and a cost is incurred for its disposal. In addition, if spent fuel is later reprocessed for initial FBR plutonium inventory, a spent fuel disposal cost is avoided. This cost savings can be considered a credit which reduces the initial cost of plutonium, and thus reduces FBR energy costs.

The second consideration is the basis for projecting the cost of uranium. Uranium cost probability functions are calculated based on cumulative uranium consumption. In order to project uranium costs for calculating the LWR's lifecycle cost, it is first necessary to project subsequent uranium consumption. In the analysis the projection of subsequent uranium consumption assumes that the FBR is introduced. This results in less uranium consumption then if the FBR were not introduced. Therefore, the cost of uranium is reduced, which reduces the LWR's life-cycle cost relative to what it would be if we assumed that the FBR were not introduced. 
Figure 4.10 illustrates the impact of these synergistic effects on the probability that the 1457-MWe FBR is economically competitive with the LWR. The reference case result is compared with the probability that the FBR is economically competitive assuming a throwaway fuel cycle and assuming a throwaway fuel cycle and increased uranium consumption when the FBR is not introduced. The figure shows that each of the major synergisms between FBR deployment and LWR energy cost delays the date for which there is a .50 probability that the FBR is economically competitive by approximately 2 years. Thus, alternative fuel cycle assumptions would make the FBR appear economically competitive 2 to 4 years earlier than those used.

\subsubsection{Impact of Advanced Converter Reactors and Advanced Isotope Separation Technology}

The introduction of new reactor or enrichment technologies to decrease uranium consumption would delay the date the FBR will become economically competitive. Two such technologies, advanced converter reactors and advanced isotope separation technologies, were evaluated. These analyses should not be

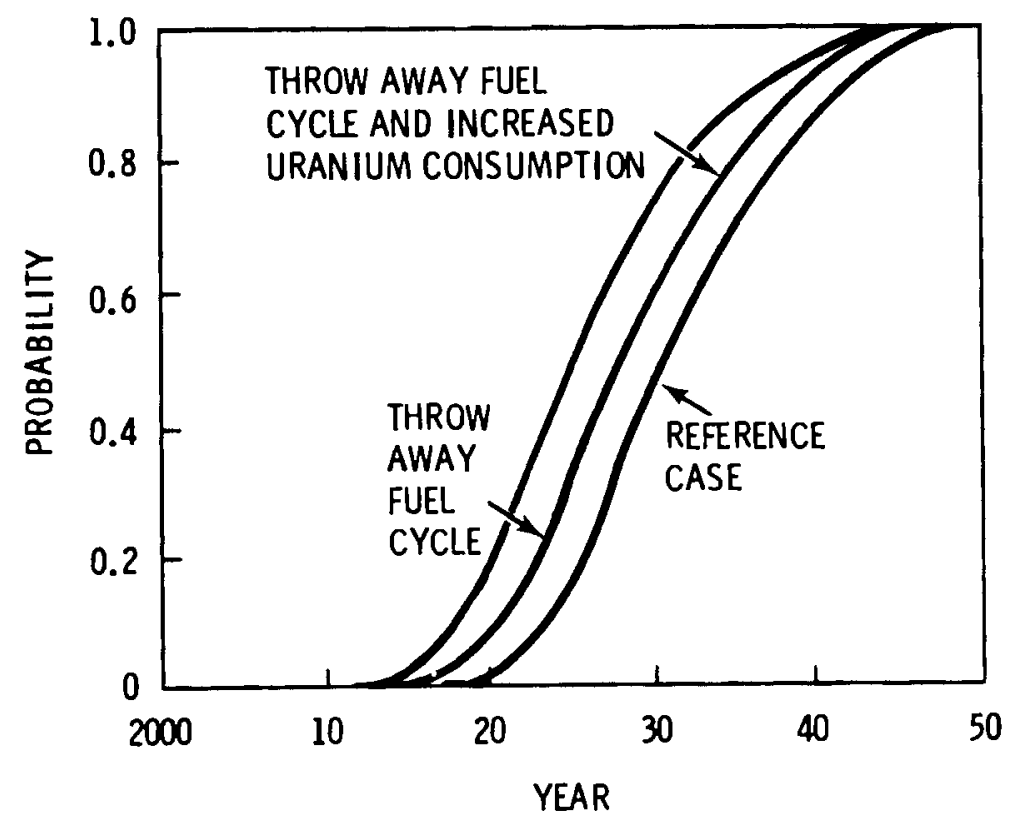

FIGURE 4.10. Impact of Synergisms Between FBR Deployment and LWR Energy Cost on the Cumulative Probability that the FBR Is Economically Competitive 
construed as a judgement of the merit of these technologies. Only their potential impact on the date the FBR becomes economically competitive is considered here. These technologies may offer advantages unrelated to FBR dep loyment.

These technologies were evaluated separately from the reference case because of the nature of the data required. The relevant data for assessing the impact of these technologies are subjective estimates of the probabilities for government or industry actions and of success of research and development efforts. A major difficulty in acquiring such subjective estimates is that some of the required data depend on the perceived result of the analysis for which they are being solicited. For example, an estimate of when or if a large advanced converter reactor development program might begin is related to the perceived date a commercial FBR will be introduced. The subjective estimates of probability used in the analyses are intended to characterize the relative likelihood of the events or activities in question as if they were unaffected by the ultimate availability of the FBR. The actual likelihood of these events will depend on the perceived availability of the FBR, and will decrease if the FBR is being developed in a timely manner. Therefore, the calculated impacts of these technologies may be overestimated.

Introduction of an Advanced Converter Reactor (ACR)

An ACR is a reactor that achieves greater uranium utilization efficiency than an LWR by consuming additional fissile material converted from fertile material during operation. For this analysis, a CANDU-type heavy water reactor using $1.2 \%$ enriched uranium fuel on a once-through cycle was assumed representative of this class of advanced reactor. This reactor, and its fuel cycle, are described in detail in Report of the Nonproliferation Alternative Systems Assessment Program (DOE 1980). The life-cycle fuel requirements for this reactor are approximately $80 \%$ of those for the improved LWR assumed for this analysis. It was assumed that this reactor would be economically competitive with the LWR.

The potential impact of such a reactor on the economic competitiveness of the FBR is largely determined by when it is introduced. Since there are currently no large government or industry programs directed toward implementing 
such reactor technology, it is unlikely that it could be introduced significantly sooner than the FBR. A companion study to this analys is (Burnham 1981) investigates the time required to develop the FBR. That study concludes that the expected completion times for the most rapid development strategies would lead to 2009 or 2010 dates for availability of a commercial FBR. This was assumed to be the earliest date that an ACR could be introduced. Since no effort is currently underway to develop this reactor, the 2010 date for ACR introduction is arbitrarily assigned a .1 probability. This is equivalent to assuming that there is a $10 \%$ likelihood that some government or commercial interest will begin a rapid program to develop this reactor this year. To bound the impact of introducing an ACR, the remaining .9 probability was assigned to a 2015 ACR introduction date. This corresponds to assessing a $90 \%$ likelihood that a program for rapid implementation of the ACR will begin in the next 5 years.

Figure 4.11 shows the impact of these assumptions for ACR introduction by comparing the cumulative probability that the FBR is economically competitive both with an ACR and without ACR introduction. The "no ACR" curve represents the reference case result. The figure shows that, for the assumed conditions, the introduction of an ACR delays points of equal probability that the FBR is economic 1 to 4 years, with the larger impact occurring if the FBR becomes economically competitive later.

Introduction of Advanced Isotope Separation Technology (AIST)

AIST refers to laser and plasma uranium enrichment techniques being developed for potential commercial introduction near the end of the century. The incentive for implementing these technologies is that they offer a potential reduction in unit separative work costs, which would make a reduced enrichment tails assay economically desirable. The impact of AIST on the date that an FBR will be economically competitive depends on three considerations:

1. whether current laboratory-scale demonstrations of scientific feasibility for AIST concepts can be scaled up to production scale;

2. whether AIST offers a unit cost advantage ( $\$ / S W U)$ over current enrichment technology; 


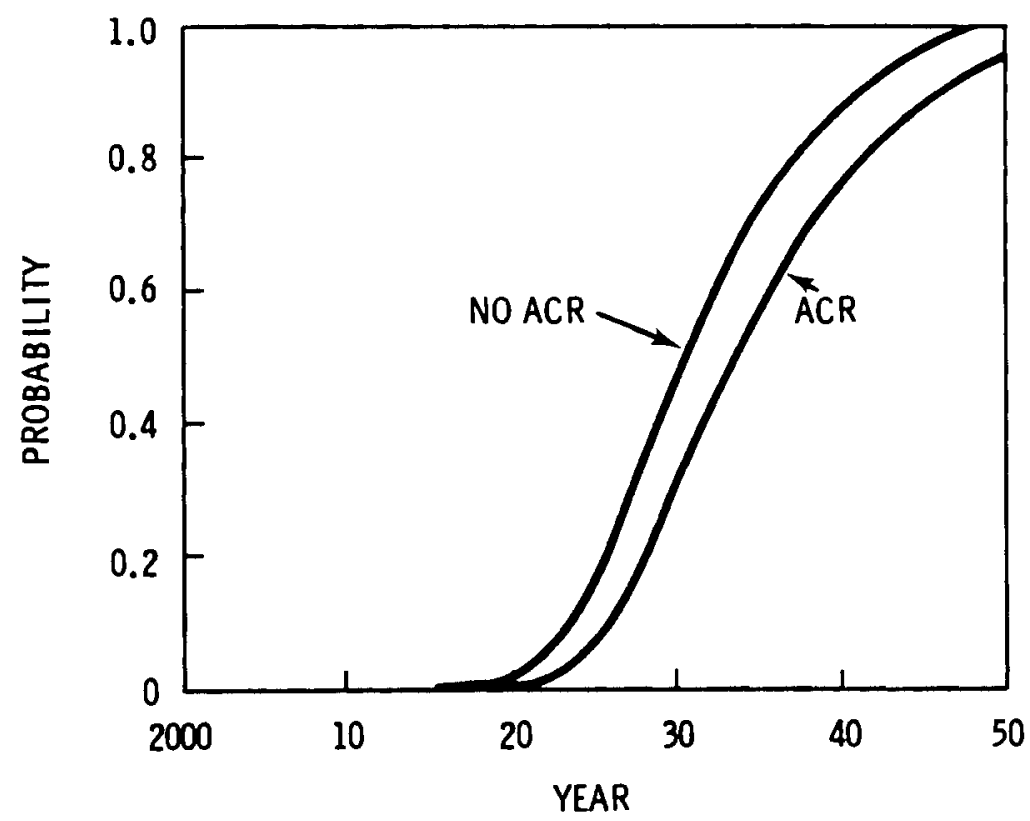

FIGURE 4.11. Comparison of the Cumulative Probability that the FBR Is Economically Competitive With an ACR And Without an ACR

3. whether production scale facilities can be introduced as currently scheduled.

These factors are difficult to evaluate. For this analysis, probabilities were subjectively assigned to possible outcomes for these factors. These subjective probabilities are intended to reflect the current degree of uncertainty in these factors. The probability of successful scale-up of AIST (factor 1) was assigned a probability of .75 . The two major sources of uncertainty of successful scale are technical uncertainty and institutional uncertainty. The technical uncertainty relates to the likelihood that the materials and processes that operate successfully at a laboratory scale will operate reliably at a production scale. This uncertainty is common to all emerging technologies. The institutional uncertainty is whether these technologies will receive continued support. Important issues leading to institutional uncertainty are the perceived need for the technology and the competition for development funds. Assuming that either of these factors has a .1 to .15 probability of precluding successful scale-up of AIST leads to the estimated .75 probability of success $(.13 \times .13 \cong .75)$. 
The likelihood that AIST will offer a reduced separative work unit cost (factor 2) was characterized by assigning a .75 probability that $\$ 50 /$ SWU and 0.05 tails assay will be achieved. Past experience in nuclear energy development shows that the perceived economic advantages of technologies that have not been demonstrated at a commercial scale do not always materialize. For example, the estimates of the cost of nuclear power in the 1960s and the estimates of the unit cost of reprocessing spent fuel in the 1960s and early 1970s were lower than what has been experienced.

The uncertainty in the third factor, when will production scale AIST facilities be available, was characterized by assuming that a range of dates from 1995 to 2000 were equally likely. The current plan is to have the first such facility on-line in 1995. These plans are contingent on the success of research currently underway, anticipated increases in enrichment capacity requirements, and continued funding. The possibility of the program's completion being delayed for 5 years after the current target date is consistent with changes in the completion dates of the facilities that have occurred in the enrichment component, as well as in other components, of domestic nuclear energy development.

Figure 4.12 shows the time dependent probability that the FBR is economic for these AIST assumptions compared with the results illustrated in Figures 4.7 through 4.9. The figure shows that these AIST assumptions delay points of equal cumulative probability of the FBR being economic 1 to 2 years. 


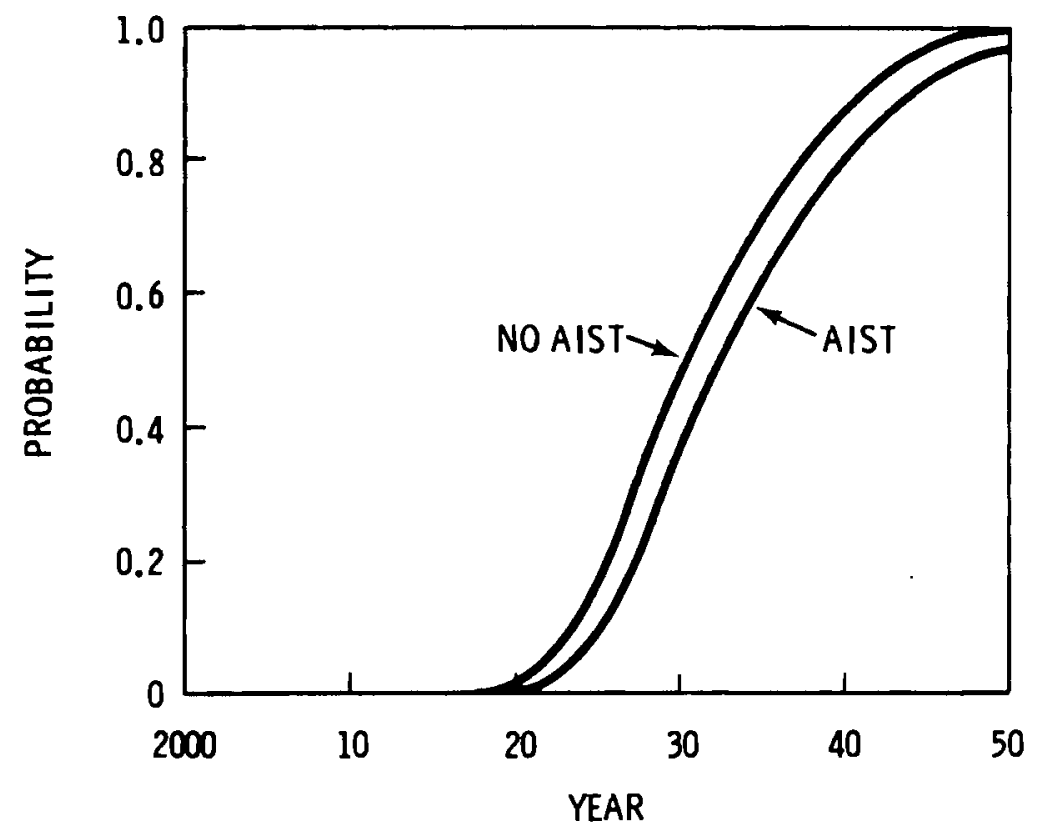

FIGURE 4.12. Comparison of the Cumulative Probability that the FBR Is Economic With and Without AIST 


\section{REFERENCES}

Boege1, A. J. and M. J. Clausen. 1981. Characterization of Alternative FBR Development Strategies. PNL-3596, Pacific Northwest Laboratory, Richland, Washington.

Burnham, J. B. et al. 1981. Analysis of Alternative FBR Development Strategies. PNL-3600, Pacific Northwest Laboratory, Richland, Washington.

Fraley, D. W. and J. B. Burnham. 1981. A Method for Selecting FBR Development Strategies in the Presence of Uncertainties. PNL-3598, Pacific Northwest Laboratory, Richland, Washington.

Manne, A. S. 1977. ETA-MACRO: A Model of Energy-Economy Interactions. EPRI-EA-592, Electric Power Research Institute, Palo Alto, California.

Matzie, R. A., ed. 1980. Uranium Resource Utilization Improvements in the Once-Through PWR Fuel Cycle. CEND-380, prepared by Combust ion Engineering, Inc. National Technical Information Service, Springfield, Virginia.

Piepe1, G. F. et al. 1981. Probabilistic Estimates of U.S. Uranium Supply. PNL-3595, Pacific Northwest Laboratory, Richland, Washington.

U.S. Department of Energy. 1980. Reactor and Fuel Cycle Descriptions. Volume 9 of Nuclear Proliferation and Civilian Power: Report of the Nonproliferation ATternative Systems Assessment Program. D0E/NE-0001/9, Government Printing Office, Washington, D.C. 

APPENDIX A

PROBABILITY REVIEW (Fraley 1981) 
APPENDIX A

\section{PROBABILITY REVIEW}

The uncertainties associated with the FBR development decision have been described probabilistically. This appendix reviews the definition and assignment of probabilities. These uncertainties are described by a probability density function. From this function, several parameters that characterize the range of possible outcomes can then be defined.

To illustrate, consider the activity completion over time. The actual completion time is uncertain and may fall anywhere within a continuous range of time. A quantitative measure is desired for the completion time of a representative case, where each time the activity is performed, the actual completion time may vary.

Let $t$ be the activity completion time in minutes. To establish a measure of $t$, an experiment is performed in which the activity is repeated a number of times and each completion time $t$ is recorded. The results of such an experiment are shown in Figure A.1. Each time the activity is completed within a two minute interval is represented by one square above that interval. Figure A.1 illustrates such a plot for 50 trial activities. The total number of trials that were completed before 41 minutes, for example, is given by the number of squares to the left of $t=41 \mathrm{~min}$, i.e., 30 .

This number can be used to predict the probability that a typical activity will be complete before 41 minutes by taking the ratio of the total number of trials to the total completed before this time i.e., 30/50, or, using compact notation:

$$
\operatorname{Prob}(t \leq 41)=30 / 50=0.6
$$

If, instead of the number of squares in Figure A.1, the area represented by the squares is considered, then the same result will be obtained by taking the 
area of the squares to the left of $t=41$ and dividing it by the total area of the squares. The area of each square can be adjusted so that the total area of all squares will be unity.

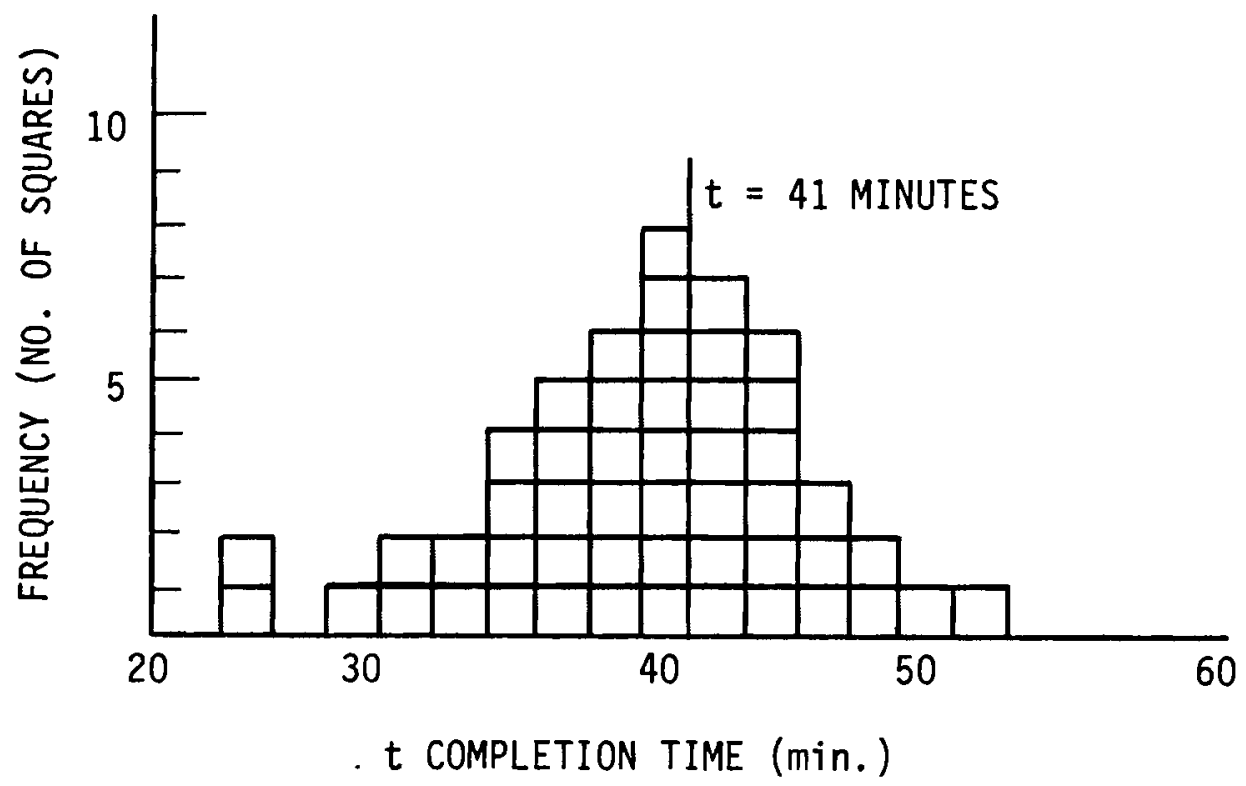

FIGURE A.1. Frequency Histograms of Activity Completion for 50 Trials

Extending the experiment to a large number $N$ of trial activities and making the time intervals vanishingly small, the plot of Figure A.1 will approach a continuous curve (Figure $A: 2^{2}$ ). Again, the total area under the curve can be normalized to unity so that $\operatorname{Prob}(t \leq b)$ will be equal to the area under the curve $f(t)$ to the left of time (b). In Figure A.2, the completion time $t$ is $a$ random variable. The function that expresses the relationship between the value of the random variable and the probability of its occurrence (expressed as a fraction of 1.0 ) is a probability density function (PDF).

Because possible completion times fall over a continuous range, the probability of an event is defined over an interval, for example the interval from time (a) to time (b) as shown. The probability that completion occurs in the time inverval from (a) to (b) is expressed by

$$
\operatorname{Prob}(a<t \leq b)=\int_{a}^{b} f(t) d t
$$




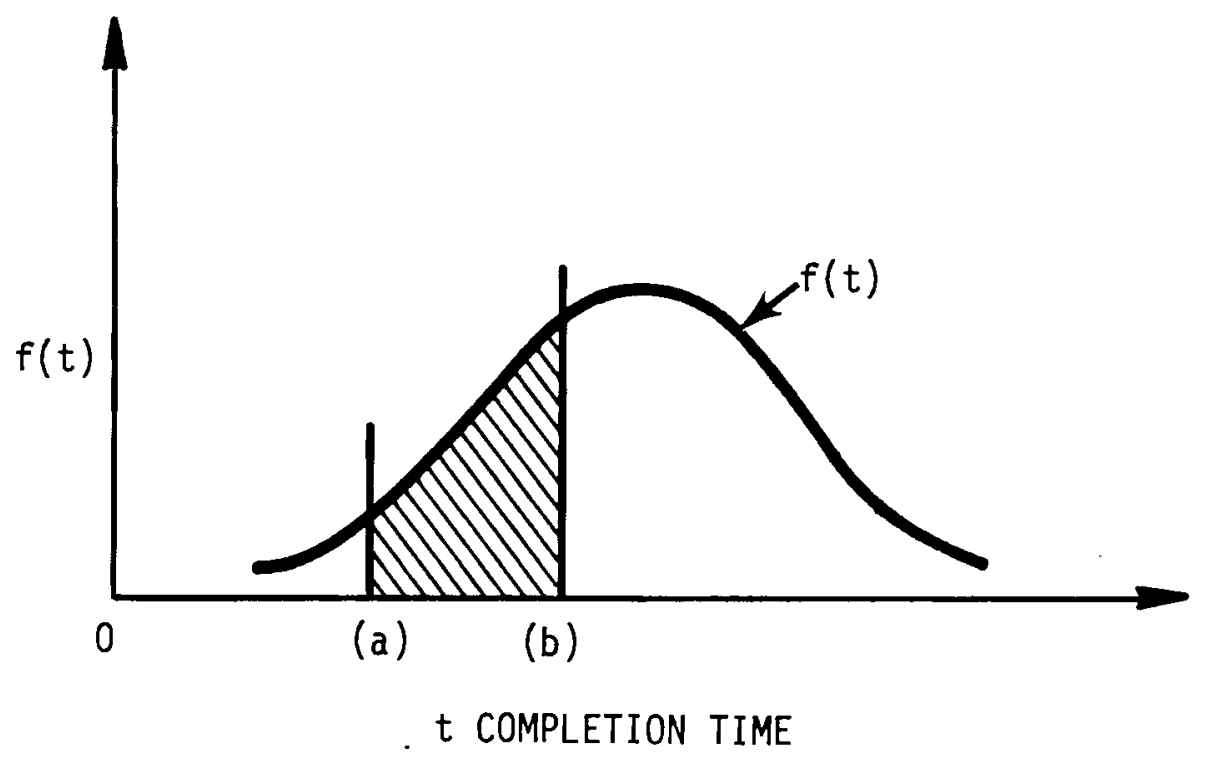

FIGURE A.2. Probability Density Function for Activity Completion

where the integral of the density function over the interval yields the area in that interval or, the probability of completion in that time period.

Uncertainty may also be expressed displaying the same information as a cumulative distribution function (CDF). The cumulative distribution function is the integral of the probability density function. It gives the probability that the value of the random variable is less than or equal to a specific event. This is defined by the same integral expression as above with the lower bound being the minimum of the range of possible outcomes:

$$
\operatorname{Prob}(t \leq b)=\int_{0}^{b} f(t) d t
$$

Figure A.3 shows the CDF for the density function given in Figure A.2. Note that its value at the latest possible time of completion is 1.0 .

It is useful to describe the information in the probability density function by a few characteristic numbers that specify its position and shape. Common parameters include the mean and variance or standard deviation. 


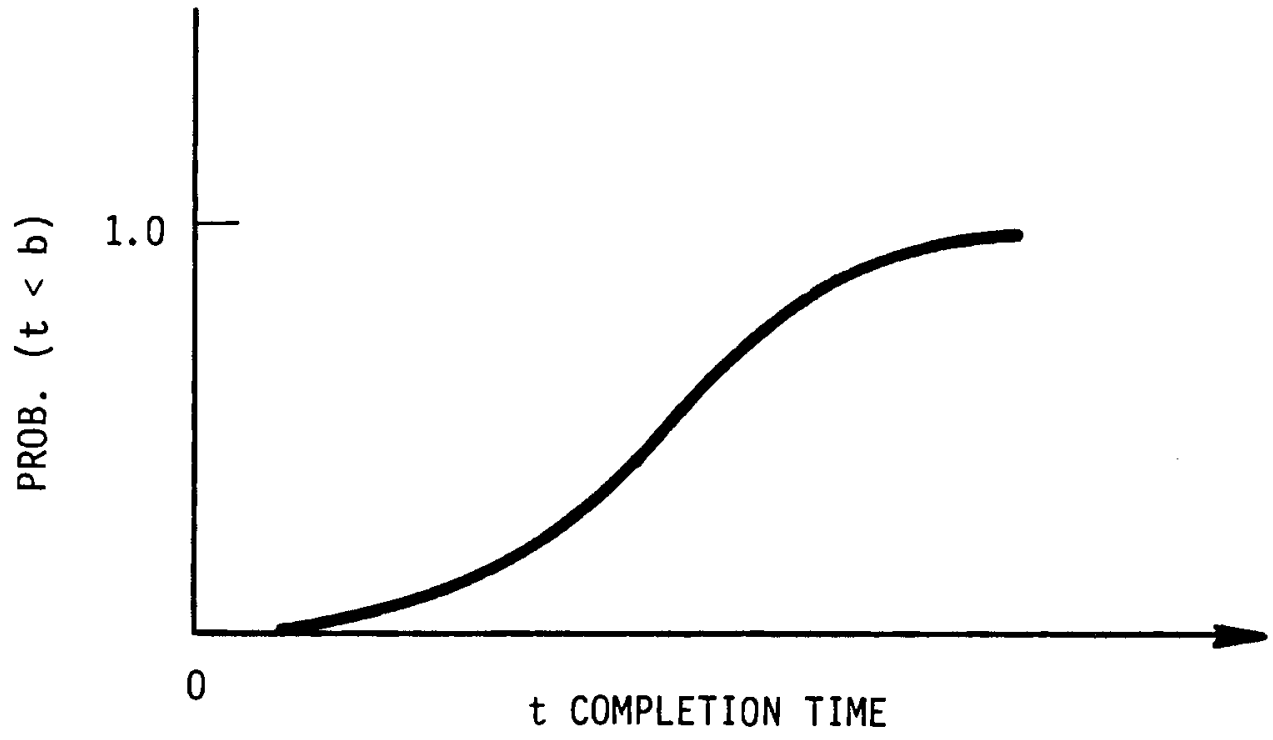

FIGURE A.3. Cumulative Distribution Function for Completion Times

The mean or expected value is a weighted integral of all possible outcomes with their probability of occurrence. It is taken over all possible outcomes as given by the expression:

$$
E(t)=\bar{t}=\int_{0}^{\infty} t f(t) d t
$$

The variance of a distribution is an indication of its spread over the range of possible outcomes:

$$
\text { Variance } t=\sigma_{t}{ }^{2}=\int_{0}^{\infty}(t-E(t))^{2} f(t) d t
$$

The square root of the variance, known as the standard deviation, is an alternative characterization of the spread or range of possible outcomes.

Other measures useful for decision making are also available. For example, several types of averages or measures of central tendency can be defined in addition to the mean. These include the median and the mode for continuous probability distributions. The median is the middle vaue of the range of 
possible outcomes. It is represented by the point where the cumulative probability is equal to 0.5 . The mode is the event or point having the highest probability. Figure A.4 shows the relative positions of the mean, median, and mode for a probability density function which is skewed to the right. For symmetrical curves the mean, median, and often the mode, all coincide.

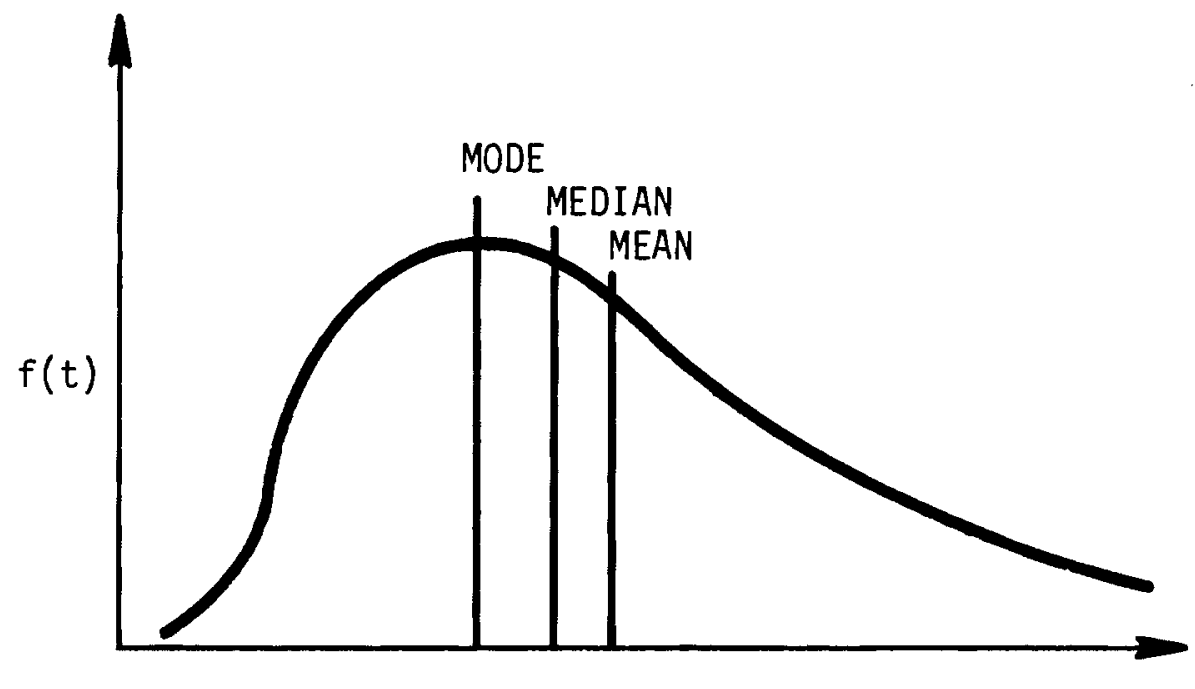

t COMPLETION TIME

FIGURE A.4. Skewed Distribution

In assessing uncertainties, the decision maker may wish to incorporate his confidence of some outcomes and consider the errors that may be associated with his assumptions. A confidence interval is an interval specified over the range of probability density function. Confidence is expressed as a probability determined from the density function. Errors are probabilities of outcomes that occur outside of the confidence interval. Figure A.5 gives an example of a confidence interval. If for example, the decision maker wishes to focus on those outcomes that occur $90 \%$ of the time, points (a) and (b) represent the minimum and maximum values of the range. The probability of outcomes in the interval from (a) to (b) is then 0.9. The "tails" or events outside the intervals have a total probability of 0.1 .

Figure A.5 shows a "two-sided" confidence interval. It is also possible to define a "one-sided" confidence interval. This is shown in Figure A.6. 
Here, a point is determined for a given confidence for outcomes which are "less than" or "greater than" the point. The confidence shown in Figure A.6 is for "greater than" confidence. This can be interpreted, for example, on a distribution over time, as the point in time after which $90 \%$ of the events are likely to occur.
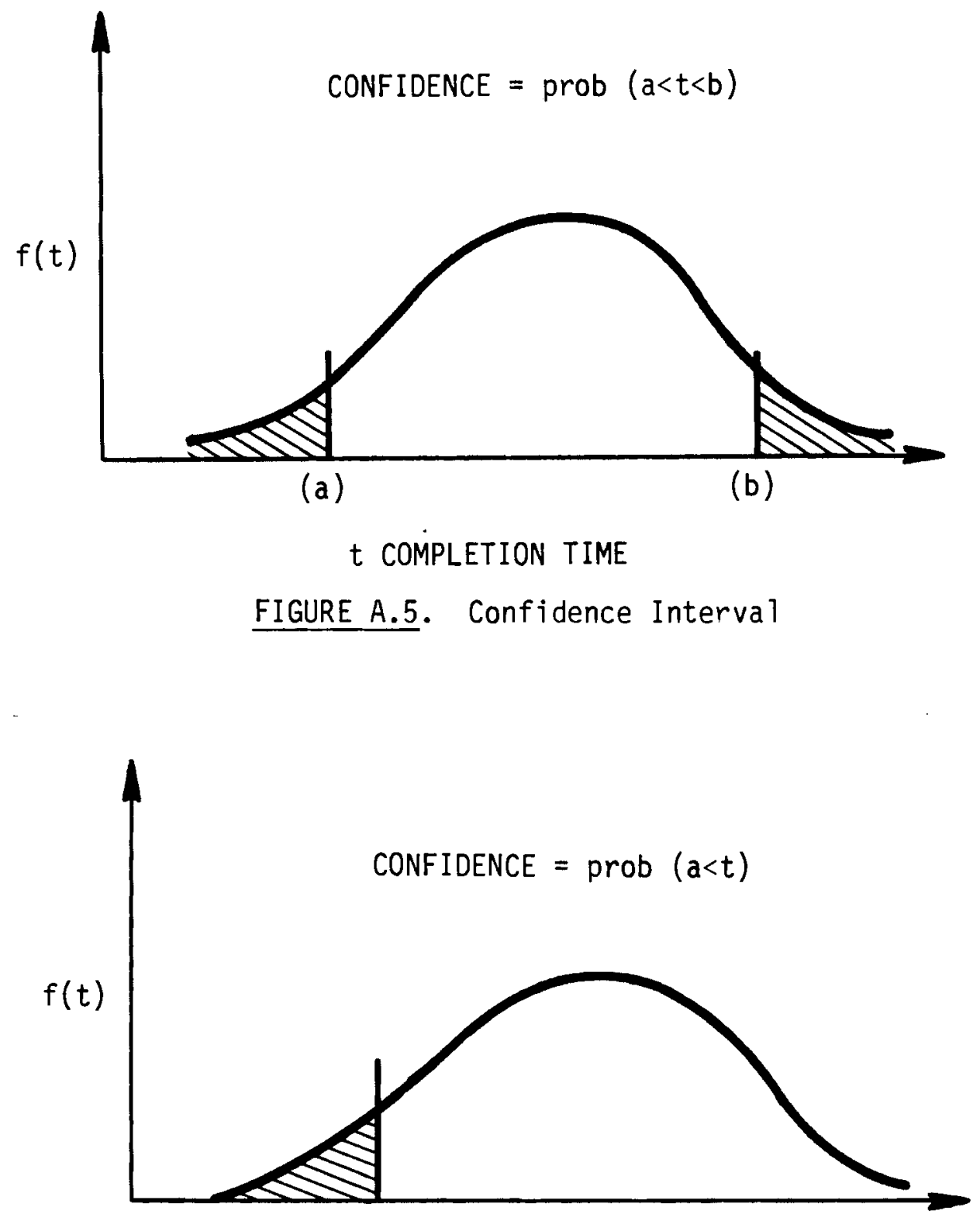

(a)

t COMPLETION TIME

FIGURE A.6. "One-Sided" Confidence Interval 
APPENDIX B

CALCULATIONAL APPROACH 
APPENDIX B

\section{CALCULATIONAL APPROACH}

A computer model (EDWIN) was developed to calculate the time-dependent probability that an FBR is commercially competitive. The model may be used to determine the probability that three potential criteria for introducing the FBR are satisfied. These criteria are listed below. Criterion 3 was selected for the analysis presented in the main body of the report.

1. resource limitations: The model calculates the time-dependent probability that all of the uranium costing less than a selected amount is consumed.

2. current energy cost: The model calculates the time-dependent probability that the FBR produces less expensive energy than an LWR based on the then current cost of uranium.

3. life-cycle cost: The model calculates the time-dependent probability that the FBR produces less expensive energy (mills/kwh) than an LWR based on the projected uranium cost for the life of the two reactors.

The model has three major components, a data set generator, a uranium consumption probability calculator, and a criteria analyzer. The data set generator calculates time-dependent uranium consumption for all combinations of input nuclear power capacity projections, LWR performance improvements, introduction schedules for two types of advanced reactors and an implementation schedule for advanced isotope separation technology. The probability calculator determines time-dependent uranium consumption probability functions based on probabilistic data for the above factors. The uranium consumption probability functions are compared with uranium availability probability data to evaluate criterion 1 or with uranium cost-given consumption probability data, to generate the time-dependent uranium cost probability functions needed 
to evaluate criteria 2 and 3 . Reactor capital cost data and fuel cycle cost data are combined with the time-dependent uranium cost data to evaluate criteria 2 and 3.

The EDWIN model has more extensive capabilities than required to perform the analysis presented in the main body of the report. As stated above, two criteria other than the reference criterion (life-cycle cost) may be used to analyze FBR introduction. Provisions are made for the potential introduction of two types of advanced reactors prior to FBR introduction. In the process of calculating the time-dependent probability of satisfying the criteria for FBR introduction, the model calculates the time-dependent uranium consumption probability, time-dependent uranium cost probability, and future reactor mix probabilities. These features make the model adaptable for analysis of general nuclear development strategy issues. The following sections describe both the analysis for this report and the additional capabilities of the model.

\section{B.1 DATA SET GENERATION}

The initial part of the analysis consists of calculating the uranium utilization data required for the subsequent probability calculations. There are two major components of the data generation calculation, which is illustrated in Figure B.1. The future mix of nuclear generation capacity is based on assumptions of future nuclear power capacity, improvements in LWR uranium utilization, and introduction of advanced reactors. The second major component uses the calculated future mix of nuclear reactor capacity, with reactor uranium consumption and enrichment tails assay assumptions, to project uranium consumption.

\section{B.1.1 Reactor Mix Calculation}

Four factors are necessary to calculate the future mix of nuclear generation capacity: 


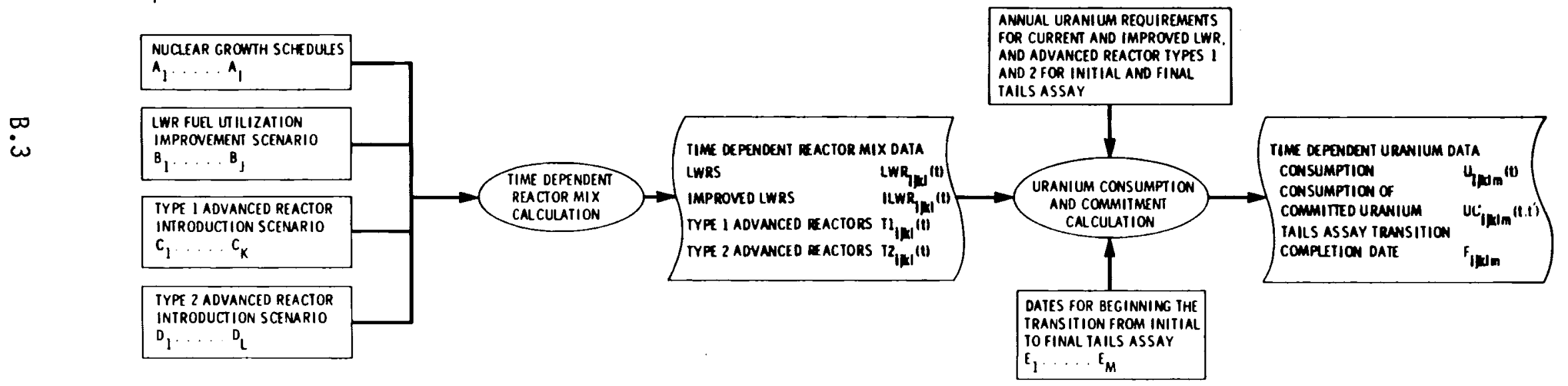

FIGURE B.1. Data Set Generation 
- nuclear power capacity projections $\left(A_{1} \ldots A_{I}\right)$-- Total future nuclear generation capacity is specified in GWe for each year for I alternative projections.

- LWR fuel utilization improvement scenarios $\left(B_{1} \ldots B_{j}\right)$-- Dates for beginning the transition from current LWR uranium utilization to decreased uranium utilization; rates of transition are specified for $\mathrm{J}$ alternative scenarios.

- type 1 advanced reactor introduction scenarios $\left(C_{1} \ldots C_{K}\right)--K$ alternative dates for introduction of type 1 advanced reactor are specified.

- type 2 advanced reactor introduction scenarios $\left(D_{1} \ldots D_{L}\right)--L$ alternative dates for introduction of type 2 advanced reactor are specified.

Each of these factors may be characterized by several alternatives. The rate of transition from the current LWR fuel cycle to one with improved uranium utilization is described by the proportion of total LWRs employing the improved fuel cycle as a function of time. This parameter may be specified for up to 30 years after the assumed availability date for the improved fuel cycle. The introduction rate for the two advanced reactor types is specified in terms of an upper limit capacity schedule for 10 years after the date that these reactors are allowed.

The total set of future nuclear power capacity scenarios is generated by constructing a 11 IXJXKXL combinations of nuclear power capacity projections, reactor uranium utilization improvement scenarios, and introduction dates for advanced reactor types 1 and 2. For each such combination ( $i j k 1$ ) the amount of new capacity required each year is calculated by determining the increase in total nuclear capacity plus the additional capacity necessary to replace reactors retired. Annual retirements are based on an assumed 30 year reactor life. Once the amount of new capacity required each year is calculated, the type of reactor capacity that will be added is determined. For each year, the most advanced form of generation capacity is added that is allowed by the conditions specified for scenario (ijkl). For a particular year, as many of type 2 advanced reactors are assumed built as is allowed by the introduction date for that reactor type and the subsequent 10-year capacity limitation. 
Required annual capacity additions above that amount are accomplished by the addition of as many advanced reactor type 1 as are required, subject to the limitations of its availability date and capacity restrictions. If any additional capacity is required, it is assumed to consist of current or improved LWRs. The proportion of current to improved LWRs is calculated from the input introduction date and implementation schedule for scenario (ijkl). Results of a typical scenario (ijkl) are illustrated in Figure B.2. The following variables are calculated for each of the IXJXKXL possible scenarios:

\section{$\operatorname{LWR}_{i j k l}(t)$ : the capacity of current LWRs at time $t$ for scenario (ijk 1$)$.}

ILWR $_{i j k l}(t)$ : the capacity of improved fuel cycle LWRs at time $t$ for scenario ( $i k j 1)$.

$T l_{i j k l}(t)$ : the capacity of type 1 advanced reactors at time $t$ for scenario ( $i j k 1)$.

$T 2_{i j k l}(t)$ : the capacity of type 2 advanced reactors at time $t$ for scenario ( $i j k 1)$.

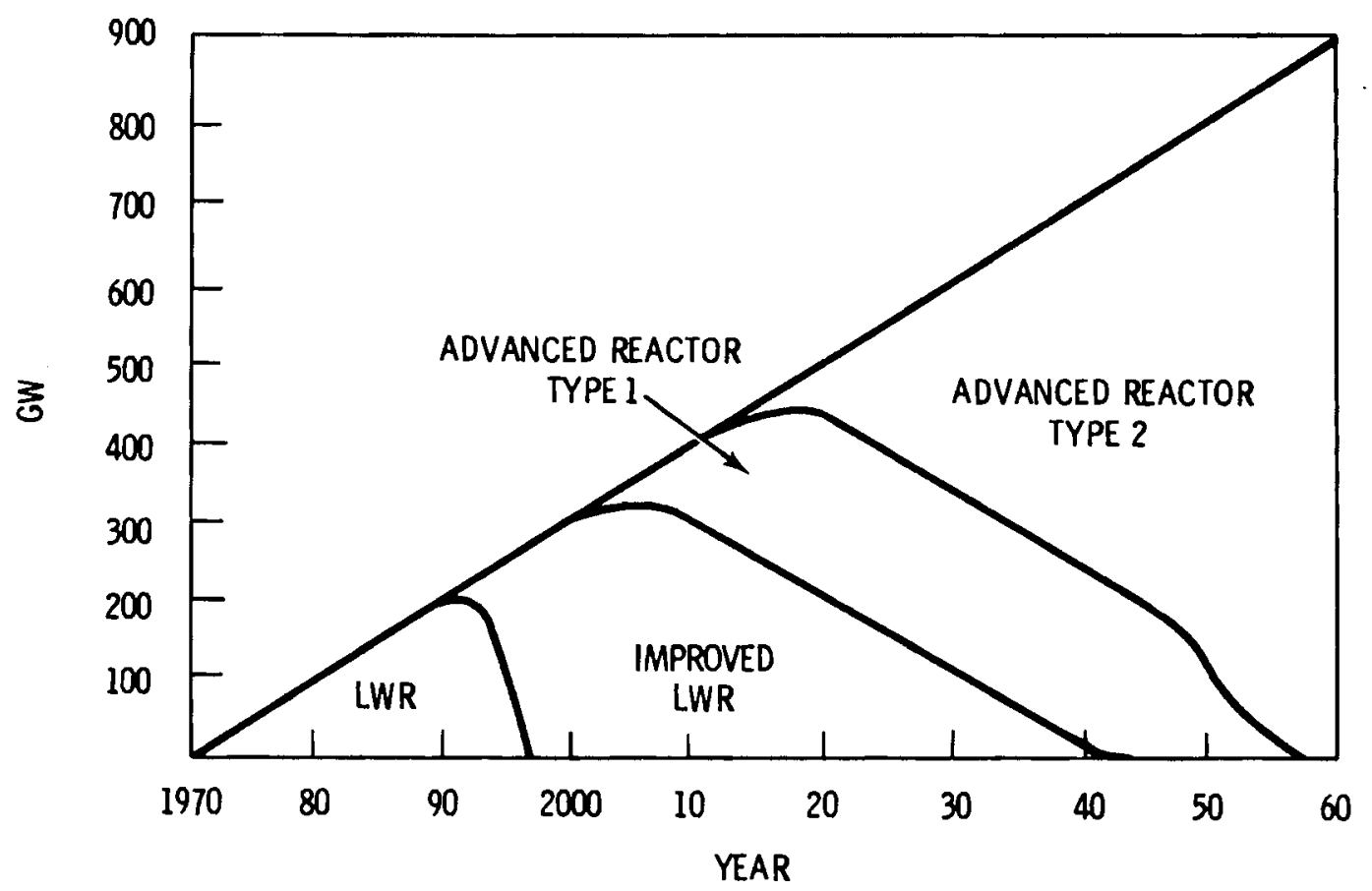

FIGURE B.2. Sample Results for Reactor Mix Calculation 


\section{B.1.2 Uranium Consumption Calculation}

After the time-dependent reactor mix is determined, the uranium consumption is calculated. Figure B.I shows that two additional data items are required for the uranium consumption calculation. Annual uranium requirements are specified for each reactor type for both the current enrichment tails assay and a future lower tails assay. Since annual data are specified, any life-cycle capacity factor profile can be simulated. The other data requirement is the date that the transition from the current to a lower enrichment tails assay begins. A number of alternative dates, $E_{1}$ to $E_{M}$, may be specified.

The time-dependent cumulative uranium consumption for each of the ( $i j k 1)$ reactor mix scenarios is calculated for both the initial and future enrichment tails assay. Figure B.3 illustrates the results of this calculation for one

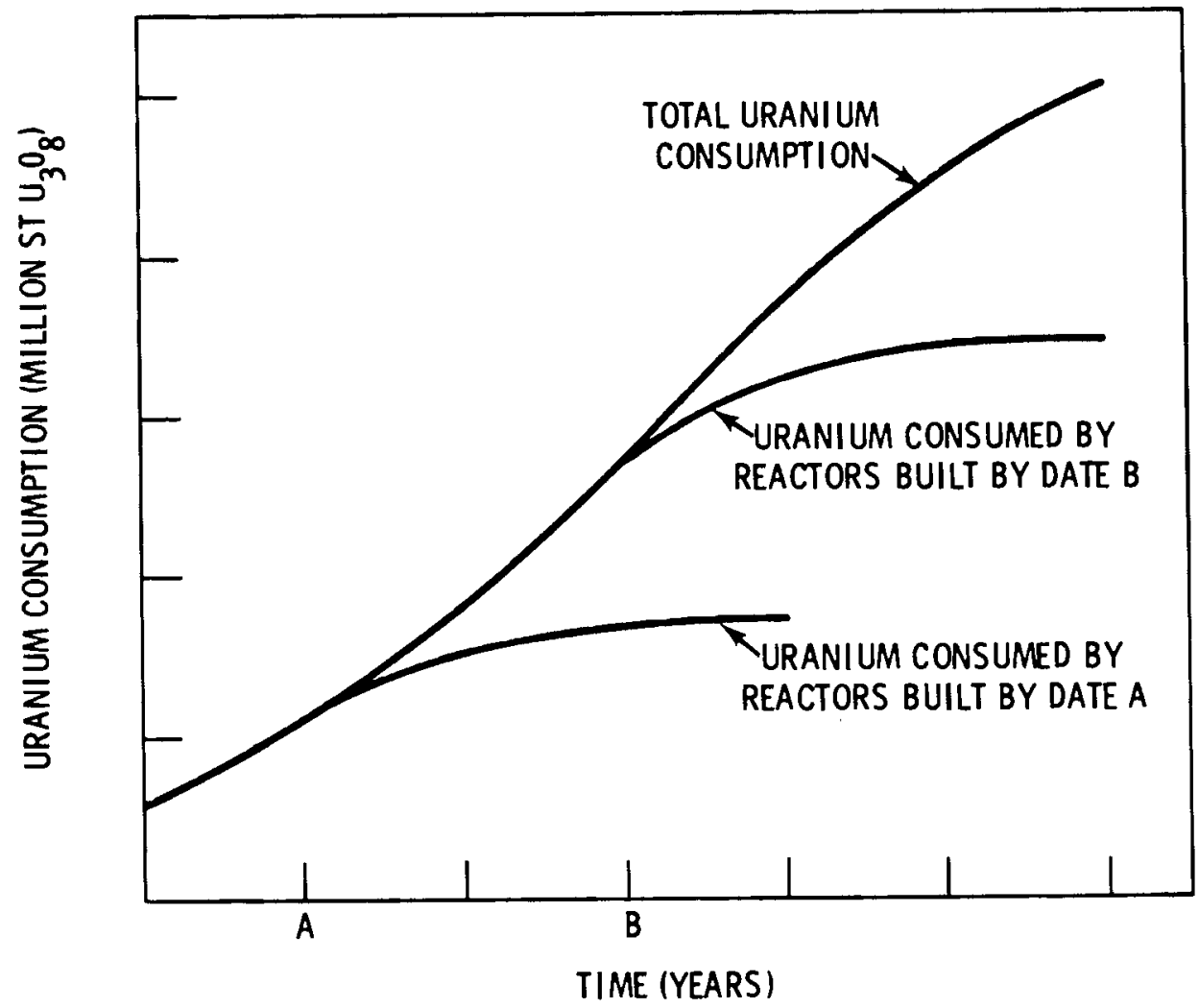

FIGURE B.3. Cumulative Uranium Consumption Results 
of the tails assays. Also displayed in the figure is the cumulative consumption of uranium by reactors built by selected dates. This represents the consumption of uranium committed by those dates if no additional reactors are built. This consumption of committed uranium is calculated for later use in the calculation of time-dependent uranium cost probability functions.

Another set of data similar to that represented by Figure B.2 is calculated for the future tails assay. The length of time for the transition from the higher to lower tails assay is determined in one of the two ways illustrated in Figure B.4. The date that the transition from the higher to lower tails assay begins (date $E_{m}$ in Figure B.4) is specified. The date at which the uranium consumption of the lower tails assay curve would be intersected if uranium consumption continued at the same annual rate as the year the transition begins is determined. This is date $F_{1}$ in Figure B.4. This transition reflects a minimal disruption of the uranium industry, since annual uranium requirements are constant for the length of time required for the transition.

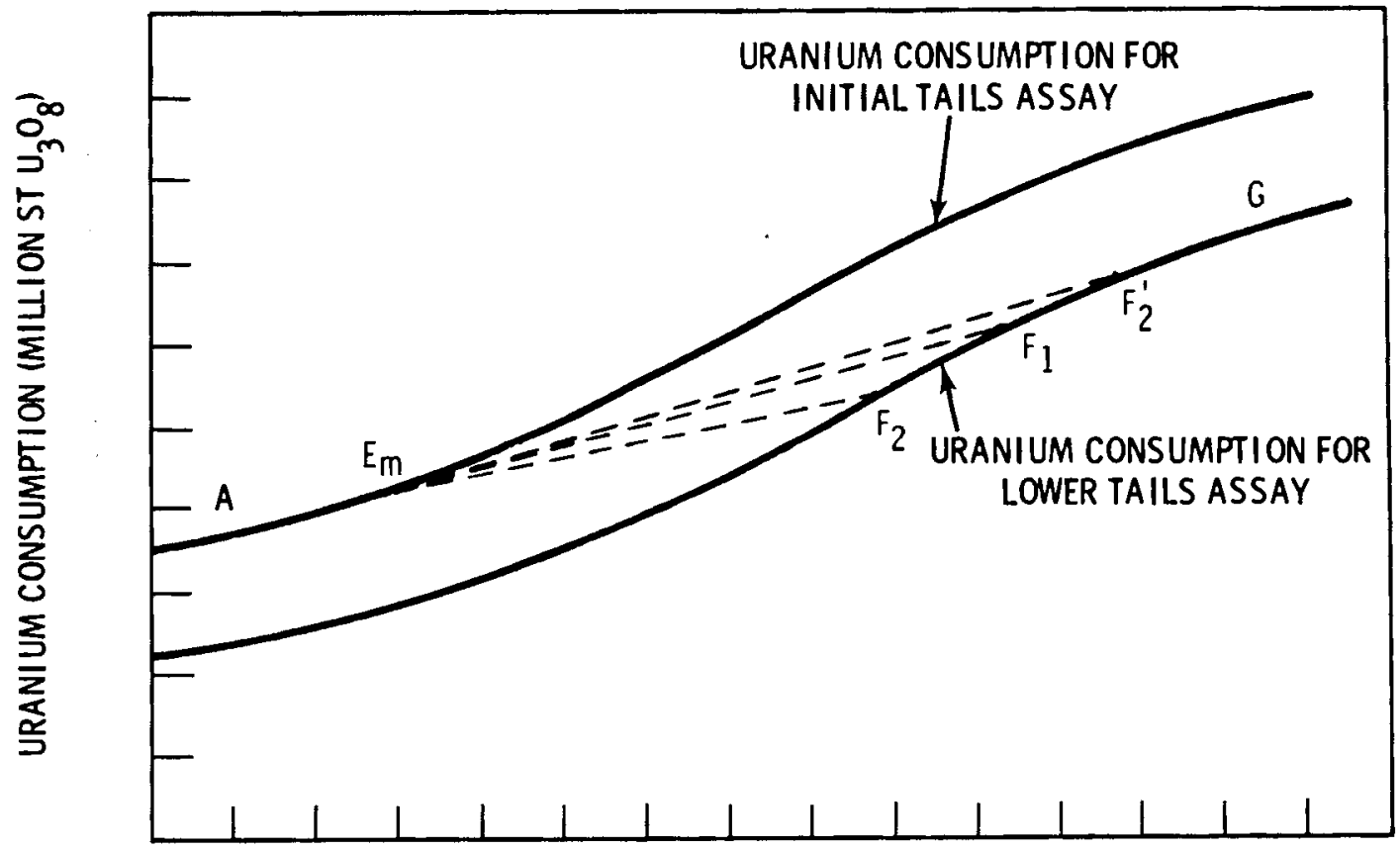

TIME (YEARS)

FIGURE B.4. Transition From Initial to Lower Tails Assay 
Another date $\left(F_{2}\right.$ or $\left.F_{2}^{\prime}\right)$ for completing the transition is determined by adding an upper limit number of years to date $E_{m}$. This simulates specifying a maximum or upper limit time for the transition from the higher to lower tails assay. An upper limit of 30 years was assumed for this study. If $E_{m}$ plus the upper limit number of years is later than date $F_{1},\left(F_{2}^{\prime}\right.$ in Figure B.4) the cumulative uranium consumption for scenario ( $i j k l m$ ) is represented by the line $A E_{m} F_{1} G$. If $E_{m}$ plus the upper limit number of years (date $F_{2}$ ) is earlier than date $F_{1}$, then cumulative uranium consumption for scenario ( $i j k l m$ ) is represented by the line $A_{m} F_{2} G_{\text {. The date the }}$ transition is completed $\left(F_{1}\right.$ or $\left.F_{2}\right)$ is called $F_{i j k l m}$. The transition to the lower tails assay for the consumption of committed uranium illustrated in Figure B.3 is calculated by interpolating between the higher and lower tails assay curves based on the degree of completion of the cumulative consumption transition.

These calculations are performed for all (IXJXKXLXM) combinations of reactor capacity mix and tails assay scenarios. The following results are calculated for use in the probability calculation:

$$
\begin{aligned}
& U_{i j k l m}(t) \text { : Cumulative uranium consumption at time } t \text { for } \\
& \text { scenario (ijklm). } \\
& U C_{i j k 1 m}\left(t, t^{\prime}\right) \text { : Cumulative consumption by time } t\left(t>t^{\prime} 10\right) \\
& \text { of uranium committed to reactors built by time } \\
& \left.t^{\prime}+10 \text { for scenario (ijk } 1 \mathrm{~m}\right) \text {. } \\
& F_{i j k l m} \text { : The completion date for the transition from the } \\
& \text { higher to lower tails assay for scenario ( } i j k l m) \text {. }
\end{aligned}
$$

The first result, $U_{i j k l m}(t)$, represents cumulative uranium consumption by time $t$ for scenario $i j k l m$ for all times $t$ prior to the introduction of an FBR. The second result shown above, $U C_{i j k}{ }_{1 m}\left(t, t^{\prime}\right)$, is used to represent the cumulative uranium consumption for scenario (ijklm) after FBR introduction. If an FBR is introduced at time $t^{\prime}$, the cumulative uranium consumption for all $t>t^{\prime}$ will be reduced. The subsequent rate of uranium consumption will be determined by how rapidly FBRs displace LWRs in the nuclear power capacity projection. For this analysis, it was assumed that new LWRs (or nonFBR advanced reactors) would be added at the same rate as specified by the 
capacity projection for 10 years after the FBR was introduced. After time $t$ ' +10 , no such capacity is added. The actual transition to adding only FBR capacity will probably take longer than 10 years, and will occur gradually rather than abruptly. The transition assumed for this analysis may underestimate the number of LWRs (or advanced reactors) that will be built after the first FBR, and therefore underestimate the subsequent rate of uranium consumption. This is offset by the fact that the calculation does not account for uranium that will be recovered from reprocessing LWR spent fuel for plutonium for FBR startup. These offsetting effects make the assumed transition a reasonable approximation for calculating uranium consumption.

\section{B.2 URANIUM CONSUMPTION PROBABILITY FUNCTION CALCULATOR}

This part of the analysis uses the information in the data set and relative probability data for the data set variables to calculate the timedependent uranium consumption probability. This calculation is illustrated in Figure B.5.

The previous section identified five major factors related to reactor consumption:

$$
\begin{aligned}
& \text { Nuclear Growth Schedules }=A_{1} \ldots A_{I} \\
& \text { LWR Improvement Scenarios }=B_{1} \ldots B_{J} \\
& \text { Type } 1 \text { Advanced Reactor } \\
& \text { Introduction Dates } \\
& \text { Type } 2 \text { Advanced Reactor } \\
& \text { Introduction Dates } \\
& \text { Beginning Dates for } \\
& \text { Transition to Lower } \\
& \text { Tails Assay }
\end{aligned}
$$

Since all possible combinations of these factors are considered in constructing the data base, there are (IXJXKXLXM) total scenarios associated with these five factors. The relative probability of each of the alternatives for each category is assigned such that each of the five factors are considered 


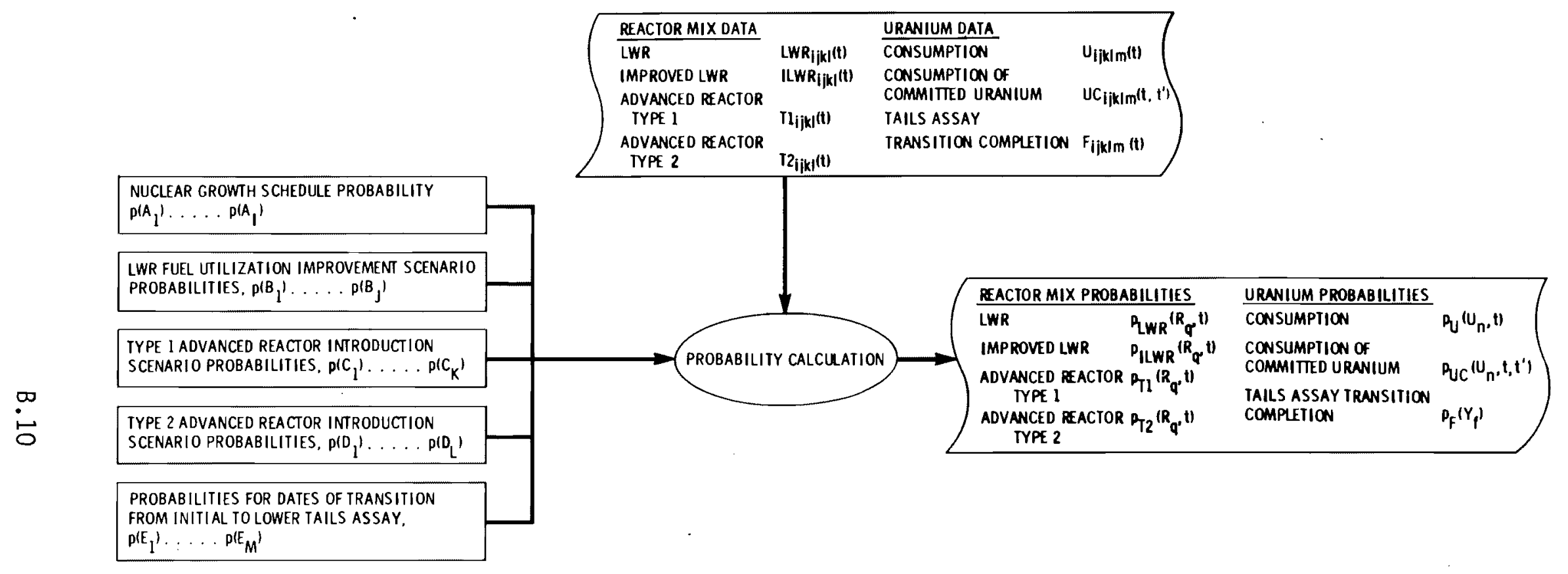

FIGURE B.5. Initial Probability Calculation 
independent. Therefore, the probability assigned to a particular scenario is the product of the probabilities of the individual factors:

$$
p\left(A_{i} B_{j} C_{k} D_{1} E_{m}\right)=p\left(A_{j}\right) \times p\left(B_{j}\right) \times p\left(C_{k}\right) \times p\left(D_{1}\right) \times p\left(E_{m}\right)
$$

To construct the probability density functions of interest, each piece of data in the data base is assigned the probability of the combination of factors which generated it. If case $A_{j} B_{j} C_{k} D_{1} E_{m}$ projects uranium consumption of $U_{i j k l m}(t)$ by time $t$, then $U_{i j k l m}(t)$ has probability $p\left(A_{j} B_{j} C_{k} D_{l} E_{m}\right)$. To construct the probability density function for uranium consumption at $t$ ime $t$, a set of intervals of uranium consumption $U_{1}$ to $U_{N}$ is constructed. Each of the calculated uranium consumptions for time $t$ in the data base is tested to see which interval it is in. For example, if $U_{n-1}<U_{i j k i m}(t)<U_{n}$, then $p\left(A_{i} B_{j} C_{k} D_{1} E_{m}\right)$ is added to the probability for the interval $U_{n-1}$ to $U_{n}$. When each of the ( $I \times J \times K \times L \times M$ ) data points is tested and its corresponding probability assigned to the appropriate interval, the probability density function $p_{U}\left(U_{n}, t\right)$ at time $t$ is complete.

Similar calculations are performed to generate the other probability density functions of interest. The results of these calculations are illustrated in Figure B.5 and surmarized below:

$P_{U}\left(U_{n}, t\right)$ : The probability that cumulative uranium consumption at time $t$ is between $U_{n-1}$ and $U_{n}$, where $n$ ranges from 1 to $N$.

$P_{U C}\left(U_{n}, t, t^{\prime}\right):$ The probability that cumulative uranium consumed at $t$ ime $t\left(t>t^{\prime}\right)$ if the $F B R$ is introduced at $t^{\prime}$ is between $U_{n-1}$ and $U_{n}$, where $n$ ranges from 1 to $N$.

$P_{L W R}\left(R_{q}, t\right):$ The probability that the capacity of current type LWRs at time $t$ is between $R_{q-1}$ and $R_{q}$, where $q$ ranges from 1 to $Q$.

$P_{\text {ILWR }}\left(R_{q}, t\right)$ : The probability that the capacity of improved fue 1 cycle LWRs at time $t$ is between $R_{q-1}$ and $R_{q}$, where $q$ ranges from 1 to $Q$. 


$$
\begin{aligned}
& P_{T 1}\left(R_{q}, t\right): \text { The probability that the capacity of type } 1 \\
& \text { advanced reactors at time } t \text { is between } R_{q-1} \text { and } \\
& R_{q} \text {, where } q \text { ranges from } 1 \text { to } Q . \\
& P_{T 2}\left(R_{q}, t\right): \text { The probability that the capacity of type } 2 \\
& \text { advanced reactors at time } t \text { is between } R_{q-1} \text { and } \\
& R_{q} \text {, where } q \text { ranges from } 1 \text { to } Q . \\
& P_{F}\left(Y_{f}\right): \text { The probability that the transition to the lower } \text { tails assay is completed between the years } Y_{f-1} \\
& \text { and } Y_{f} \text {, where } f \text { ranges from } 1980 \text { to } 2090 .
\end{aligned}
$$

The first two of these probability density functions are used directly in evaluating the criteria for FBR introduction. The other functions provide additional information about the impact of advanced reactor or enrichment technology on uranium utilization.

\section{B.3 CRITERIA ANALYSES}

The probability density functions for uranium consumption are used to analyze the three criteria for FBR introduction. These criteria differ in the type of uranium availability data required. The first criterion requires data expressing the probability of various amounts of uranium. Criteria 2 and 3 require data concerning the probable cost of uranium as a function of how much is consumed. The analyses of these criteria are discussed in the following sections.

\section{B.3.1 Analysis of Criterion 1}

Criterion 1 is evaluated by comparing the uranium consumption probability density function with the probabilistic uranium supply function to determine the probability that all of the uranium costing less than some selected cost has been consumed. This evaluation can be made for $t^{\prime}$, the date of FBR introduction, or $t^{\prime}+30$, the end-of-life for other reactors coming on-line in 


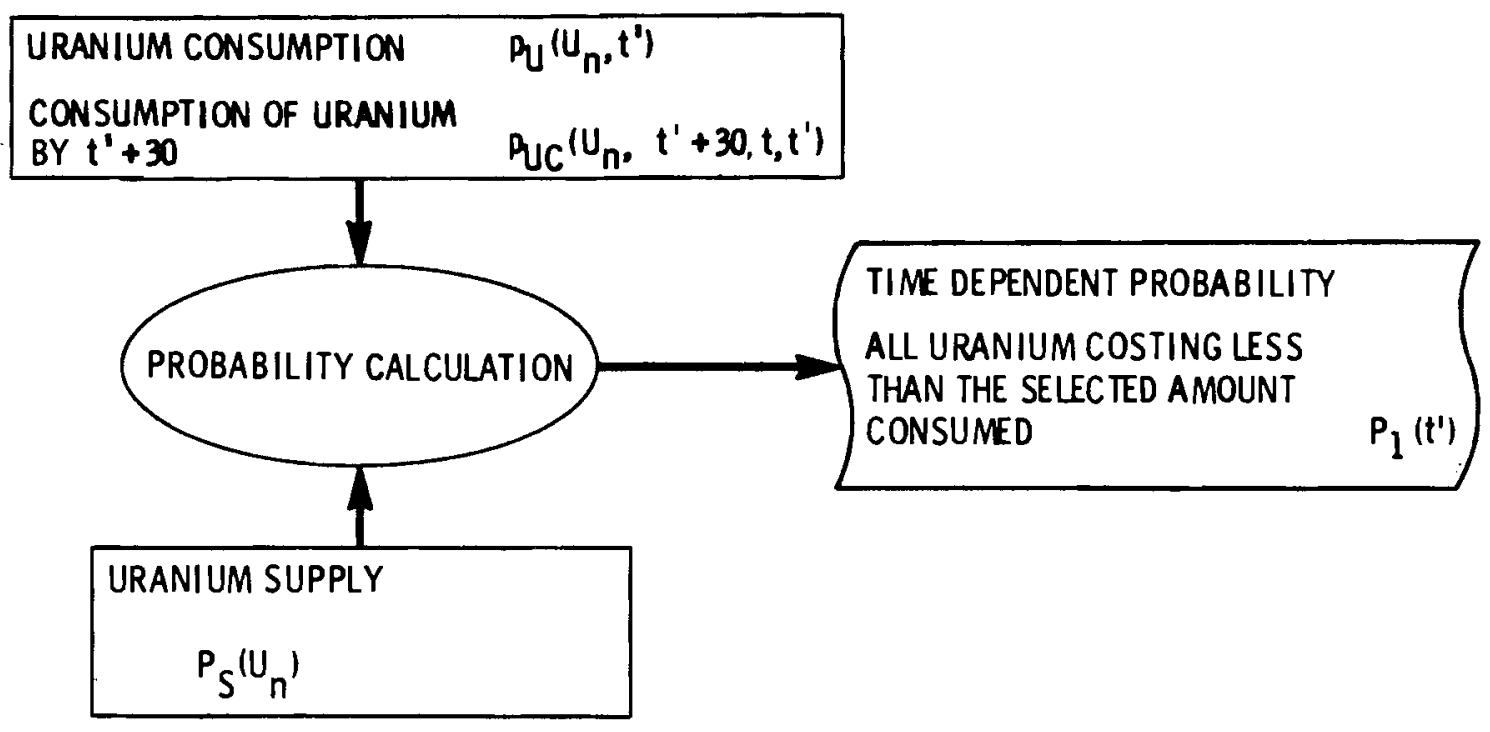

FIGURE B.6. Criteria 1 Evaluation

year $t^{\prime}$. This is illustrated in Figure B.6. The uranium supply probability is in the form of a cumulative probability, or probability distribution function. The uranium supply data, $P_{S}\left(U_{n}\right)$, consist of the cumulative probability that there is $U_{n}$ or less uranium available at the cost selected for evaluating Criterion 1 . To evaluate Criterion 1 for time $t$ ', the FBR introduction date, the following calculation is performed:

$$
P_{1}\left(t^{\prime}\right)=\sum_{n=1}^{N} p_{U}\left(U_{n}, t^{\prime}\right) P_{S}\left(U_{n}\right)
$$

where

$$
\begin{aligned}
P_{1}\left(t^{\prime}\right)= & \text { the cumulative probability that all of the uranium at the } \\
& \text { selected cost is consumed or committed by time } t^{\prime} \text {, which is } \\
& \text { the probability that Criterion } 1 \text { is satisfied. } \\
p_{U}\left(U_{n}, t^{\prime}\right)= & \text { the probability that the amount of uranium consumed or } \\
& \text { committed by time } t \text { is between } U_{n-1} \text { and } U_{n} \\
p_{S}\left(U_{n}\right)= & \text { the probability that there is } U_{n} \text { or less uranium at } \\
& \text { the selected cost. }
\end{aligned}
$$


This calculation is repeated a number of times to construct the complete timedependent probability density function $P_{1}(t)$ of satisfying criterion 1 . If the probability that all of the uranium costing less than a selected amount by $t^{\prime}+30$ is desired, then $P_{u c}\left(U_{n}, t^{\prime}+30, t^{\prime}\right)$ is substituted in the equation for $P_{u}\left(U_{n}, t^{\prime}\right)$.

\section{B.3.2 Analys is of Criteria 2 and 3}

The calculations performed to analyze whether criteria 2 and 3 are satisfied are illustrated in Figure B.7. Since analysis of these criteria requires energy cost comparisons, they also require uranium cost data. These data are input in the form of the conditional probabilities of uranium cost being within cost intervals $C_{1}$ to $C_{R}$ when selected amounts of uranium have been consumed. For example, $p_{C}\left(C_{r} \mid U_{n}\right)$ represents the probability that uranium cost is in the interval $C_{r-1}$ and $C_{r}$ when the amount $U_{n}$ uranium has been consumed. To calculate the uranium cost probability at time $t$, the following calculation is performed:

$$
p_{C}\left(C_{r}, t\right)=\sum_{n=1}^{N} p_{C}\left(C_{r} \mid U_{n}\right) p_{U}\left(U_{n}, t\right)
$$

where

$$
\begin{aligned}
p_{C}\left(C_{r}, t\right)= & \text { the probability that uranium costs between } C_{r-1} \text { and } \\
& C_{r} \text { at time } t \\
p_{C}\left(C_{r} U_{n}\right)= & \text { the probability that uranium cost is in the interval } \\
& C_{r-1} \text { to } C_{r} \text { when } U_{n} \text { uranium has been consumed } \\
p_{U}\left(U_{n}, t\right)= & \text { the probability that } U_{n-1} \text { to } U_{n} \text { uranium has been } \\
& \text { consumed by time } t .
\end{aligned}
$$

This calculation is repeated for $C_{1}$ to $C_{R}$ to construct the entire uranium cost probability density function $p_{C}\left(C_{r, t}\right)$ for time $t$. If the time-dependent uranium cost based on consumption of uranium after the FBR is introduced is required, $P_{U C}\left(U_{n}, t, t^{\prime}\right)$ is substituted for $P_{U}\left(U_{n}, t\right)$ in the equation. 


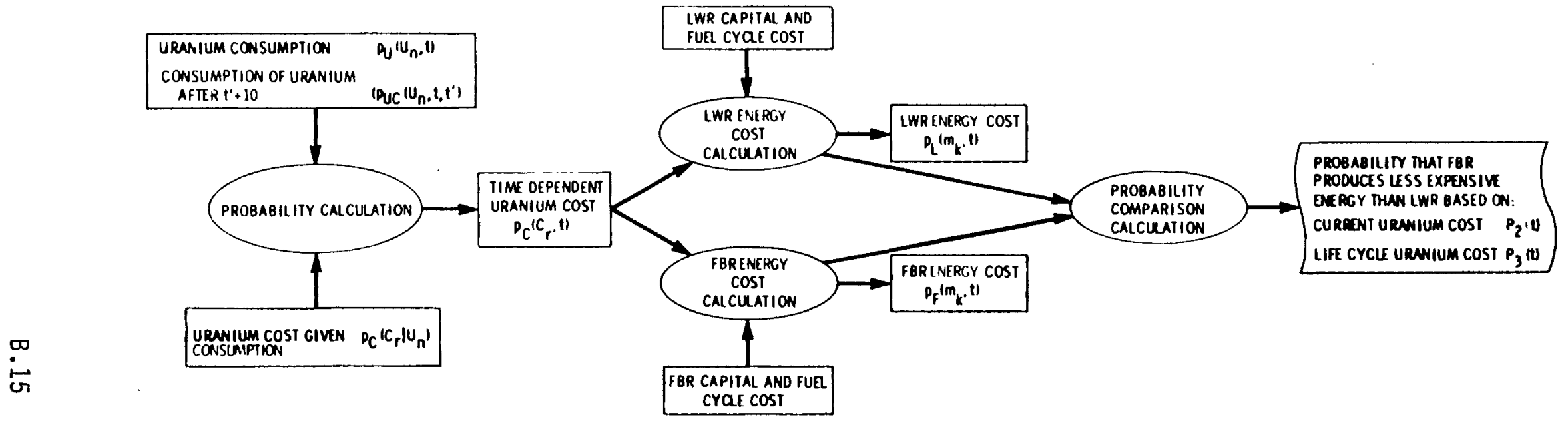

FIGURE B.7. Criteria 2 and 3 Evaluation 
Additional economic data are required to analyze criteria 2 and 3 . These criteria require comparing the cost of LWR and FBR energy. As shown in Figure B.7, all non-uranium energy costs for these reactors are required. The data for LWR energy cost consist of a levelized cost in mills/kWh representing capital, operating and maintenance, and non-uranium fuel cycle costs, and a set of sensitivity coefficients relating the cost of LWR energy to uranium cost. These sensitivity coefficients represent the contribution to the levelized life-cycle cost per $\$ / 1 b \mathrm{U}_{3} \mathrm{O}_{8}$ for different intervals during the life of the reactor. Thus, the relatively higher contribution of the early fuel requirements to levelized life-cycle cost of the early fuel requirements is modeled in a manner that also allows recognition of the increased uranium cost with time. The levelized energy cost from an LWR starting at time $t$ is represented by the equation:

$$
L(t)=C_{L}+A_{1} C_{1}+A_{2} C_{2}+\ldots \cdot A_{7} C_{7}
$$

where

$$
\begin{aligned}
L\left(t^{\prime}\right)= & \text { levelized } L \text { WR energy cost at time } t \\
C_{L}= & \text { levelized capital operating and maintenance, } \\
& \text { and non-uranium fuel cost } \\
A_{1} \ldots A_{7}= & \text { sensitivity coefficient of levelized energy } \\
& \text { cost per } \$ / 1 b U_{30} \text { for intervals } 1 \text { through } 7 \\
c_{1}= & \text { cost of uranium } t^{\prime}-2 \text { to } t^{\prime}+2 \\
c_{2}= & \text { cost of uranium from } t^{\prime}+3 \text { to } t^{\prime}+7 \\
c_{7}= & \text { cost of uranium from } t^{\prime}+28 \text { to } t^{\prime}+32
\end{aligned}
$$

The derivation of this equation and evaluation of constants for this study may be found in Appendix $C$. A probability density function for LWR energy cost is constructed by combining, as prescribed by the equation, the probability density function representing the capital, operating and maintenance, and nonuranium fuel cycle costs with probability density functions for the uranium cost at the required time intervals. Since uranium costs are not independent from one interval to the next, the probability density functions are assumed 
correlated. For example, low uranium costs in the first interval are assumed to correspond to the lower values in each of the uranium cost probability density functions for subsequent intervals. Uranium costs from one interval to the next are aligned on the basis of equal cumulative probability. This means that if the uranium cost in the first period is the median cost for the period, then subsequent uranium costs are the medians of their respective probability density functions. The same is true for all other values of cumulative probability. With this assumption the LWR's levelized life-cycle cost is calculated, and its corresponding probability is assigned to the appropriate energy cost interval. Evaluating the LWR energy cost equation for all $R$ intervals of uranium cost gives the probability density function for LWR energy cost:

$$
\begin{aligned}
p_{L}\left(M_{k}, t^{\prime}\right)= & \text { probability that the levelized LWR life-cycle cost } \\
& \text { at time } t \text { is in the interval } M_{k-1} \text { to } M_{k}(\text { mills } / k W h) .
\end{aligned}
$$

The equation for FBR energy cost is similar. A set of sensitivity coefficients represents the relationship of FBR's levelized life-cycle cost to uranium costs in various time intervals. These coefficients represent the relationship between the value (cost) of plutonium and the cost of uranium. The levelized life-cycle cost of energy from the FBR starting at time $t$ is:

$$
F\left(t^{\prime}\right)=C_{F}+B_{1} C_{1}+B_{2} C_{2} \ldots B_{7} C_{7}
$$

where

$$
\begin{aligned}
F(t)= & \text { levelized } F B R \text { energy cost for a reactor coming on-line } \\
& \text { at } t \text { ime } t^{\prime} \\
C_{F}= & \text { levelized capital, operating and maintenance, and } \\
& \text { non-uranium fuel cycle cost } \\
B_{1} \ldots B_{7}= & \text { sensitivity coefficient of } F B R \text { levelized energy } \\
& \text { cost per } \$ / l b U_{3} 0_{8} \text { for intervals } 1 \text { through } 7 \\
c_{1}= & \text { cost of uranium from } t^{\prime}-2 \text { to } t^{\prime}+2 \\
c_{2}= & \text { cost of uranium from } t^{\prime}+3 \text { to } t^{\prime}+7 \\
c_{7}= & \text { cost of uranium from } t^{\prime}+28 \text { to } t^{\prime}+32
\end{aligned}
$$


The derivation of this equation and the values of the constants are discussed in Appendix C. A probability density function representing the levelized cost of energy is constructed in a similar manner to that described for the LWR. A probability density function representing the capital, operating and maintenance, and non-uranium fuel cycle costs is combined with probability density functions for the uranium cost at the required intervals. The probability density function for capital, operating and maintenance, and non-uranium fue 1 cycle costs is constructed with intervals having equal probabilities as in the equivalent probability density function for LWR energy cost. This facilitates the comparison of LWR and FBR life-cycle costs. The probability density function for the FBR's life-cycle cost is:

$$
\begin{aligned}
p_{F}\left(M_{k}, t^{\prime}\right)= & \text { probability that the levelized FBR life-cycle cost } \\
& \text { for a reactor coming on-line at time } t \text { is in the } \\
& \text { interval } M_{k-1} \text { to } M_{k} .
\end{aligned}
$$

Comparisons between LWR and FBR life-cycle costs are made as the respective probability density functions are calculated. The probability density functions for LWR's and FBR's levelized capital costs, operating and maintenance costs, and non-uranium fuel cycle costs $\left(C_{L}\right.$ and $\left.C_{r}\right)$ are assumed correlated. The correspondence between values from the two probability density functions is made on the basis of equivalent cumulative probability. For example, the median value for the LWR cost component corresponds to the median value of the FBR cost component.

LWR and FBR energy costs are calculated for corresponding values of $C_{L}$ and $C_{F}$ and for projected uranium cost probability functions. Projected uranium costs are correlated, as previously discussed. Corresponding LWR and FBR energy costs are compared. A probability density function representing the difference (mills/Kwh) between the LWR's and FBR's life-cycle cost is constructed. The difference between each corresponding pair of $L W R$ and FBR energy costs is calculated, and the probability of the combination of $C_{L}, C_{F}$, and uranium cost projection for that energy cost pair is assigned to the difference. Repeating this calculation for all possible combinations of $C_{L}, C_{F}$ and uranium cost yields the probability density function: 


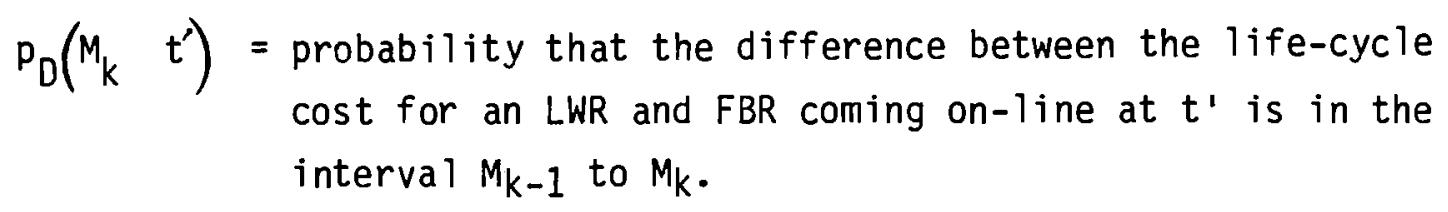

Negative values of $M_{k}$ correspond to the FBR's life-cycle costs being less than the LWR's life-cycle costs.

This calculation is performed in two slighty different ways to determine whether criteria 2 and 3 are satisfied. Criterion 2 is based on the cost of uranium at the time the LWR and FBR come on-line. To evaluate the timedependent probability that FBR's energy cost is less than LWR's energy cost at the time the reactors come on-line, $p_{D}\left(M_{k}, t^{\prime}\right)$ is calculated for various dates assuming the uranium cost remains constant for the life of the reactors. Criterion 3 is based on the life-cycle uranium cost projection. To evaluate the time-dependent probability that the FBR's life-cycle cost is less than LWR's life-cycle cost, $p_{D}\left(M_{k}, t\right)$ is calculated for various dates assuming projected life-cycle uranium costs.

The probability that criterion 2 or 3 is satisfied is equal to the probability that $M_{k}<0$ in the respective probability density functions, $p_{D}\left(M_{k}, t^{\prime}\right)$. The probabilities that these criteria are satisfied are:

$$
\begin{aligned}
P_{2}\left(t^{\prime}\right)= & \text { probability for reactors coming on-line at time } t^{\prime} \\
& \text { that the FBR produces less expensive energy than the } \\
& \text { LWR based on the current cost of uranium (Criterion } 2) \\
P_{3}\left(t^{\prime}\right)= & \text { probability for reactors coming on-line at time } t^{\prime} \\
& \text { that the FBR produces less expensive energy than the } \\
& \text { LWR based on the projected life-cycle uranium cost for } \\
& \text { the two reactors (Criterion } 3) .
\end{aligned}
$$





\section{APPENDIX C}

NUCLEAR GROWTH SCHEDULE CALCULATION 
APPENDIX C

\section{NUCLEAR GROWTH SCHEDULE CALCULATION}

One of the major uncertainties that bears on the commercial introduction of the FBR is how much light water reactor (LWR) generating capacity will be installed in the future. The growth of LWR capacity determines the rate at which the domestic uranium resources will be used, and therefore the time the FBR will become economically competitive. This analysis assumed three primary factors controlling future LWR capacity growth: the uranium supply, the relative costs of LWR power and its alternatives, and the future demand for electrical energy. The interaction among these factors was evaluated using the econometric simulation model ETA-MACRO. That model is described briefly here and in detail in ETA-MACRO: A Model of Energy-Economy Interactions

(Manne 1977).

ETA-MACRO is designed to compare technology options available to the U.S. economy in a manner that accounts for the interaction between energy supply and demand. The model simulates the U.S. market economy by optimally balancing supplies and demands in each time period. To focus on the long-term energy-economic issues such as resource exhaustion and the introduction rate for technologies, the model is composed of two parts:

1. ETA, Energy Technology Assessment, represents the energy sector of the economy. ETA is divided into electric energy and non-electric energy. Up to 20 technologies can be considered, including new technologies, availability dates, deployment rates, and initial and mature costs.

2. MACRO is a macroeconomic growth model of the remainder of the economy. It provides for substitution between capital, labor, and energy inputs to the economy.

ETA-MACRO measures economic growth in terms of the U.S. gross national product (GNP). Potential GNP growth is specified as an input, realized GNP 
growth is provided as a model output. The difference between the two is an indicator of the extent of the linkage between energy and economic growth.

The model simulates the market economy through a dynamic, nonlinear optimization process. Supplies, demands, and prices are matched in each time period, and there are "look-ahead" features to allow for interactions between periods. The key linkage between the energy and the economic sectors is through the elasticity of substitution, which indicates how well energy may be substituted for other inputs to the economy. This is defined as the percent reduction in total demand for energy associated with a $1 \%$ increase in the price of energy relative to that of capital and labor. The lower the value of the elasticity, the closer the linkage between energy consumption and economic growth, and the higher the demand for energy.

For this report, ETA-MACRO was used to project LWR generating capacity for specified combinations of uranium supply and elasticity of substitution. For each of three uranium supply functions a nuclear growth schedule was calculated for four different elasticities of substitution. The individual growth schedules for a particular uranium supply function were assigned relative probabilities based on the probability of the elasticity of substitution used to calculate that growth schedule. The four growth schedules and associated probabilities for a particular uranium supply function comprise the LWR capacity growth input data for a selected uranium supply described in Chapter 4 of this report.

LWR capacity growth between now and the mid 1990s is largely determined by the number of reactors under construction or ordered to date. The long lead time for nuclear construction precludes any significant increase in capacity over that currently committed. Therefore, 1995 LWR capacity input to ETA-MACRO was limited to $180 \mathrm{GW}$. There are currently 159-GW LWR capacity scheduled on-line by 1995 (Platt and Robinson 1980). The 180-GW projection for 1995 would require four to five reactor orders per year between now and 1985. Table C.1 shows the 1995 nuclear capacity assumptions from a variety of recent sources. The 180-GW 1995 projection used as input to ETA-MACRO is slightly lower than the projections from these sources. 
TABLE C.1. Comparison of Nuclear Growth Schedules (EIA 1979)

\begin{tabular}{lc}
\multicolumn{1}{c}{ Source } & $\begin{array}{c}1995 \\
\text { Nuclear } \\
\text { Capacity (GW) }\end{array}$ \\
\hline NASAP Growth Schedules & $200-275$ \\
1978 DOE Annual Report & $186-225$ \\
$\begin{array}{l}\text { Data Resources, Inc. } \\
\text { (April 1979) }\end{array}$ & 205 \\
$\begin{array}{l}\text { Westinghouse Corporation } \\
\text { (December 1978) }\end{array}$ & 246 \\
Babcock \& Wilcox Co. (March 1979) & 200
\end{tabular}

Post-1995 LWR capacity growth was calculated by ETA-MACRO. Upper limits of $240 \mathrm{GW}$ by 2000 and $500 \mathrm{GW}$ by 2010 were specified to allow a transition period between the current minimal rate for new reactor orders and the 30- to 35-GW annual addition rate achieveable with current industrial capacity (EIA 1979).

The ETA-MACRO input data for LWR energy cost are described in Appendix D of this report. The three uranium supply functions are input as shown in Table C.2. The data describing non-nuclear energy sources are detailed in another report in this series (Fraley and Burnham 1981). In that report ETAMACRO is used to calculate the benefit of introducing the FBR. The non-nuclear energy source data used to calculate LWR capacity growth is the same as was used for that calculation. In general these data and assumptions are consistent with those recommended for use by the Energy Modeling Forum (EMF), an organization created by the Elecric Power Research Institute (EPRI) to improve the practical application of energy models to policy issues and planning.

The estimates of the relative probabilities of elasticities of substitution used to assign probabilities to the uranium supply-dependent growth schedules were derived from a survey of the EMF members. The participants were asked to estimate the probability that the primary energy demand elasticity 
TABLE C.2. Supply of Uranium at Selected Costs for Assumed Total Supplies (Millions of ST U308)

Cost $(\$ / 1 b, \$ 1980)$

\begin{tabular}{llllllll}
\hline 50 & $\$ 70$ & $\$ 100$ & $\$ 150$ & $\$ 200$ & $\$ 250$ & $\underline{\$ 350}$ & $\underline{\$ 500}$ \\
1.89 & 3.09 & 4.37 & 5.41 & 5.73 & 5.88 & 6.05 & 6.26 \\
2.16 & 3.49 & 4.91 & 6.11 & 6.49 & 6.66 & 6.84 & 7.05 \\
2.43 & 3.82 & 5.47 & 6.86 & 7.31 & 7.53 & 7.71 & 7.92
\end{tabular}

exceeded various values. The results of that survey are discussed in Fraley and Burnham (1981). Figure C.1 shows the results of that survey. Demand elasticity values of $.2, .35, .5$, and .7 were selected to represent four ranges of demand elasticity having equal probability. Corresponding

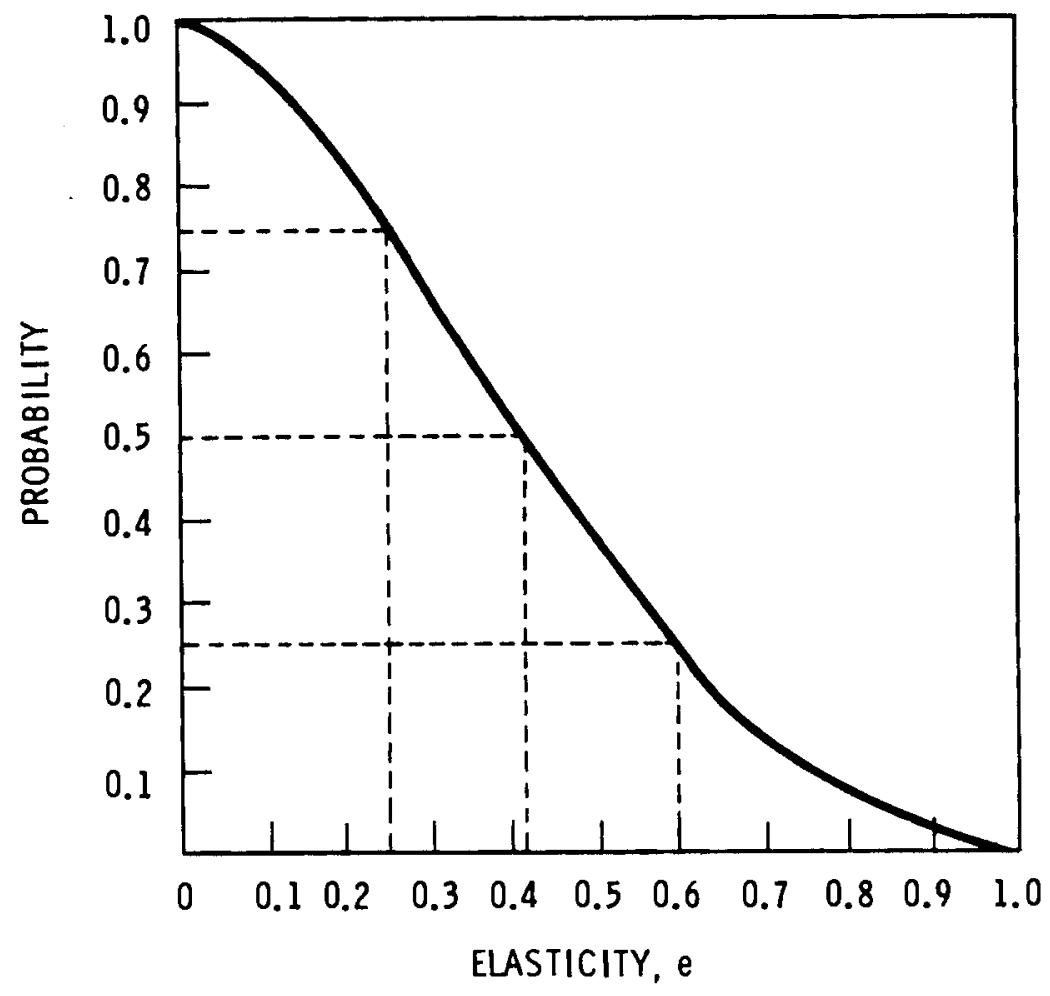

FIGURE C.1. Cumulative Probability that Primary Demand Elasticity Is Greater than e 
elasticities of substitution of $.18, .32, .45$, and .63 were calculated (Fraley and Burnham 1981) and used for calculating equally probable nuclear capacity growth projections.

Selected results of the 12 ETA-MACRO calculations are given in Table C.3 to illustrate the interaction of uranium supply and elasticity to influence GNP and nuclear electric generation. Note that the variation in uranium supply (high supply $27 \%$ greater than low supply) has essentially no influence on the GNP (less than 1\%), but has a significant influence on nuclear electric capacity (2 to $11 \%$ ). The variation of the elasticity of substitution from .18 to .63 increases the average GNP growth rate by $0.25 \%$, which amounts to over $\$ 1$ trillion by 2030. In 2030 the GNP is $13 \%$ greater and nuclear electric capacity 40 to $45 \%$ less if the elasticity of substitution is .63 rather than .18 .

The growth schedules calculated by ETA-MACRO for combinations of uranium supply functions and demand elasticity are shown in Figures C.2, C.3, and C.4. Since each of the elasticities represents an equally probable range of elasticities, the four growth schedules for each uranium supply have equal probability. Figure C.2 shows the four growth schedules for the high uranium

TABLE C.3. Summary of Results of ETA-MACRO Calculations

\begin{tabular}{|c|c|c|c|c|c|c|}
\hline \multirow[b]{2}{*}{$\begin{array}{l}\text { Uranium } \\
\text { Supply }\end{array}$} & \multirow[b]{2}{*}{$\begin{array}{l}\text { Elasticity } \\
\text { of Sub- } \\
\text { stitution } \\
\end{array}$} & \multirow{2}{*}{$\begin{array}{c}\text { Average } \\
\% \text { GNP } \\
\text { Growth } \\
1980-2030 \\
\end{array}$} & \multicolumn{4}{|c|}{ Selected Results in 2030} \\
\hline & & & $\begin{array}{c}\text { GNP in } \\
\text { Trillion } \$\end{array}$ & $\begin{array}{l}\text { Electri } \\
\text { Energy, } \\
\text { TkWh }\end{array}$ & $\begin{array}{c}\% \\
\text { Nuclear }\end{array}$ & $\begin{array}{l}\text { Nuc lear } \\
\text { GWe }\end{array}$ \\
\hline High & $\begin{array}{l}.18 \\
.32 \\
.45 \\
.63\end{array}$ & $\begin{array}{l}2.23 \\
2.36 \\
2.42 \\
2.48\end{array}$ & $\begin{array}{l}7.94 \\
8.45 \\
8.71 \\
8.97\end{array}$ & $\begin{array}{r}11.75 \\
10.39 \\
8.86 \\
7.27\end{array}$ & $\begin{array}{l}63 \\
62 \\
60 \\
56\end{array}$ & $\begin{array}{r}1300 \\
1130 \\
930 \\
720\end{array}$ \\
\hline Middle & $\begin{array}{l}.18 \\
.32 \\
.45 \\
.63\end{array}$ & $\begin{array}{l}2.23 \\
2.36 \\
2.42 \\
2.48\end{array}$ & $\begin{array}{l}7.93 \\
8.45 \\
8.71 \\
8.97\end{array}$ & $\begin{array}{r}11.57 \\
10.28 \\
8.83 \\
7.25\end{array}$ & $\begin{array}{l}63 \\
62 \\
60 \\
56\end{array}$ & $\begin{array}{r}1270 \\
1110 \\
920 \\
715\end{array}$ \\
\hline Low & $\begin{array}{l}.18 \\
.32 \\
.45 \\
.63\end{array}$ & $\begin{array}{l}2.22 \\
2.36 \\
2.42 \\
2.48\end{array}$ & $\begin{array}{l}7.89 \\
8.44 \\
8.71 \\
8.97\end{array}$ & $\begin{array}{r}10.81 \\
9.95 \\
8.75 \\
7.19\end{array}$ & $\begin{array}{l}62 \\
61 \\
59 \\
56\end{array}$ & $\begin{array}{r}1170 \\
1060 \\
910 \\
710\end{array}$ \\
\hline
\end{tabular}




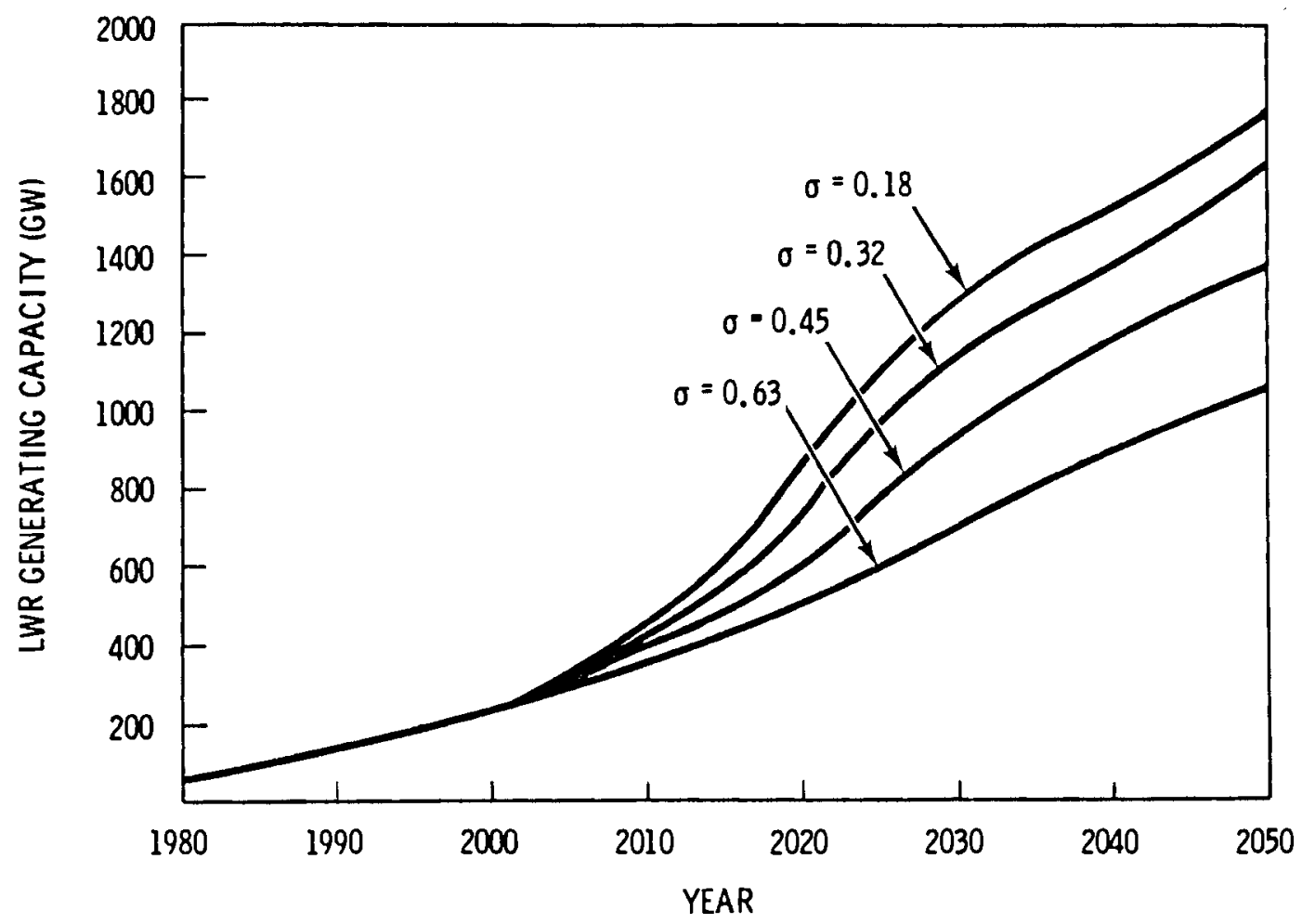

FIGURE C.2. LWR Growth Schedule for $7.92 \mathrm{Million}$ ST $\mathrm{U}_{3} 0_{8}$ Uranium Supply

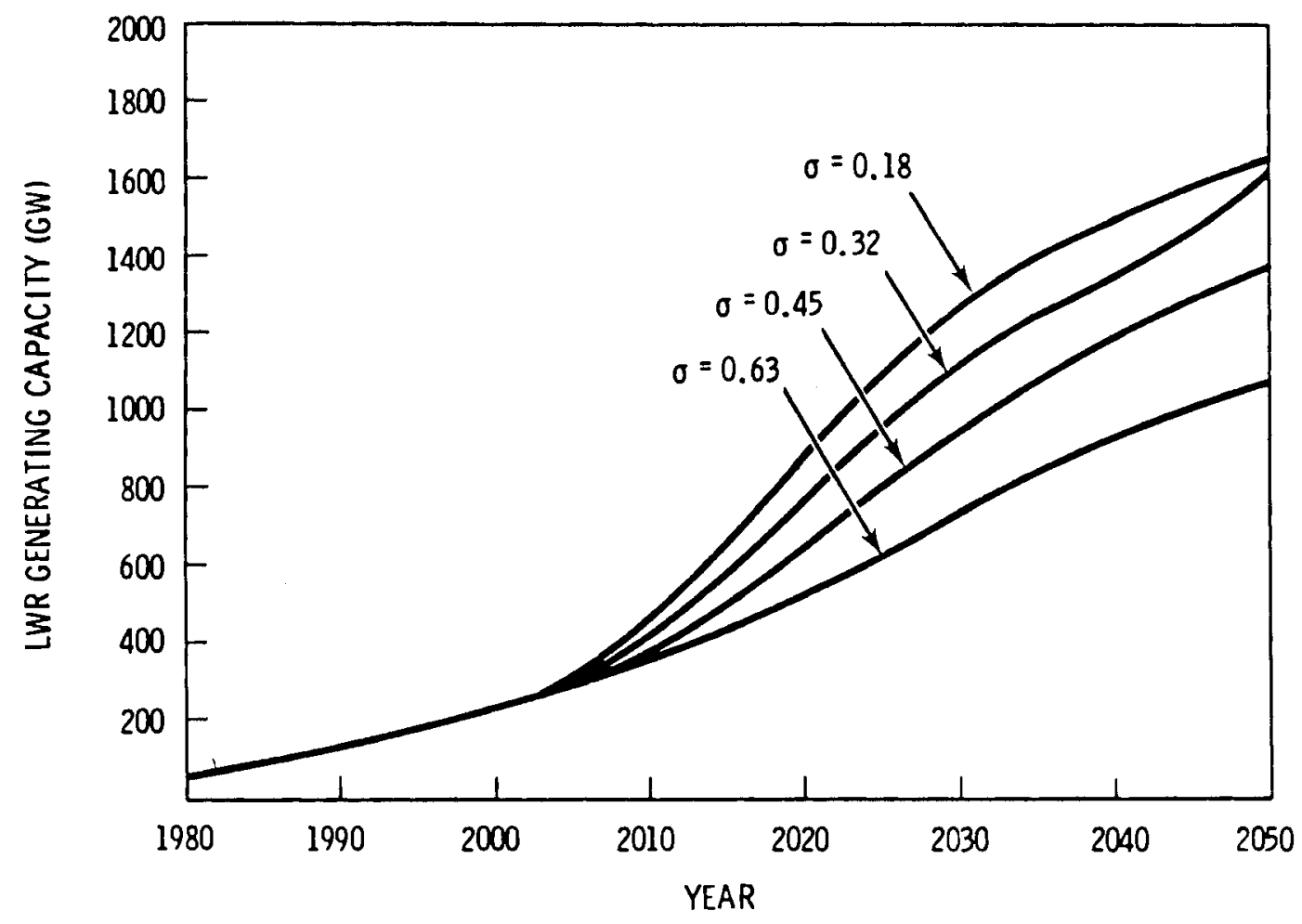

FIGURE C.3. LWR Growth Schedule for 7.05 Million ST $U_{308}$ Uranium Supply 


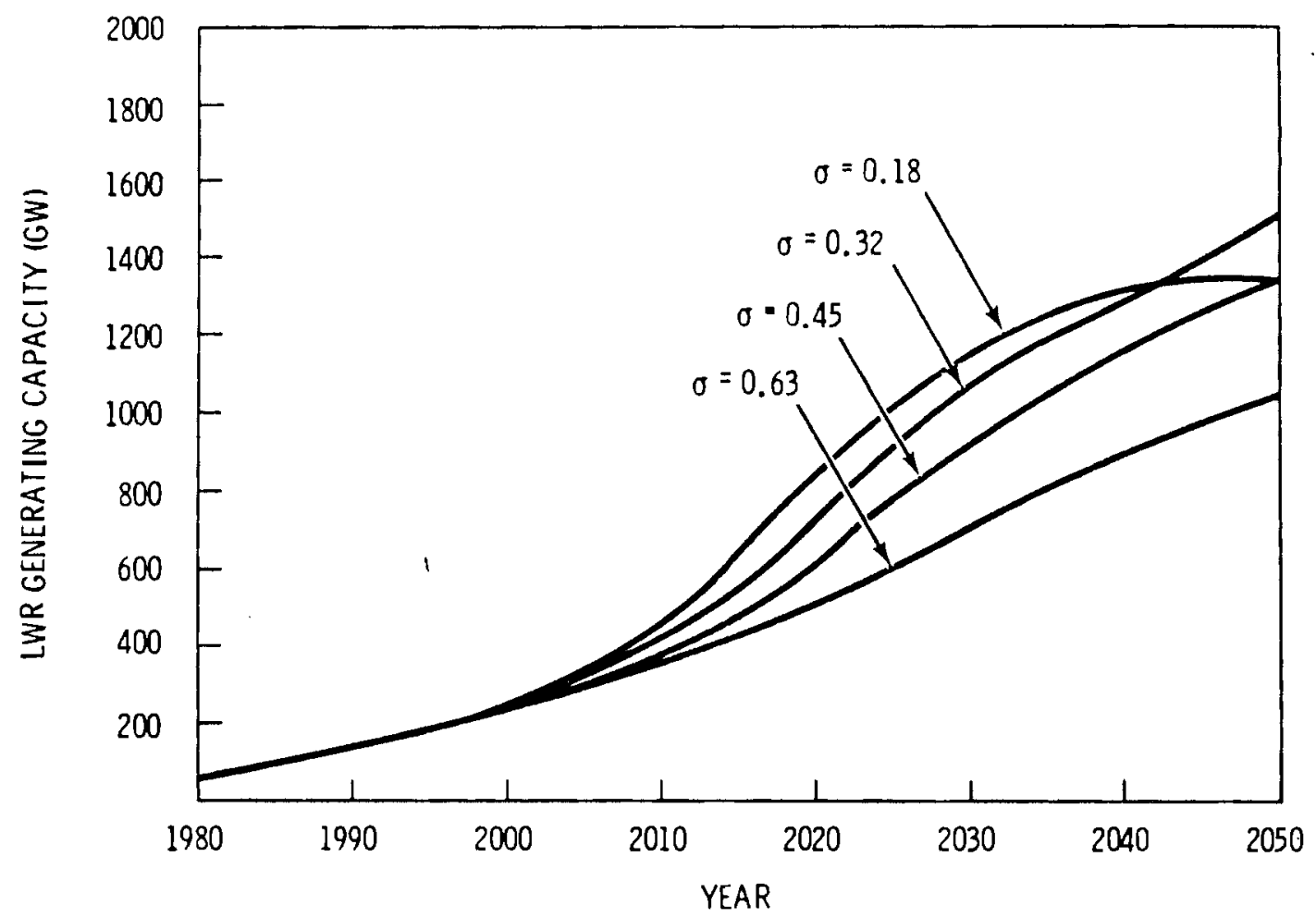

FIGURE C.4. LWR Growth Schedule for 6.26 Million ST U ${ }_{3} 0_{8}$ Uranium Supply

supply from Table C.2, 7.92 million ST $U_{3} 0_{8}$. LWR capacity growth is fairly uniform for all elasticities, with lower elasticities requiring greater LWR capacity to satisfy the greater demand for energy.

Figure C.3 illustrates the calculated growth schedules for the middle uranium supply, 7.05 million $\mathrm{ST}_{3} \mathrm{U}_{8}$. In this case, the high demand for energy for the .18 and .32 elasticity of substitution causes the more limited uranium supply to be committed early, which depresses the growth in the later periods relative to that shown in Figure C.2.

Figure $C .4$ shows the growth schedules for the low uranium supply, 6.26 million ST $\mathrm{U}_{3} \mathrm{O}_{8}$. In this case, the limited uranium supply is comitted early for the .18 elasticity of substitution, and severely limits growth in the later periods. The lower overall energy demand for the .32 elasticity of substitution allows a more gradual use of the uranium supply. In this case there is enough of the assumed uranium supply left to continue growth at the same rate in the later period, and the calculated nuclear capacity exceeds that 
for the .18 elasticity of substitution. The total uranium consumption is approximately the same for the two cases. The limited uranium supply slightly depresses the growth of LWR capacity for the $.32, .45$, and .43 elasticity relative to that shown on Figure C.3.

\section{REFERENCES}

Fraley, D. W. and J. B. Burnham. 1981. A Method for Selecting FBR Development Strategies in the Presence of Uncertainties. PNL-3598, Pacific Northwest Laboratory, Richland, Washington.

Manne, A. S. 1977. ETA-MACRO: A Model of Energy-Economy Interactions. EPRI-EA-592, Electric Power Research Institute, PaTo ATto, California.

Platt, A. M. and J. R. Robinson. 1980. Commercial Nuclear Reactors and Waste: The Current Status. PNL-3317-1, Pacific Northwest Laboratory, Richland, Washington.

U.S. Energy Information Administration (EIA). 1979. Annual Report to Congress 1978. DOE/EIA-0172/3, Vol. 3. U.S. Government Printing Office, Washington, D.C. 
APPENDIX D

ENERGY COST CALCULATIONS 
APPENDIX D

\section{ENERGY COST CALCULATIONS}

The model used to calculate the probability that the FBR is economically competitive with an LWR compares probability density functions of life-cycle cost $(\$ / k w h)$ for the two reactors. The following material describes how these energy costs are calculated. The financial parameters for this calculation are discussed in Appendix F.

\section{D.1 CAPITAL COSTS AND OPERATING AND MAINTENANCE COSTS}

The LWR and FBR are assumed to operate 30 years. Both reactors represent mature designs and were assumed to operate at a $65 \%$ capacity factor. The component of life-cycle cost due to a reactor's capital costs is calculated by levelizing those capital costs over the total energy generated in that period. The values of the parameters used in the levelization calculation are shown in Table D.1.

The fixed charge rate is calculated as follows:

$$
L C C=\frac{\left[\begin{array}{c}
\text { PW Facility Capital Cost }+(1.0-\text { ITC }) \text { PW Equipment } \\
\text { Capital Cost }-t \text { PW Depreciation }
\end{array}\right]}{(1-t)(\text { PW Operating Years })}
$$

where

$$
\begin{aligned}
& \text { LCC = levelized capital cost } \\
& P W=\text { present worth } \\
& P W \text { Facility Capital Cost }=\sum_{n=-9}^{0} \frac{{ }_{n} F}{(1+i)^{n}} \\
& P W \text { Equipment Capital Cost }=\sum_{n=-9}^{0} \frac{{ }_{n} E}{(1+i)^{n}}
\end{aligned}
$$




$$
\begin{aligned}
& \text { PW Depreciation }=\sum_{n=1}^{16} \frac{2(17-n) C}{(16)(17)(1+i)^{n}} \quad \text { (tax 1ife = } 16 \text { years) } \\
& \text { PW Operating years }=\sum_{n=1}^{30} \frac{1}{(1+i)^{n}} \quad \text { (economic life }=30 \text { years) } \\
& \begin{aligned}
\text { ITC } & =\text { investment tax credit } \\
t & =\text { tax rate } \\
f_{n} & =\text { fraction of capital cost in year } n \\
F & =0.55 C \\
C & =\text { total electric plant cost } \\
E & =0.45 C \\
i & =\text { after tax weighted cost of capital. }
\end{aligned}
\end{aligned}
$$

Substituting the values from Table 0.1 gives:

$$
\begin{aligned}
C R F & =\frac{1.1275 F+(1.0-0.1) 1.1275 E-(0.5)(0.8316 C)}{(1.0-0.5) 18.9819} \\
& =\frac{0.6201 C+4566 C-0.4158 C}{9.491} \\
& =0.0696 C
\end{aligned}
$$

Property tax, insurance costs, and decommissioning costs also depend on the capital cost. The property tax and insurance rates are given in Table 0.1 . Decommissioning is calculated as follows:

PW Decommissioning Cost $=\frac{0.1 C}{(1+i)^{n+1}}$

where

$$
\begin{aligned}
0.1 C & =\text { decommissioning cost } \\
C & =\text { total electric plant cost } \\
i & =\text { after tax weighted cost of capital } \\
n & =\text { economic life. }
\end{aligned}
$$


These three components are combined in Table 0.2 to obtain a fixed charge rate of $10.16 \%$. The fixed charge rate is used to calculate levelized capital costs.

TABLE D.1. Parameters for Reactor Capital Cost Levelization Calculation (Constant 1980 Dollars)

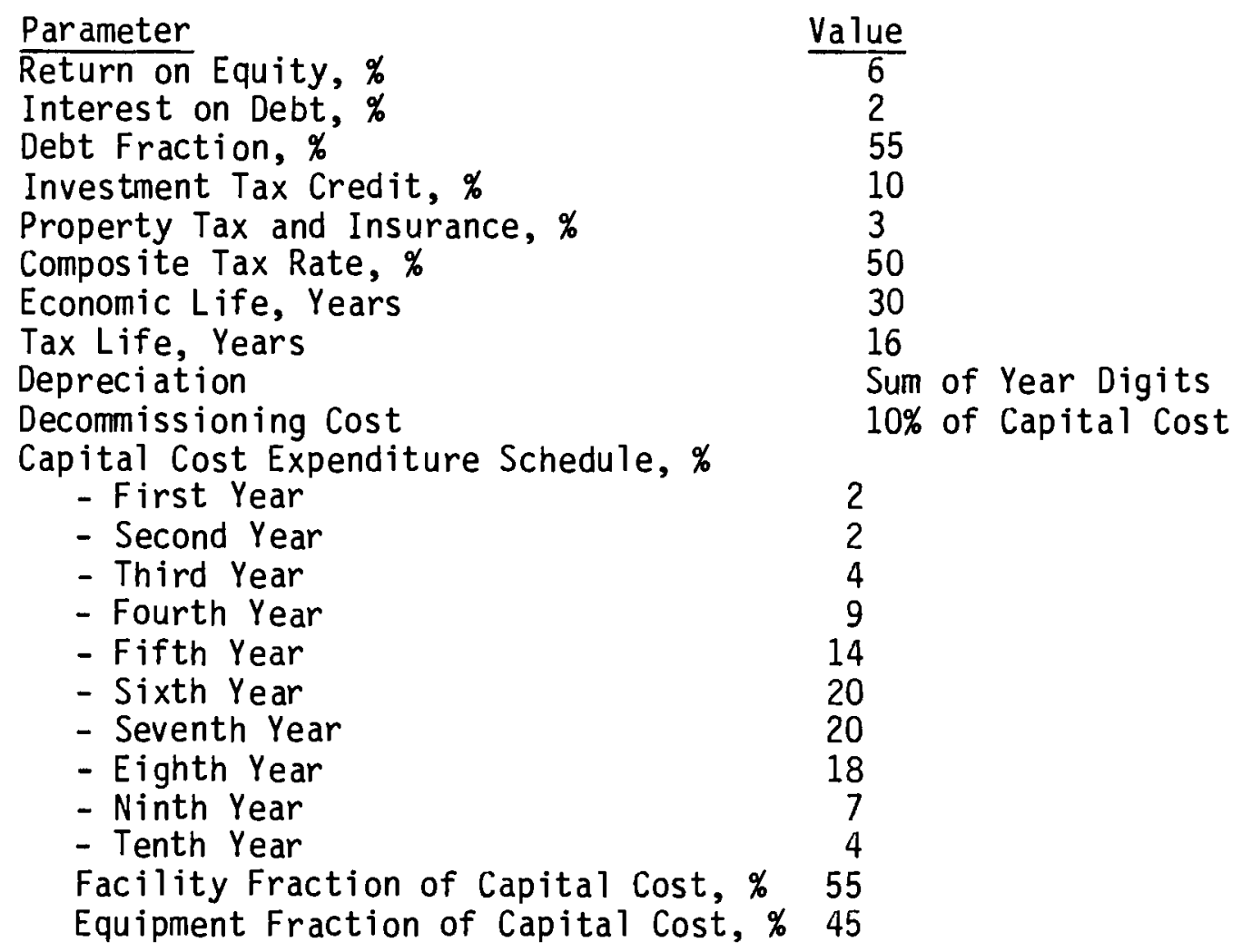

TABLE 0.2. Fixed Charge Rate (\%)

$\begin{array}{lr}\text { Capital Recovery } & 6.96 \\ \text { Property Tax and Insurance } & 3.00 \\ \text { Decommissioning } & \underline{0.20} \\ \quad \text { TOTAL } & 10.16 \%\end{array}$




\section{D.1.1 Levelized LWR Capital and Operating and Maintenance Costs}

Capital cost estimates for LWRs and FBRs were solicited from reactor vendors and architect-engineers for use in this analysis. Details of these estimates may be found in Characterization of Alternative FBR Development Strategies (Boegel and Clausen 1981). That analysis resulted in a probability function for LWR and FBR capital costs. The probability density function for LWR capital cost is a normal distribution, with a mean of $\$ 1100 / \mathrm{kW}$ and a standard deviation of $\$ 150 / \mathrm{kW}$. These figures do not include interest during construction. The fixed charge rate includes a component for interest during construction. Using the fixed charge rate from Table 0.2 the component of life-cycle cost due to capital cost may be calculated as follows:

$$
\begin{aligned}
\text { Capital Cost }\left(\frac{\mathrm{mills}}{\mathrm{kWh}}\right) & =\frac{0.1016 \times \text { Reactor Capital Cost }(\$ / \mathrm{kW}) \times 1000 / \mathrm{mills} / \$}{365 \text { Days } \times 24 \mathrm{hr} \times 0.65 \text { Capacity Factor }} \\
& =0.0178 \times \text { Reactor Capital Cost }(\$ / \mathrm{kW}) \\
& =0.0178 \times 1100 \\
& =19.58 \mathrm{mill} \mathrm{s} / \mathrm{kWh}
\end{aligned}
$$

The range, plus and minus three standard deviations, is from 11.57 to 27.59 $\mathrm{mills} / \mathrm{kWh}$.

The component of life-cycle cost due to annual operating and maintenance (O\&M) expense is calculated in a similar manner:

$$
\begin{aligned}
\operatorname{O\& M}\left(\frac{\mathrm{mills}}{\mathrm{kWh}}\right) & =\frac{\text { Annual } 0 \& \mathrm{M}(\$ / \mathrm{kW}) \times 1000 / \mathrm{mi} l \mathrm{~s} / \$}{365 \text { Days } \times 24 \mathrm{hr} \times 0.65 \text { Capacity Factor }} \\
& =0.17560 \& M(\$ / \mathrm{kW})
\end{aligned}
$$

Annual O\&M costs were estimated to be $\$ 17 / \mathrm{kW}$. This estimate is based on an estimate of $\$ 14 / \mathrm{kW}$ ( $\$ 1978$ ) quoted in NASAP's Report of the Nonproliferation Alternative Systems Assessment Program (DOE 1980) inflated at $10 \% / y r$ to $\$ 1980$. This results in a levelized $0 \& M$ cost of $2.99 \mathrm{mills} / \mathrm{kWh}$. The total capital and $0 \& M$ cost is then $22.57 \mathrm{mills} / \mathrm{kWh}$, with a range of 14.56 to $30.58 \mathrm{mills} / \mathrm{kWh}$. 


\section{D.1.2 Levelized FBR Capital and Operating and Maintenance Cost}

Capital cost estimates for a 1000-MWe and 1457-MWe FBR are detailed in Characterization of Alternative FBR Development Strategies (Boegel and Clausen 1981), where the uncertainties in capital cost/ $\mathrm{kW}$ for these reactors are characterized in terms of probability density functions. The probability density

function for the 1000 -MWe FBR has a range of $\$ 1000$ to $\$ 2640 / \mathrm{kW}$ with an expected value of $\$ 1580 / \mathrm{kW}$. The range for the $1457-M W e$ FBR is $\$ 820$ to $\$ 2000 / \mathrm{kW}$ with an expected value of $\$ 1285 / \mathrm{kW}$. These estimates do not include interest during construction.

Using this data in the previously derived levelized cost formula gives a capital cost range of 17.80 to $46.94 \mathrm{mills} / \mathrm{kWh}$ for the 1000 -MWe FBR and 14.60 to $35.60 \mathrm{mills} / \mathrm{kWh}$ for the $1457-M W e$ FBR. The expected values for the capital costs are 28.12 and $22.87 \mathrm{mills} / \mathrm{kWh}$ respectively.

Annual 0\&M expenses for a FBR are estimated to be $\$ 22 / \mathrm{kWh}$. This is based on an estimate of $\$ 18 / \mathrm{kW}$ ( $\$ 1978$ ) from NASAP's Report of the Nonproliferation Alternative Systems Assessment Program (DOE 1980) inflated by $10 \% / y r$ to $\$ 1980$. This corresponds to a levelized 0\&M cost of $3.86 \mathrm{mills} / \mathrm{kWh}$. This cost added to the capital cost gives a range of 21.66 to $50.85 \mathrm{mills} / \mathrm{kWh}$ for the 1000 -MWe FBR and 18.46 to $39.46 \mathrm{mills} / \mathrm{kWh}$ for the $1457-M W e$ FBR. The expected values are 31.98 and $26.73 \mathrm{mills} / \mathrm{kWh}$ respectively.

\section{D.2 FUEL CYCLE COSTS}

Levelized fuel cycle costs for the LWR and FBR were calculated by computing and levelizing the costs for the first core and 29 equilibrium reloads over the 30-yr life of the reactor. Fuel cycle costs were calculated assuming that nuclear fuel is capitalized for tax purposes, but investment tax credit was not taken. Straight-line depreciation was used for both LWR and FBR fuel. This assumption is an approximation, since some FBR fuel and all LWR fuel will be in-reactor long enough to qualify for accelerated depreciation and tax credits. This approximation changes the levelized fuel cycle cost by about 1 to $2 \%$. Reload batch sizes and residence times were selected consistent with a $65 \%$ capacity factor. 


\section{D.2.1 Levelized LWR Fuel Cycle Costs}

LWR fuel cycle costs were calculated for the "improved" PWR fuel cycle as described in Uranium Resource Utilization Improvement in the Once-Through PWR Fuel Cycle (Matzie 1980). Table 0.3 lists the fuel management parameters used in the fuel cycle cost levelization calculation. Uranium enrichment and fabrication are assumed to be purchased 1 year prior to charging fuel to the reactor. Since energy cost for this reactor will be compared with that of an FBR, it is assumed that the LWR is operated in a stowaway fuel cycle. This means that discharged fuel is stored at the LWR for eventual sale to the builder of an FBR or use in the LWR. Since the exact nature of the eventual transaction is unknown, spent fuel is assumed to have zero salvage value. This assumption decreases the cost of LWR power relative to the current throwaway fuel cycle, in which spent fuel is a liability because of the assumed cost of spent fuel disposal.

Alternative assumptions for the backend of the LWR fuel cycle are spent fuel disposal or reprocessing and recovery of fissionable material. Spent fuel disposal results in a net cost for the backend of the fuel cycle. Reprocessing can result in either a credit or a cost, depending on the cost of reprocessing

\section{TABLE D.3. PWR Fuel Management Parameters}

\begin{tabular}{lc} 
Parameter & Value \\
\hline Capacity Factor, \% & 65 \\
Fraction of the Core Replaced/Refueling & 0.16 \\
Refueling Interval, Years & 1 \\
Equilibrium Cycle Enrichment, \% & 4.70 \\
Tails Assay, \% & 0.10 \\
Fabrication Requirements, kg/MW & \\
First Core & 74.6 \\
Annual Equilibrium Reload & 12.4 \\
U308 Requirements, lb/MW & \\
First Core & 661 \\
Annual Equilibrium Reload & 223 \\
Separative Work Requirements, SWU/MW & \\
First Core & 274 \\
Annual Equilibrium Reload & 124
\end{tabular}


and waste management relative to the value of the recovered fissionable material. The LWR energy cost equations derived include a term for backend fuel cycle costs. This term is zero for the reference case, and positive for spent fuel disposal. LWR recycle has not been evaluated.

Tables D.4 and D.5 show the costs and depreciation per MW associated with the first PWR core and a PWR equilibrium reload. The expenses and depreciation are given for uranium (uranium cost/1b), fabrication (LWR fabrication and transportation costs $/ \mathrm{kg}$ ), enrichment (enrichment cost $/ \mathrm{SWU}$ ) and backend cost (backend cost $/ \mathrm{kg}$ ). The annual depreciation is calculated assuming straightline depreciation of the fuel based on its residence time in-reactor. Backend costs are assumed expensed at the time they occur.

\section{TABLE D.4. Expenses and Depreciation Per MW for the First PWR Core}

\begin{tabular}{|c|c|c|c|c|c|}
\hline Year & Uranium & Enrichment & Fabrication & Backend Cost & Depreciation \\
\hline 0 & $661 U$ & $274 \mathrm{E}$ & $74.6 \mathrm{~F}_{1}$ & & \\
\hline 1 & & & & & $269 U+112 E+30.4 F_{1}$ \\
\hline 2 & & & & & $159 U+66 E+18.0 F_{1}$ \\
\hline 3 & & & & & $105 U+43 E+11.8 F_{1}$ \\
\hline 4 & & & & & $68 \mathrm{U}+28 \mathrm{E}+7.7 \mathrm{~F}_{1}$ \\
\hline 5 & & & & & $41 U+17 E+4.6 F_{1}$ \\
\hline 6 & & & & & $19 U+8 E+2.1 F_{1}$ \\
\hline 11 & & & & $12.4 W$ & $12.4 W$ \\
\hline 12 & & & & $12.4 W$ & $12.4 W$ \\
\hline 13 & & & & $12.4 \mathrm{~W}$ & $12.4 \mathrm{~W}$ \\
\hline 14 & & & & $12.4 W$ & $12.4 W$ \\
\hline 15 & & & & $12.4 W$ & $12.4 \mathrm{~W}$ \\
\hline 16 & & & & $12.4 W$ & $12.4 \mathrm{~W}$ \\
\hline
\end{tabular}


TABLE D.5. Expenses and Depreciation Per MW for PWR Equilibrium Reload N

$\begin{array}{llll}\frac{\text { Year }}{n} & \frac{\text { Uranium }}{223 U} \frac{\text { Enrichment }}{124 E} \frac{\text { Fabrication }}{12.4 F_{1}} & & \text { Backend Cost } \\ n+1 & & & 38 U+21 E+2.1 F_{1} \\ n+2 & & 37 U+21 E+2.1 F_{1} \\ n+3 & & 37 U+21 E+2.1 F_{1} \\ n+4 & & 37 U+21 E+2.1 F_{1} \\ n+5 & & 37 U+20 E+2.0 F_{1} \\ n+6 & & & 37 U+20 E+2.0 F_{1} \\ n+16 & & 12.4 W & 12.4 W\end{array}$

Using the data in Table D.4 for the first core, Table D.5 for 29 annual reloads, and the economic parameters shown in Table D.1, the levelized fuel cycle cost may be calculated by the formula:

Levelized Fuel Cycle Cost $=\frac{1}{1-t}\left[\frac{\left(\begin{array}{c}\text { PW Fue } 1 \\ \text { Cycle Cost }\end{array}\right)-t \text { (PW Depreciation) }}{\text { PW Energy }}\right]$

where

$t=\operatorname{tax}$ rate

PW Fuel cycle Cost $=\sum_{n=1}^{30} \frac{\text { Annual Fuel Cycle Cost (Year } n)}{(1+i)^{n}}$

PW Depreciation $\quad=\sum_{n=1}^{30} \frac{\text { Annual Depreciation (Year } n)}{(1+i)^{n}}$

PW Energy

$=\sum_{n=1}^{30} \frac{\text { Annual Energy }(\text { Year } n)}{(1+i)^{n}}$

$i=$ after tax weighted cost of capital

$=(1-t) \times$ Interest on Debt $\times$ Debt Fraction + Return on Equity $x$ (1 - Debt Fraction) 
Performing the levelization calculation with these assumptions and employing the uranium cost conventions shown in Table D.6, results in the equation for life-cycle levelized fuel cycle cost are shown below:

$$
\begin{aligned}
& \text { Levelized Fuel Cycle Cost }=0.0263 \mathrm{E}+0.0031 \mathrm{~F}_{1}+0.00173 \mathrm{~W}+0.0109 \mathrm{U}_{1}+0.0097 \mathrm{U}_{2} \\
& \mathrm{mills} / \mathrm{kWh} \\
& +0.0083 \mathrm{U}_{3}+0.0071 \mathrm{U}_{4}+0.0060 \mathrm{U}_{5} \\
& +0.0051 U_{6}+0.0018 U_{7}
\end{aligned}
$$

Substituting $\$ 100 /$ SWU, $145 / \mathrm{kg}$ fabrication, and zero for spent fuel disposal gives:

Levelized Fuel Cycle Cost $=3.08+0.0109 \mathrm{U}_{1}+0.0097 \mathrm{U}_{2}+0.0083 \mathrm{U}_{3}+0.0071 \mathrm{U}_{4}$ $\mathrm{mills} / \mathrm{kWh}$

$$
+0.0060 U_{5}+0.0051 U_{6}+0.0018 U_{7}
$$

A spent fuel disposal cost of $\$ 65 / \mathrm{kg}$ plus a spent fuel transportation cost of $\$ 26 / \mathrm{kg}$ would increase this cost by $0.16 \mathrm{mills} / \mathrm{kWh}$.

\section{D.2.2 Levelized FBR Fuel Cycle Costs}

Levelized FBR fuel cycle costs were calculated for the reference design for the DOE Conceptual Design Study (CDS). The CDS objective is to design the next reactor to be deployed in the U.S. breeder development program. The fue 1 cycle calculations for the reference design are based on an $80 \%$ capacity

TABLE D.6 Uranium Cost Convention

\begin{tabular}{ll}
\multicolumn{1}{c}{ Fuel } & Cost \\
\cline { 1 - 2 } First Core, Reloads $1+2$ & $U_{1}$ \\
Reloads $3-7$ & $U_{2}$ \\
Reloads $8-12$ & $U_{3}$ \\
Reloads 13-17 & $U_{4}$ \\
Reloads 18-22 & $U_{5}$ \\
Reloads 23-27 & $U_{6}$ \\
Reloads 28 -29 & $U_{7}$
\end{tabular}


factor. For this analysis, the reload fuel requirement and core residence times were modified to reflect a $65 \%$ capacity factor. The $65 \%$ capacity factor is consistent with that assumed for the LWR.

The reference design fuel consists of core and axial blanket assemblies, internal blanket assemblies, and radial blanket assemblies. At $80 \%$ capacity factor, one half of the core and axial blanket assemblies and one half of the internal blanket assemblies are replaced each year. The radial blanket assemblies are replaced at 3-, 4-, or 5- year intervals. Reducing the capacity factor to $65 \%$ increases the average residence time of each type of fuel.

Table 0.7 shows the fuel mass flows used for this cycle's cost calculation. The FBR life-cycle fuel requirements are assumed to consist of an initial core and 29 equilibrium reloads. Plutonium charges and discharges are shown in terms of actual mass and equivalent LWR plutonium mass. The discharge masses are corrected for an assumed $2 \%$ loss in plutonium recovery. The isotopic composition, and therefore the economic value, of plutonium varies depending on its source. The isotope content of the various types of plutonium is shown in Table C.8. The transformation of actual mass to equivalent LWR plutonium mass was performed using the isotope correlation coefficients for plutonium requirements found in Jenquin and Newman (1979).

TABLE 0.7. FBR Fuel Mass Flows (kg/MW at 65\% Capacity Factor)

$$
\text { Heavy Metal Pu Equivalent LWR Pu }
$$

Initial Core

Core + Axial Blanket

Internal Blanket

Radial Blanket

Equilibrium Reload

Core + Axial Blanket

Internal Blanket

Radial Blanket

Equilibrium Discharge

Core + Axial Blanket

Internal Blanket

Radial Blanket
36.93

19.74

35.00

15.00

8.02

7.67

15.00

8.02

7.67

D. 10
4.558

0

0

5.764

0

0

2.279

0

0

0

0

2.068

0.311

0.186
1.844

0.230

0.136 
TABLE D.8. Plutonium Isotopic Composition (\%)

LWR

Core Charge

Core + Axial Blanket Reload

Core + Axial Blanket Discharge

Internal $B$ lanket Discharge

Radial Blanket Discharge

$\begin{array}{lllll}\frac{P u-238}{0.0} & \frac{P u-239}{46.8} & \frac{P u-240}{27.2} & \frac{P u-241}{15.4} & \frac{P u-242}{10.6}\end{array}$

$\begin{array}{lllll}0.0 & 86.7 & 11.4 & 1.7 & 0.2\end{array}$

$\begin{array}{lllll}1.0 & 67.3 & 19.2 & 10.1 & 2.4\end{array}$

$\begin{array}{lllll}0.8 & 66.6 & 22.3 & 7.5 & 2.8\end{array}$

$\begin{array}{lllll}0.0 & 95.4 & 4.5 & 0.1 & 0.0\end{array}$

$\begin{array}{lllll}0.0 & 96.5 & 3.4 & 0.1 & 0.0\end{array}$

Tables D.9 and D.10 show the expenses, credits, and depreciation per MW for the initial core and an equilibrium reload. All plutonium charges and credits are shown in terms of equivalent LWR plutonium. Depreciation is calculated based on the plutonium's value at the beginning of the cycle. It is assumed that just enough plutonium is discharged the first year for a reload and that the second discharge is an equilibrium discharge. $P(n)$ is the value of plutonium at year $n$ in $\$ / k g . F_{1}$ is the cost of fabricating FBR blankets in $\$ / \mathrm{kg} . \quad F_{2}$ is the cost of transporting $(U, P u) O_{2}$ from the reprocessing plant to the refabrication plant plus the cost of fabricating the FBR core and axial blanket fuel. $R$ is the cost (in $\$ / \mathrm{kg}$ ) of the transportation, reprocessing, and waste management of FBR spent fuel.

The levelized fuel cycle costs for the FBR's initial core and 29 equilibrium reloads are calculated with the same formula used to calculate PWR's levelized fuel cycle costs (section D.2.1). This calculation is an approximation, since the first and last reloads are not equilibrium. This approximation will have a minimal effect on the calculated fuel cycle cost. $F_{1}, F_{2}$, and $R$ are assumed constant for the life of the reactor. Plutonium values are assumed constant for 5-year intervals, as shown in Table D.11. 
TABLE D.9. Expenses, Credits, and Depreciation Per MW for Initial FBR Core and Blankets

Core + Axial Blanket

\begin{tabular}{|c|c|c|c|c|}
\hline Year & $\mathrm{Pu}$ & Fabrication & Reprocessing & Depreciation \\
\hline 0 & $5.764 P(0)$ & $36.93 \mathrm{~F}_{2}$ & & \\
\hline 1 & & & & $24.81 F_{2}+24.81 R+0.452 P(0)$ \\
\hline 2 & & & & $9.81 F_{2}+9.81 R+0.179 P(0)$ \\
\hline 3 & $-2.068 P(3)$ & & $15.00 R$ & $2.31 F_{2}+2.31 R+0.042 P(0)$ \\
\hline 4 & $-2.068 P(4)$ & & $15.00 R$ & \\
\hline 5 & $-0.955 P(5)$ & & $6.93 R$ & \\
\hline
\end{tabular}

Internal Blanket

\begin{tabular}{|c|c|c|c|c|}
\hline Year & $\mathrm{Pu}$ & Fabrication & Reprocessing & Depreciation \\
\hline 0 & & $19.74 \mathrm{~F}_{1}$ & & \\
\hline 1 & & & & $13.26 F_{1}+13.26 R-0.414 P(0)$ \\
\hline 2 & & & & $5.24 F_{1}+5.24 R-0.204 P(0)$ \\
\hline 3 & $-0.211 P(3)$ & & $8.02 R$ & $1.24 \mathrm{~F}_{1}+1.24 \mathrm{R}-0.047 \mathrm{P}(0)$ \\
\hline 4 & $-0.311 P(4)$ & & $8.02 R$ & \\
\hline 5 & $-0.143 P(5)$ & & $3.70 R$ & \\
\hline
\end{tabular}

\section{Radial B lanket}

\begin{tabular}{|c|c|c|c|c|}
\hline Year & $\mathrm{Pu}$ & Fabrication & Reprocessing & Depreciation \\
\hline 0 & & $35.00 F_{1}$ & & \\
\hline 1 & & & & $16.84 F_{1}+16.84 R-0.222 P(0)$ \\
\hline 2 & & & & $9.17 F_{1}+9.17 R-0.222 P(0)$ \\
\hline 3 & & & $7.67 R$ & $5.34 F_{1}+5.34 R-0.130 P(0)$ \\
\hline 4 & $-0.186 P(4)$ & & $7.67 R$ & $2.78 F_{1}+2.78 R-0.068 P(0)$ \\
\hline 5 & $-0.186 P(5)$ & & $7.67 R$ & $0.87 F_{1}+0.87 R-0.021 P(0)$ \\
\hline 6 & $-0.186 P(6)$ & & $7.67 R$ & \\
\hline 7 & $-0.105 P(7)$ & & $4.32 R$ & \\
\hline
\end{tabular}


TABLE D.10. Expenses, Credits, and Depreciation Per MW for the FBR's Equilibrium Reload N

\section{Core + Axial Blanket}

$\begin{array}{llccc}\frac{\text { Year }}{n} & \frac{P u}{2.279 P(n)} \frac{\text { Fabrication }}{15.00 F_{2}} & \text { Reprocessing } & \text { Depreciation } \\ n+1 & & & 6.35 F_{2}+6.35 R+0.089 P(n) \\ n+2 & & & 6.35 R_{2}+6.35 R+0.089 P(n) \\ n+3 & & & 2.30 F_{2}+2.30 R+0.033 P(n) \\ n+4 & -1.113 P(n+4) & 8.07 R & \\ n+5 & -0.955 P(n+5) & 6.93 R & \end{array}$

Internal Blanket

\begin{tabular}{|c|c|c|c|c|}
\hline Year & $\mathrm{Pu}$ & Fabrication & Reprocessing & Depreciation \\
\hline $\mathrm{n}$ & & $8.02 F_{1}$ & & \\
\hline$n+1$ & & & & $3.39 F_{1}+3.39 R-0.132 P(n)$ \\
\hline$n+2$ & & & & $3.39 F_{1}+3.39 R-0.132 P(n)$ \\
\hline$n+3$ & & & & $1.24 F_{1}+1.24 R-0.047 P(n)$ \\
\hline$n+4$ & $-0.168 P(n+4)$ & & $4.32 R$ & \\
\hline$n+5$ & $-0.143 P(n+5)$ & & $3.70 \mathrm{R}$ & \\
\hline
\end{tabular}

Radial Blanket

\begin{tabular}{|c|c|c|c|c|}
\hline Year & $\mathrm{Pu}$ & Fabrication & Reprocessing & Depreciation \\
\hline $\mathrm{n}$ & & $7.67 \mathrm{~F}_{1}$ & & \\
\hline$n+1$ & & & & $1.70 F_{1}+1.70 R-0.041 P(n)$ \\
\hline$n+2$ & & & & $1.70 F_{1}+1.70 R-0.041 P(n)$ \\
\hline$n+3$ & & & & $1.70 F_{1}+1.70 R-0.041 P(n)$ \\
\hline$n+4$ & & & & $1.70 F_{1}+1.70 R-0.041 P(n)$ \\
\hline$n+5$ & & & & $0.87 F_{1}+0.87 R-0.022 P(n)$ \\
\hline$n+6$ & $-0.081 P(n+6)$ & & $3.35 R$ & \\
\hline$n+7$ & $-0.105 P(n+7)$ & & $4.32 R$ & \\
\hline
\end{tabular}


TABLE D.11. Plutonium Values

$\begin{array}{ll}P(0) \text { to } P(2)(\$ / \mathrm{kg}) & P_{1}(\$ / \mathrm{g}) \\ P(3) \text { to } P(7)(\$ / \mathrm{kg}) & P_{2}(\$ / \mathrm{g}) \\ P(8) \text { to } P(12)(\$ / \mathrm{kg}) & P_{3}(\$ / \mathrm{g}) \\ P(13) \text { to } P(17)(\$ / \mathrm{kg}) & P_{4}(\$ / \mathrm{g}) \\ P(18) \text { to } P(22)(\$ / \mathrm{kg}) & P_{5}(\$ / \mathrm{g}) \\ P(23) \text { to } P(27)(\$ / \mathrm{kg}) & P_{6}(\$ / \mathrm{g}) \\ P(28) \text { and above } & P_{7}(\$ / \mathrm{g})\end{array}$

The resulting equation for FBR fuel cycle costs is shown below:

Levelized Fuel Cycle Cost $=0.0034 \mathrm{~F}_{1}+0.0031 \mathrm{~F}_{2}+0.0047 \mathrm{R}+0.1974 \mathrm{P}_{1}$ (mills/kwh) $-0.0074 P_{2}-0.0104 P_{3}-0.0089 P_{4}-0.0075 P_{5}$ $-0.0064 \mathrm{P}_{6}-0.0814 \mathrm{P}_{7}$

For the purposes of the analysis we assumed that plutonium would be valued at its cost of recovery from LWR spent fuel for the initial inventory $\left(P_{1}\right)$ and at its LWR indifference value subsequently. This is the value at which an LWR operator is economically indifferent to using LWR generated plutonium to displace uranium in subsequent LWR cycles or selling that plutonium. This assumption approximates the transition of plutonium's value from a period of excess plutonium because of a backlog of unreprocessed LWR spent fuel to a period of limited breeder capacity growth because of limited plutonium availability.

The net cost of recovering plutonium from LWR spent fuel consists of the cost of reprocessing the spent fuel and disposing of the waste generated, minus the value of the uranium recovered from reprocessing the spent fuel. Table D.12 summarizes the content of spent fuel from the improved LWR fuel cycle. This is the fuel assumed reprocessed to accumulate the plutonium for the initial FBR inventory. 
TABLE D.12. Composition of LWR Spent Fue 1 Discharge

from the Improved LWR Per $\mathrm{kg}$ Heavy Metal

Charged

\begin{tabular}{lr} 
Isotope & grams \\
\hline U-235 & 4.51 \\
U-236 & 7.39 \\
U-238 & 921.89 \\
Pu-239 & 4.60 \\
Pu-740 & 2.68 \\
Pu-241 & 1.51 \\
Pu-242 & 1.04
\end{tabular}

The value of the $933.79 \mathrm{~g}$ of recovered uranium $(0.483 \% \mathrm{U}-235,0.791 \% \mathrm{U}-236)$ is calculated by determining the $\mathrm{U}_{3} \mathrm{O}_{8}$ and separative work it displaces if it is recycled to make $1 \mathrm{~kg}$ of fresh fuel $(4.7 \% \mathrm{U}-235)$ for the improved LWR. At a $0.1 \%$ tails assay these credits are $0.9941 \mathrm{~b} \mathrm{U}_{3} \mathrm{O}_{8}$ and $-0.722 \mathrm{SWU}$, respectively. Therefore, the equation for the value (cost) of the initial plutonium is :

$$
P_{1}(\$ / g)=\frac{R_{1}-(0.944 U-0.722 E)}{9.83 g}=0.102 R_{1}-0.096 U+0.073 E
$$

where

$$
\begin{aligned}
R_{1}= & \text { LWR spent fue } 1 \text { transportation, reprocessing, and waste management } \\
& \operatorname{cost}(\$ / \mathrm{kg}) \\
U= & U_{3} 0_{8} \cos t(\$ / 1 \mathrm{~b}) \\
E= & \text { enrichment cost }(\$ / \mathrm{kg})
\end{aligned}
$$

Subsequent plutonium purchases and credits are valued using the indifference value for recycling plutonium in an LWR. Valuing plutonium in this manner simulates the competition for plutonium between the LWR and FBR, since the FBR operator will have to pay at least what it is worth to the LWR operator once fuel recycle is an established practice. The Final Generic Environmental 
Impact Statement on the Use of Recycle Plutonium in Mixed Oxide Fuel in Light Water Cooled Reactors (NRC 1976) employed the equation shown below to express this indifference value:

Pu Value $(\$ / g$ fissile $)=$ Value $93 \%$ enriched uranium

$$
\begin{aligned}
& x\left[0.85-1.6\left(\frac{242 \mathrm{Pu}}{239 \mathrm{Pu}+{ }^{241} \mathrm{Pu}}\right)\right] \\
& -\frac{\text { Pu fabrication penalty, } \$ / \mathrm{kg} \mathrm{M0} x}{\text { g fissile/kg M0 } \mathrm{x}}
\end{aligned}
$$

Assuming $0.1 \%$ tails assay, the plutonium isotopic content of LWR spent fue 1 shown in Table D.12, the fabrication costs discussed in Appendix E, and $27.7 \mathrm{~g}$ fissile plutonium/kg MO ${ }_{x}$ fuel (HEDL 1979) yields the equation:

$$
\begin{aligned}
\text { Pu Value }(\$ / g \text { fissile }) & =0.2691 U+0.2063 E-\$ 9.16 \\
\text { Pu Value }(\$ / g) & =0.1673 U+0.1282 E-\$ 5.69
\end{aligned}
$$

Combining these assumptions for plutonium value with the previously developed equation for fuel cycle cost results in the equation:

$$
\begin{aligned}
& \text { Levelized FBR Fuel Cycle Cost }=0.0034 \mathrm{~F}_{1}+0.0031 \mathrm{~F}_{2}+0.0047 \mathrm{R}+0.0201 \mathrm{R}_{1} \\
& \text { (mills/kWh) } \\
& -0.0012 \mathrm{E}-0.69-0.0190 \mathrm{U}_{1}-0.0012 \mathrm{U}_{2} \\
& -0.0017 U_{3}-0.0015 U_{4}-0.0013 U_{5}-0.0011 U_{6} \\
& -0.0136 \mathrm{U}_{7}
\end{aligned}
$$

where

$$
\begin{aligned}
F_{1}= & F B R \text { blanket fabrication cost }(\$ / \mathrm{kg}) \\
F_{2}= & F B R \text { core fabrication cost }+ \text { cost of }\left(U_{1}, P u\right) 0_{2} \text { transportation } \\
& (\$ / \mathrm{kg}) \\
R= & F B R \text { spent fuel transportation, reprocessing and waste } \\
& \text { management cost }(\$ / \mathrm{kg})
\end{aligned}
$$




$$
\begin{aligned}
& R_{1}= \text { LWR spent fue } 1 \text { transportation, reprocessing and waste } \\
& \text { management costs }(\$ / \mathrm{kg}) \\
& E= \text { LWR fuel enrichment cost }(\$ / \mathrm{SWU}) \\
& U_{1} \ldots U_{7}=U_{3} O_{8} \text { cost at } 5 \text {-yr intervals }\left(\$ / 1 \mathrm{~b} U_{3} \mathrm{O}_{8}\right)
\end{aligned}
$$

Substituting the fuel cycle cost data from Appendix $D$ and enrichment cost of $\$ 100 /$ SWU gives:

$$
\begin{aligned}
\mathrm{F}_{1} & =\$ 145 / \mathrm{kg} \\
\mathrm{F}_{2} & =\$ 620 / \mathrm{kg} \\
\mathrm{R} & =\$ 419-\$ 526 / \mathrm{kg} \\
\mathrm{R}_{1} & =250-375 / \mathrm{kg} \\
\mathrm{E} & =100 / \text { SWU }
\end{aligned}
$$

and

Levelized FBR Fuel Cycle Cost $=9.291$ to $12.307-0.0190 \mathrm{U}_{1}-0.0012 \mathrm{U}_{2}$

$$
\begin{aligned}
(\mathrm{mills} / \mathrm{kWh}) \quad & -0.0017 \mathrm{U}_{3}-0.0015 \mathrm{U}_{5}-0.0013 \mathrm{U}_{5}-0.0011 \mathrm{U}_{6} \\
& -0.0136 \mathrm{U}_{7}
\end{aligned}
$$

To evaluate the economic introduction date for the FBR when the LWR is employing a throwaway fue 1 cycle, $R$ is reduced by $\$ 91 / \mathrm{Kg}$. This corresponds to a credit of $1.82 \mathrm{mills} / \mathrm{kWh}$ for the cost savings for not disposing of LWR spent fue 1 . 


\section{REFERENCES}

Boegel, A. J. and M. J. Clausen. 1981. Characterization of Alternative FBR Deve lopment Strategies. PNL-3596, Pacific Northwest Laboratory, Richland, Washington.

Hanford Engineering Development Laboratory (HEDL). 1979. "Gas Cooled and Liquid Metal Fast Breeder Reactor Systems." Fuel Cycle Data Base. TC-1552, Vo 1. 5, Book 6. Prepared for U.S. DOE by Westinghouse Hanford Co., Richland, Washington.

Jenquin, U. P. and D. F. Newman. 1979. The Dependence of LMFBR Fue 1 Requirements on Plutonium Isotopic Composition. PNL-3255, Pacific Northwest Laboratory, Richland, Washington.

Matzie, R. A., ed. 1980. Uranium Resource Utilization Improvements in the Once-Through PWR Fuel cycle. CEND-380, prepared by Combustion Engineering, Inc. NationaT Technical Information Service, Springfield, Virginia.

U.S. Department of Energy (DOE). 1980. Reactor and Fuel Cycle Descriptions. Volume 9 of Nuclear Proliferation and Civilian Nuclear Power. Report of the Nonproliferation Alternative Systems Assessment Program. DOE/NE000179 , U.S. Government Printing Office, Washington, D.C.

U.S. Nuclear Regulatory Commission (NRC). 1976. Final Generic Environmental Statement on the Use of Recycle Plutonium in Mixed Oxide Fuel in Light Water Cooled Reactors. NUREG-0002, National Technical Information Service, Springfield, Virginia. 
APPENDIX E

FUEL CYCLE COSTS 


\section{APPENDIX E}

\section{FUEL CYCLE COSTS}

The cost of LWR and FBR energy depends on the cost of fuel cycle services. The costs of these services have been calculated using data developed by the Department of Energy's Alternative Fuel Cycle Assessment Program (AFCEP). These data were developed as input to the Nonproliferation Alternative Systems Assessment Program (NASAP). Tables E.1 and E.2 show the cost data from the AFCEP Fuel Cycle Data Base (HEDL 1979) for those fuel cycle activities relevant to LWR and FBR fuel cycle costs. Costs from that reference have been inflated from 1978 to 1980 do 11 ars using a rate of $10 \%$ /year.

TABLE E.1. Fue 1 Cycle Facility Cost Data

\begin{tabular}{|c|c|c|c|c|}
\hline & \multicolumn{2}{|c|}{ Capital Costs $\left(10^{6} \$\right)$} & \multicolumn{2}{|c|}{ Operating Costs $\left(10^{6} \$\right) / \mathrm{yr}$} \\
\hline LWR Spent Fuel Repository & 595 & 65 & 33 & 26 \\
\hline $\begin{array}{l}\text { LWR Reprocessing } \\
(1500 \mathrm{MT} / \mathrm{yr})\end{array}$ & $581-1016$ & $387-678$ & $29-44$ & $19-29$ \\
\hline LWR Waste Repository & 597 & 68 & 33 & 44 \\
\hline $\begin{array}{l}\text { FBR Reprocessing } \\
(1500 \mathrm{MT} / \mathrm{yr})\end{array}$ & $799-1162$ & $532-774$ & $36-51$ & $24-34$ \\
\hline FBR Waste Repository & 560 & 115 & 36 & 99 \\
\hline $\begin{array}{l}\text { FBR Core and Axial Blanke } \\
\text { Fabrication ( } 480 \mathrm{MT} / \mathrm{yr})\end{array}$ & 411 & 278 & 30 & 81 \\
\hline $\begin{array}{c}\text { FBR Blanket Fabrica- } \\
\text { tion }(520 \mathrm{MT} / \mathrm{yr})\end{array}$ & 27 & 36 & 16 & 33 \\
\hline $\begin{array}{l}\text { LWR MO } x \text { Fabrication } \\
(480 \mathrm{MT} / \mathrm{yr})\end{array}$ & 254 & 254 & 30 & 34 \\
\hline $\begin{array}{l}\text { LWR } \mathrm{UO}_{2} \text { Fabrication } \\
(520 \mathrm{MT} / \mathrm{yr})\end{array}$ & 38 & 41 & 18 & 28 \\
\hline
\end{tabular}


TABLE E.2. Fuel Transportation Costs

$\begin{array}{ll}\text { LWR Spent Fuel } & \$ 26 / \mathrm{kg} \\ \text { FBR Spent Fuel } & \$ 95 / \mathrm{kg} \\ \text { (U,Pu } \mathrm{O}_{2} & \$ 21 / \mathrm{kg} \text { reprocessed }\end{array}$

\section{E.1 COMMERCIAL FUEL CYCLE SERVICES}

Reprocessing and fabrication are assumed to be commercial services. Waste management is a government service. The assumptions used to calculate unit costs from the data in Table E.1 are shown in Table E.3. The return on equity and interest assumptions for industry are discussed in detail in Appendix F. The cost of capital to the government was assumed to be $2 \%$, which corresponds to the interest rate used for the commercial fuel cycle services. This is an upper limit, since the cost of borrowing money is typically less for the government than for industry.

The basic method for computing unit cost was to use a discounted cash flow technique to equate present worth costs and revenues. Implicit in this formulation is the assumption that property taxes and insurance, capital equipment replacement, operating costs, and decommissioning costs are expensed for tax purposes. The formula used is shown below:

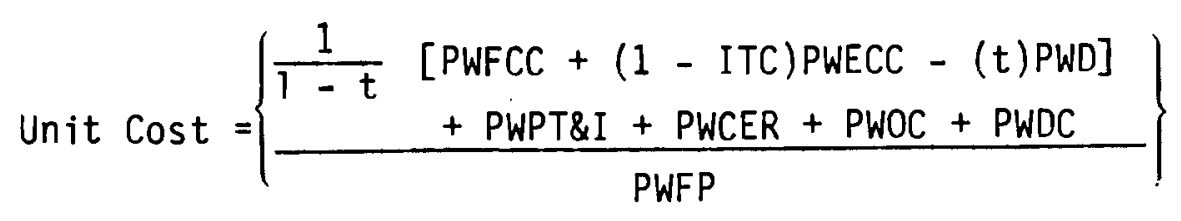

where

$$
\begin{aligned}
t & =\text { tax rate } \\
P W & =\text { present worth } \\
\text { PWFCC } & =\text { facility capital cost: } \sum_{n=-5}^{0} \frac{f_{n} F}{(1+i)^{n}}
\end{aligned}
$$


TABLE E.3. Parameters Used to Calculate Fuel Cycle Unit Costs

Value

Return on Equity Investment (Industry), \%

Interest on Debt (Industry and Government), \%

2

Debt Fraction (Industry)

Debt Fraction (Government)

Compos ite Tax Rate, \%

Property Tax Rate, \%

Insurance Rate, \%

Investment Tax Credit, \%

7

Inter im Replacement Rate, \%

Plant Operation, \%

- First Year

- Second Year

- Remaining Life

Commercial Operation Period, Years

20

Depreciation Period, Years

Construction Payment Schedule, \%

- First Year

- Second Year

- Third Year

18.2

- Fourth Year

- Fifth Year

- Sixth Year

27.1

1.5

Preoperational Payment Schedule, $\%$ of Operating Cost

- First Year

- Second Year

- Third Year

- Fourth Year

- Fifth Year

- Sixth Year 


$$
\begin{aligned}
i= & \text { after tax weighted cost of capital } \\
= & (1-t) \times \text { debt fraction } \times \text { interest on debt } \\
& +(1-\text { debt fraction }) \times \text { return on equity } \\
f_{n}= & \text { fraction of capital cost in year } n \\
F= & \text { total facility capital cost } \\
\text { ITC = } & \text { investment tax credit }
\end{aligned}
$$

PWECC = equipment capital cost: $\sum_{n=-5}^{0} \frac{f_{n} E}{(1+i)^{n}}$

$E=$ total equipment capital cost

$$
\text { PWD = depreciation: } \sum_{n=1}^{16} \frac{2}{(16)(17)} \frac{(16-n+1)}{(1+i)^{n}}(F+E)
$$

PWPT\&I $=$ property tax and insurance: $\sum_{n=1}^{N} \frac{P(F+E)}{(1+i)^{n}}$

$N=$ facility 1 ife

$P=$ property tax rate + insurance rate

PWCER $=$ capital equipment replacement rate: $\sum_{n=1}^{N} \frac{e E}{(1+i)^{n}}$

e = equipment replacement rate

PWOC = operating cost: $\sum_{n=-5}^{N} \frac{{ }_{n} O P}{(1+i)^{n}}$

$0_{n}=$ fraction of steady state operating cost in year $n$

$O P=$ steady state operating cost

PWDC = decommissioning costs: $\frac{0.1 \cdot(F+E)}{(1+i)^{N+1}}$

PWFP = facility production: $\sum_{n=1}^{N} \frac{t_{n} T P}{(1+i)^{n}}$

$t_{n}=$ fraction of steady state facility throughput in year $n$

$\mathrm{TP}=$ steady state annual throughput 
LWR and FBR fuel reprocessing and FBR core and blanket fabrication are assumed to be commercial fuel cycle services. Using the financial data for fuel cycle industries shown in Table E.1 in the formula presented above gives:

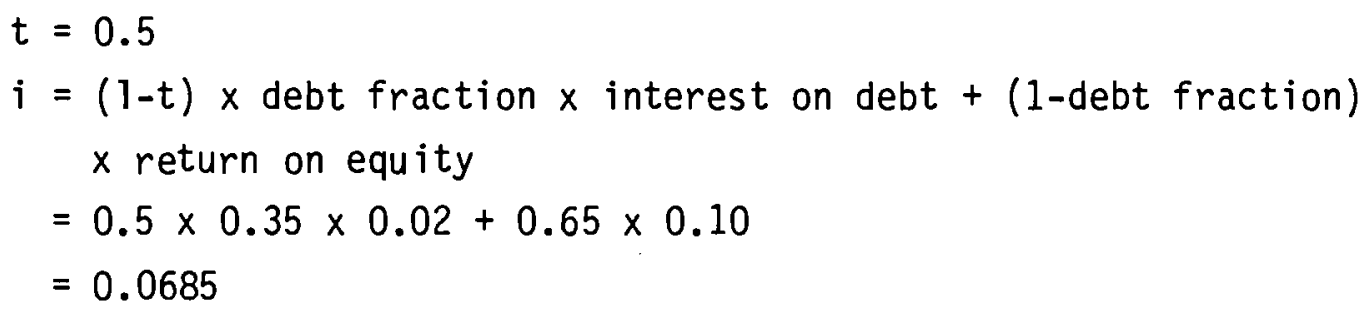

PW facility capital cost $=1.1508 \mathrm{~F}$

$(1-I T C)=0.93$

$\mathrm{PW}$ depreciation $=0.6933(\mathrm{~F}+\mathrm{E})$

$\mathrm{PW}$ property tax and insurance $=0.3216(\mathrm{~F}+\mathrm{E})$

$\mathrm{PW}$ equipment replacement $=0.5359 \mathrm{E}$

$\mathrm{PW}$ operating costs $=12.3325 \mathrm{OP}$

$\mathrm{PW}$ decomissioning costs $=0.0249(\mathrm{~F}+\mathrm{E})$

$\mathrm{PW}$ facility production $=9.8028 \mathrm{TP}$

$$
\begin{aligned}
\text { Unit Cost } & =\frac{\left\{\begin{array}{l}
\frac{1}{0.5}[1.1508 F+(1-0.07) 1.1508 E-(0.5)(0.6933)(F+E)] \\
+0.3216(F+E)+0.5359 E+12.33250 P+0.0249(F+E)
\end{array}\right\}}{9.8028 T P} \\
& =\frac{0.1994 F+0.2376 E+1.2581 O P}{T P}+
\end{aligned}
$$

Applying this formula to the cost data for commercial fuel cycle services shown in Table E.1 gives the fuel cycle service unit costs shown in Table E.4.

The extremes of the ranges shown for LWR and FBR reprocessing were calculated by combining the low capital cost estimates with the low operating cost estimates and the high capital cost estimates with the high operating cost estimates. The AFCEP fuel cycle data base gave no indication of the most likely values within the cost ranges or of any correlation between the capital cost estimate and the operating cost estimate. Therefore, symmetric probability density functions were chosen to represent these ranges, reflecting the intuitive feeling that unit costs near the middle of the range are more likely 
TABLE E.4. Commercial Fuel Cycle Service Unit Costs

Service

LWR Reprocessing

FBR Reprocessing

FBR Core Fabrication

FBR Blanket Fabrication

LWR $\mathrm{UO}_{2}$ Fabrication

LWR MO ${ }_{x}$ Fabrication
Costs $(\$ / \mathrm{kg})$

$179-304$

$241-348$

599

145

145

399

than unit costs at the extremes of the range. Figures E.1 and E.2 show the assumed probability density functions for LWR and FBR reprocessing.

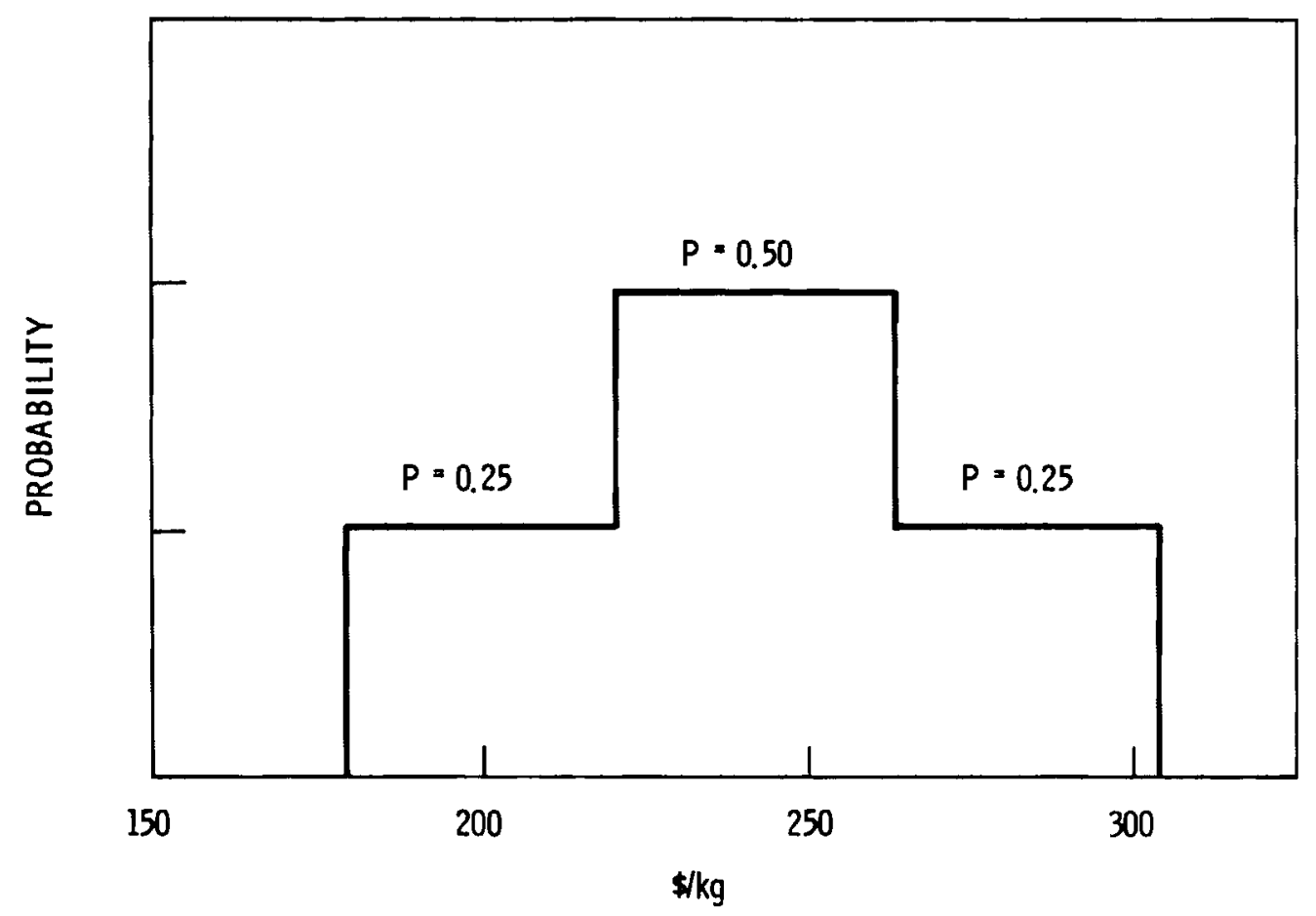

FIGURE E.1. Probability Density Function for LWR Reprocessing 


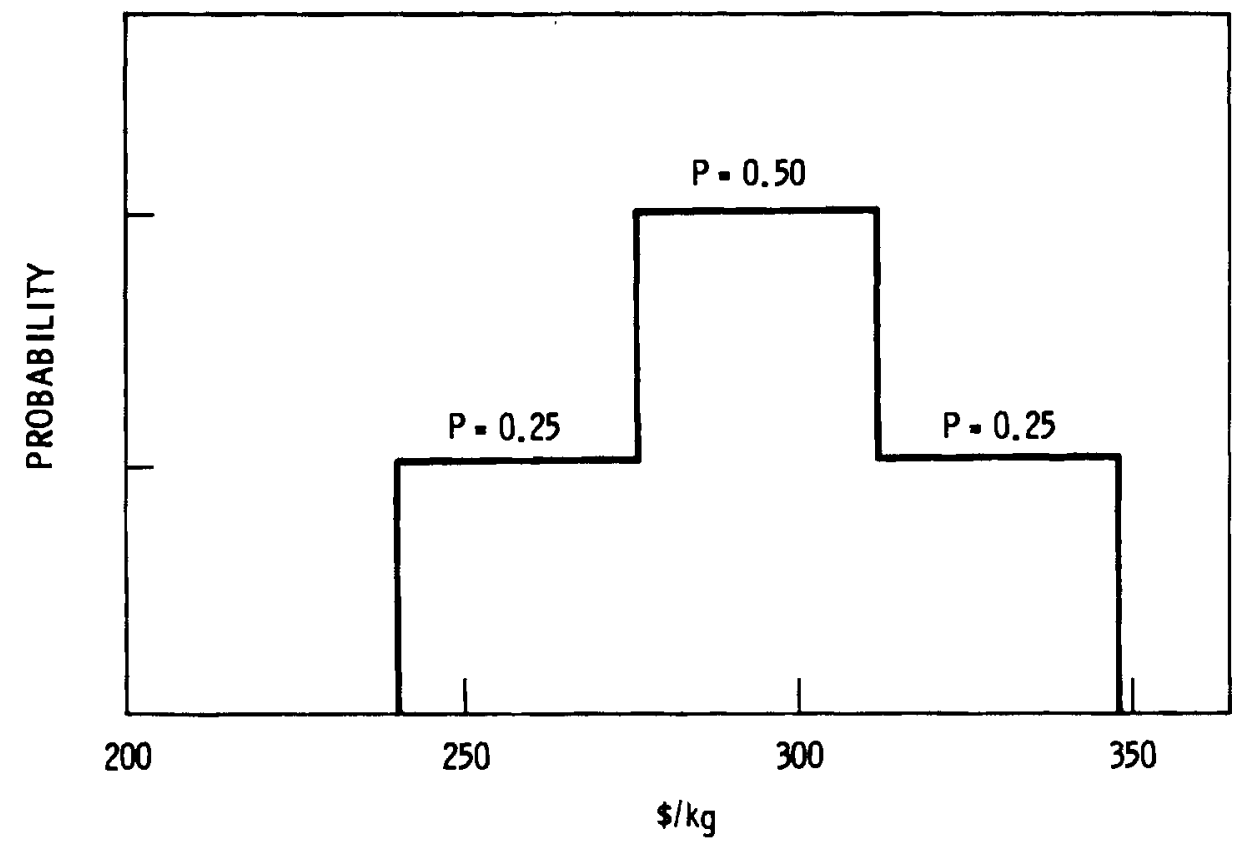

FIGURE E.2. Probability Density Function for FBR Reprocessing

\section{E.2 GOVERNMENT FUEL CYCLE SERVICES}

Disposal of recycle wastes from the LWR and FBR fuel cycles and disposal of LWR spent fuel are assumed to occur at a government-operated repository. The AFCEP data used for repository cost estimates are shown in Table E.1. The lifetimes assumed in the data base for these repositories differ depending on the repository area required per year for disposing of the wastes from 100 1000-MWe reactors. These data are summarized in Table E.5. 
TABLE E.5. AFCEP Repository Data

Data

Repository Storage Area, hectares

Fuel Changed/100 1000-MWe LWRs (Throwaway)

a $75 \%$ Capacity Factor, MTHM

Spent Fue 1 Repository Storage Area/100

1000-MWe LWRs (Throwaway), hectares

d 75\% Capacity Factor

Repository Lifetime (LWR throwaway fuel cycle), years

Fuel Charged/100 1000-MWe LWRs (Recycle), MTHM

a 75\% Capacity Factor

Recycle Waste Repository Storage Area/100 1000-MWe LWRs, hectares

(a 75\% Capacity Factor

Repository Lifetime (LWR Recycle Fuel Cycle), years

Fuel Charged/100 1000-MWe FBRs, MTHM o $75 \%$ Capacity Factor

Repository Area/100 1000-MWe FBRs, hectares (a) 75\% Capacity Factor

Repository Lifetime (FBR Fuel Cycle), years
Value

670

1613.0

26.7

25

2686.4

28

2803.4

57.8

12 
The unit cost equation was solved using the parameters appropriate for a government operated facility:

$$
\begin{aligned}
& t=0.0 \\
& i=0.02 \\
& 1-I T C=1.0
\end{aligned}
$$

$\mathrm{PW}$ facility capital cost $=1.0424 \mathrm{~F}$

$\mathrm{PW}$ equipment capital cost $=1.0424 \mathrm{E}$

PW depreciation $=0.0$

PW property tax + insurance $=0.0$

PW equipment replacement (LWR Throwaway) $=0.9762 \mathrm{E}$

PW equipment replacement (LWR Recycle) $=1.0641 \mathrm{E}$

$\mathrm{PW}$ equipment replacement $(\mathrm{FBR})=0.5288 \mathrm{E}$

PW operating costs (LWR Throwaway) $=21.0193$ OP

$\mathrm{PW}$ operating costs (LWR Recycle) $=22.7771 \mathrm{OP}$

$\mathrm{PW}$ operating costs $(\mathrm{FBR})=12.0712$ OP

$\mathrm{PW}$ decommissioning costs (LWR-Throwaway) $=0.0598(\mathrm{~F}+\mathrm{E})$

$\mathrm{PW}$ decommissioning costs $(\mathrm{LWR})=0.0563(\mathrm{~F}+\mathrm{E})$

PW decommissioning costs $(F B R)=0.0773(F+E)$

PW repository throughput (LWR Throwaway) $=19.5235 \mathrm{TP}$

PW repository throughput (LWR Recycle) $=21.2813 \mathrm{TP}$

$\mathrm{PW}$ repository throughput $(\mathrm{FBR})=10.5753 \mathrm{TP}$

LWR Recycle Repository Unit Cost $=\frac{1.0987 F+2.1628 E+22.7771 \text { OP }}{21.2813 \mathrm{TP}}$

$$
=\frac{0.0516 F+0.1016 E+1.07030 P}{T P}
$$

$$
\begin{aligned}
\text { FBR Repository Unit Cost } & =\frac{1.1197 \mathrm{~F}+1.6485 \mathrm{E}+12.07120 \mathrm{P}}{10.5753 \mathrm{TP}} \\
& =\frac{0.1059 \mathrm{~F}+0.1559 \mathrm{E}+1.14150 \mathrm{P}}{\mathrm{TP}}
\end{aligned}
$$

LWR Throwaway Repository Unit Cost $=\frac{1.1022 \mathrm{~F}+2.0784 \mathrm{E}+21.0784 \mathrm{OP}}{19.5235 \mathrm{TP}}$

$$
=\frac{0.0565 F+0.1065 E+1.07960 P}{T P}
$$


Substituting the cost data from Table E.1 and the annual throughput data from Table E.4 into these equations gives waste management unit costs of $\$ 65 / \mathrm{kg}$ LWR spent fuel disposal, $\$ 45 / \mathrm{kg}$ LWR fuel for LWR recycle waste disposal and $\$ 83 / \mathrm{kg} F B R$ fuel for $F B R$ waste disposal.

\section{REFERENCES}

Hanford Engineering Development Laboratory (HEDL). 1979. "Gas Cooled and Liquid Metal Fast Breeder Reactor Systems." Fuel Cycle Data Base. TC-1552, Vol. 5, Book 6. Prepared for U.S. DOE by Westinghouse Hanford Co., Richland, Washington. 


\section{APPENDIX $F$}

FINANCIAL ASSUMPTIONS 
APPENDIX F

FINANCIAL ASSUMPTIONS

The estimated cost of power from future LWRs and FBRs is determined by the capital structure of the operating utility. Financial assumptions for the utility must be consistent with the assumptions made in projecting the future costs of uranium and fuel cycle services, since both sets of assumptions will exist in the same financial environment. Table F.l shows the financial assumptions used to characterize utilities, fuel cycle industries such as reprocessors and refabricators, and uranium mining companies. The values on the table represent constant dollar returns and interest rates. The effects of inflation have been removed to provide a set of parameters appropriate for a constant dollar comparison of future power costs.

TABLE F.1. Financial Assumptions, \%

$$
\text { Utility Fuel Cycle Industry Uranium Industry }
$$

Return on Equity

Capital

6.0

10.0

10.0

Interest Rate on Debt

2.0

2.0

Debt/Equity Ratio

$55 / 45$

$35 / 65$

$35 / 65$

Although no set of financial parameters can be selected as uniquely correct for an analysis of this sort, the values in Table F.I were found to be internally consistent and within the general range usually considered for each parameter. These parameters represent a synthes is of the values est imated using two approaches. The first approach yielded estimates based on historical data for interest rates and return on equity, adjusted to reflect the differences in financial risk for utilities, fuel cycle industries, and the uranium industry. The second approach compared values used in other analyses of similar nature. The results of the two approaches and the rationale for the parameter values selected for Table F.I are discussed below. 


\section{F.1 HISTORICAL DATA FOR INTEREST ON DEBT AND RETURN ON EQUITY CAPITAL}

Power costs can be compared in terms of either constant dollars (no inflation) or current dollars (inflation included). A current dollar analys is requires forecasting inflation to determine future fuel cycle costs and operating and maintenance costs. Since this is impractical for the extended time period of this study, we have chosen a constant dollar analysis. A recent economic assessment of alternative power generating technologies noted that, "if a study is being performed without inflation for fuel and O\&M costs, the costs of capital and other components of the fixed charge rate must be reduced by the inflation component in order to have all costs on a consistent basis" (EPRI 1979). The interest rate and return on equity assumptions for this analysis do not include the effects of inflation.

Interest rates and the return on equity capital are related to the general economic conditions and can be derived by a comparison and evaluation of financial risk incurred by the purchasers of stocks and bonds. A recent publication by the Financial Analysts Research Foundation (Ibbotson and Sinquefield 1979) expressed the components of returns to stock and bond investments (excluding inflation) as:

$$
\text { Real Bond Return } \quad \begin{aligned}
= & \text { Real Riskless Rate of Return } \\
& + \text { Bond Maturity Premiums } \\
& + \text { Bond Default Premiums }
\end{aligned}
$$

Real Common Stock Return $=$ Real Riskless Rate of Return + Equity Risk Premium

The same publication examined before-tax rates of return (yields) for stocks, corporate bonds, long term government bonds and short-term government bonds for the period 1926-1978 to determine values for the parameters in the above equations. The calculated values of the parameters were:

$$
\begin{array}{ll}
\text { Real Riskless Rate of Return } & =0.0 \% \\
\text { Bond Maturity Premium } & =0.7 \% \\
\text { Bond Default Premium } & =0.6 \% \\
\text { Equity Risk Premium } & =6.2 \%
\end{array}
$$


Using the derived values in the above equation gives:

$\begin{array}{ll}\text { Real Bond Return } & =1.3 \% \\ \text { Real Common Stock Returns } & =6.2 \%\end{array}$

These values represent the historical yield on the average corporate bond and the average common stock. Deriving the appropriate financial parameters for this analysis requires determining the relationship between utilities, fuel cycle industries, uranium mining industries, and the "average" issuers of corporate bonds or common stock. The financial parameters for the utility, fuel cycle, and uranium industries may differ from the market average because of differences in the financial risk of investing in these industries. In terms of the equations shown for real bond return and real common stock return, differences in the financial risk for these industries would result in differences in the bond default premium and the equity risk premium.

To determine the relationship between the yield on light, power, and gas utility bonds and domestic corporate bonds (Baa or higher), historical data from Moody's Investor Service (1979) were examined. The differences between the corporate and utility bond yields from 1926 to 1978 were averaged. This period was selected for consistency with the previously discussed market average bond yield data. The mean value for the difference in yields for that period was $0.017 \%$ (corporate bond yield exceeding utility bond yield), with a standard deviation of $0.160 \%$. Therefore, for this analysis, the yield on corporate and utility bonds can be considered equal. It was also assumed that the representative fuel cycle company and uranium mining company would have the same bond rating and, therefore, the same bond yield.

The relationship between the market average return or equity returns for utilities, fuel cycle industries, and uranium mining industries is somewhat more difficult to assess, since the relative financial risk of investing in these stocks is not obvious. One common way of expressing the relationship between risk and return is to employ the Capital Asset Pricing Mode 1 (CAPM) (Weston 1973). The CAPM assumes a perfect market. Within this approximation it is useful in predicting returns. This model expresses the relationship between return on equity and risk as: 
Real Return on Equity = Risk Free Rate of Return

$+\beta$ (Average Market Return - Risk Free

Rate of Return).

Beta $(\beta)$ in the equation is a measure of the volatility of the individual security returns relative to the average stock market return. Values of beta are not particularly time-dependent, as long as the economic environment is stable.

Beta values for individual companies can be found in the Value Line Investment Survey (Arnold Bernhard and Co. 1980), an investment service that provides financial information for most publicly traded companies. The beta values for 102 electrical utilities listed in the survey ranged from 0.5 to 0.85 , and averaged 0.65 . Basic chemical companies were assumed representative of the type of companies that would perform fuel cycle services. Beta values for 20 companies in this category ranged from 0.90 to 1.25 , and averaged 1.06. Beta values for nine coal, uranium and geothermal companies ranged from 0.65 to 1.25, and averaged 1.05. Using these values with the before-tax, real, risk-free rate of return $(0.0 \%)$ and real average market return (6.2\%) previously discussed in the CAPM equation leads to the results shown in Table F.2. The real interest rate on debt is assumed to be equal to the historical average bond return previously discussed (1.3\%) for utilities, fuel cycle industries, and uranium mining industries.

TABLE F.2. Estimated Financial Parameters (\%)

Real Rate

of Return on

Equity Capital

Range Average

Real Interest Rate on Debt

Utility

$3.1-5.3$

4.0

1.3

Fuel Cycle Industry

$5.6-7.8$

6.6

1.3

Uranium Industry

4.0-7.8

6.5

1.3 


\section{F.2 FINANCIAL PARAMETERS USED IN OTHER ANALYSES}

Tables F.3 and F.4 show the values of the financial parameters that have been used in other studies of this nature. In some cases, the financial parameters were reported based on a specified level of inflation. The formula below was used to calculate the equivalent interest rate with inflation removed (Higgins 1977).

$$
\text { Real Interest Cost }=\left(\frac{\text { Interest Rate with Inflation }+1}{\text { Inflation Rate }+1}\right)-1
$$

The EPRI analysis (1979) recomended utility financial parameters of $8 \%$ interest on debt and $13.5 \%$ return on equity. The report stated that these were consistent with a $6 \%$ inflation rate. Using the above formula to correct these financial parameters gives the values shown in Table F.3. Another study, Breeder Reactor Economics (Stauffer et al. 1975), reported the real interest on debt and return on equity. The financial values used for that parameter study are also shown in Table F.3.

TABLE F.3. Utility Financial Parameters Used in Other Analyses (\%)

\begin{tabular}{llc} 
& $\begin{array}{l}\text { Interest } \\
\text { on Debt }\end{array}$ & $\begin{array}{c}\text { Return on } \\
\text { Equity }\end{array}$ \\
\cline { 2 - 3 } EPRI & 1.9 & 7.1 \\
Breeder Reactor Economics & 2.75 & 5.5
\end{tabular}

The analyses reported by the Nonproliferation Alternative Systems Assessment Program (DOE 1980) used the financial parameters shown in Table F.4. The utility parameters were reported both with and without a $5.5 \%$ inflation rate. However, only financial parameters including inflation were reported for fuel cycle industries. These were corrected in the manner previously discussed, assuming that the $5.5 \%$ inflation rate discussed for the utility financial parameters was also applicable to the industry financial parameters. 
TABLE F.4. NASAP Financial Parameters (\%) Interest on Debt Return on Equity

$\begin{array}{lll}\text { Utility } & 2.5 & 7.0 \\ \text { Industry } & 2.7 & 8.1\end{array}$

Those studies also assume a debt equity ratio for utility financing to calculate the average cost of utility capital. The debt equity assumption used in each study is shown in Table F.5, along with the average debt equity ratios from value line (Arnold Bernhard and Co. 1980) for the 20 basic chemical companies assumed representative of fuel cycle industries and the nine coal, uranium and geothermal companies.

TABLE F.5. Debt/Equity Ratio Assumptions (\%)

$\begin{array}{lccc}\text { Value Line } & \text { Utility } & \begin{array}{c}\text { Fuel Cycle } \\ \text { Industry }\end{array} & \begin{array}{c}\text { Uranium } \\ \text { Industry }\end{array} \\ \text { EPRI } & -- & 34 / 66 & 33 / 67 \\ \begin{array}{l}\text { Breeder Reactor } \\ \text { Economics }\end{array} & 50 / 50 & -- & -- \\ \text { NASAP } & 55 / 45 & -- & -- \\ \text { N } & 55 / 45 & 35 / 65 & --\end{array}$

\section{F.3 SELECTED FINANCIAL PARAMETERS}

Historical data indicate that the real bond interest rate has been $1.3 \%$, and that the interest on corporate and utility bonds is approximately equal. Similar analyses have used real interest rates ranging from $1.9 \%$ to $2.7 \%$. A value of $2 \%$ was selected for this analysis. This is in the lower end of the range of values used in other analyses, but slightly higher than the historical yield on bonds.

Table F.2 shows estimated returns on equity for utilities, fuel cycle industries and the uranium industry based on historical data adjusted for the relative financial risk of those investments. These estimates show a range of 
$3.1 \%$ to $5.3 \%$ for real return on utility equity, and $4.0 \%$ to $7.8 \%$ for real return on equity for fuel cycle and uranium industries. Other similar studies have used a range of real return on utility equity of $5.5 \%$ to $7.1 \%$ and a fue 1 cycle industry return on equity of $8.1 \%$.

These ranges represent returns for typical utility or industry investments. However, for utilities building a nuclear power plant or companies engaged in fuel cycle services or uranium mining, the risk inherent in a new project (LWR, FBR, reprocessing plant, refabrication plant, uranium mine, etc.) can be considered greater than the industry or company average because of higher degrees of uncertainty prevailing in the market and in the regulatory environment. Therefore, the return on equity required for projects of this type would be greater than the company or industry average, in order to compensate investors for the increased risk. Appropriate rates of return for these projects would be in the high end of the range of company averages, or perhaps above the ranges. In terms of the Capital Asset Pricing Model, this just means that the beta for a project of this type is greater than the overall beta for a particular company. Assessing individual projects within a company at a higher or lower discount rate (cost of capital) to reflect differences in their relative $r i s k$ is a standard technique of financial analysis (Higgins 1977). The values selected for returns on equity in Table F.1 reflect the greater risk of these activities relative to the industry average risks (and returns) portrayed in Table F.2. The selected value for return on utility equity is slightly higher (less than 1\%) than the historical range. The $10 \%$ return on equity selected to characterize the fuel cycle and uranium mining industry is approximate $1 y 2 \%$ higher than the historical range of typical returns for these types of companies. The larger estimated increase above the historical range of returns on equity for fuel cycle and uranium industries reflects the greater financial risk of those activities. 


\section{REFERENCES}

Arnold Bernhard Co., Inc. 1980. Value Line Investment Survey. New York.

Electric Power Research Institute (EPRI). 1979. Technical Assessment Guide. EPRI PS-1201-SR, pp. 3-14. Electric Power Research Institute, Palo Alto, California.

Higgins, R. C. 1977. Financial Management, Theory and Applications, Science Research Associated, Inc. Chicago, Illinois.

Ibbotson, R. G. and R. A. Sinquefield. 1979. Stocks, Bonds, Bills, and Inflation: Historical Returns (1926 to 1978). Financial Analysts Research Foundation, Char lottesville, Virginia.

Moody's Investor Service. 1979. Moody Public Utility Manual. New York.

Stauffer, T. R., R. S. Palmer, and H. L. Wyckoff. 1975. Breeder Reactor Economics. Prepared for Breeder Reactor Corporation by General Electric Co., Sunnyvale, California.

Weston, J. F. 1973. "Investment Decisions Using the Capital Asset Pricing Mode l," Financial Management Jour.

U.S. Department of Energy (DOE). 1980. Reactor and Fuel Cycle Descriptions. Volume 9 of Nuclear Proliferation and Civilian Nuclear Power. Report of the Nonprol iferation Alternative Systems Assessment Program. DOE/NE- 0001/9, U.S. Government Printing Office, Washington, D.C. 


\section{DISTRIBUTION}

No. of

Copies

OFFSITE

A. A. Churm

DOE Patent Division

9800 South Cass Avenue

Argonne, IL 60439

Gary Boyer

United Nuclear Homestake

P.0. Box 98

Grants, NM 87020

E. M. Craig

Dawn Mining Co.

P.0. Box 25

Ford, WA 99013

Simcha Golan

Bechtel National Inc.

Engineers and Constructors

Fifty Beale Street

P.0. Box 3965

San Francisco, CA 94119

Stanley M. Davies

General Electric company

310 Deguigne Drive

P.0. Box 508

Sunnyvale, CA 94086

Tom Hand

Westinghouse Electric Corporation

P.0. Box 158

Madison, PA 15663

Tom DiFrancisco

Burns and Roe, Inc.

496 Kinderkamack Road

Orade 11, NJ 07649
No. of

Copies

John H. Crowley

United Engineers and Constructors

300 South 17 Street

Philadelphia, PA 19101

George Garabedian

Stone and Webster Engineering Corp.

Power Division

245 Summer Street

Boston, MA 02107

Judy Grange

Science Applications, Inc.

40 Denver Tech Center West

7925 E. Prentice

Englewood, CO 80111

Bob Miller

United Nuclear

Drawer QQ

Gallup, NM 87301

Charles Stanley

Kerr McGee

Box 218

Grants, NM 87020

C. L. Storrs

C-E Power Systems

Combustion Engineering, Inc. 1000 Prospect Hill Rd.

Windsor, CT 06095

27 DOE Technical Information Service P. 0. Box 62

Oak Ridge, TN 37830 
No. of

Copies

Noel Gonzaga

S. M. Stoller Corporation

1250 Broadway

New York, NY 10001

10 J. P. Thereault

U.S. Department of Energy

Washington D.C. 20545

W. W. Ballard

U.S. Department of Energy

Washington D.C. 20545

S. T. Brewer

U.S. Department of Energy

Washington D.C. 20545

Hugh Kendrick

U.S. Department of Energy

Washington D.C. 20545

R. G. Staker

U.S. Department of Energy

Washington D.C. 20545

J. R. Longenecker

U.S. Department of Energy

Washington D.C. 20545

John Patterson

U.S. Department of Energy

Washington D.C. 20545

Roger Gagne

U.S. Department of Energy

Washington D.C. 20545

Tom Dillon

U.S. Department of Energy

Washington D.C. 20545

Neal Goldberg

U.S. Department of Energy

Washington D.C. 20545

Richie Williamson

U.S. Department of Energy

Washington D.C. 20545
No. of

Copies

Dave Bodde

U.S. Department of Energy

Washington D.C. 20545

Bob Bown

U.S. Department of Energy

Washington D.C. 20545

Eli Goodman

U.S. Department of Energy Washington D.C. 20545

A. J. Snyder

U.S. Department of Energy

Washington D.C. 20545

Ross Humphreys

U.S. Department of Energy

Washington D.C. 20545

Tom Werner

U.S. Department of Energy

Washington D.C. 20545

D. M. Blanchfield

Grand Junction Office

U.S. Department of Energy

P.0. Box 2567

Grand Junction, CO 81501

B. Boyer

Grand Junction Office

U.S. Department of Energy

P.0. Box 2567

Grand Junction, CO 81501

M. E. Crew

Grand Junction Office

U.S. Department of Energy

P.0. Box 2567

Grand Junction, CO 81501

D. L. Curry

Grand Junction Office

U.S. Department of Energy

P.0. Box 2567

Grand Junction, CO 81501 
No. of

Copies

J. Franco

Grand Junction Office

U.S. Department of Energy

P.0. Box 2567

Grand Junction, CO 81501

P. de Vergi

Grand Junction Office

U.S. Department of Energy

P.0. Box 2567

Grand Junction, CO 81501

D. L. Everhart

Grand Junction Office

U.S. Department of Energy

P.0. Box 2567

Grand Junction, CO 81501

M. Hansen

Grand Junction Office

U.S. Department of Energy

P.0. Box 2567

Grand Junction, CO 81501

R. C. Malan

Grand Junction Office

U.S. Department of Energy

P.0. Box 2567

Grand Junction, CO 81501

L. Kovisars

MET Research

2403 Thomas Avenue

Dallas, TX 75201

R. A. MCLaren

Union Carbide Nuclear Division

P.0. Box P Mail Stop \#17

Oak Ridge, TN 37830

C. E. Ford

Union Carbide Nuclear Division

P.0. Box P Mail Stop \#17

Oak Ridge, TN 37830
No. of

Copies

P. Rogers

Bendix Field Engineering Corporation

Grand Junction Operations

P.0. Box 1569

Grand Junction, CO 81501

Lewis Per 1

National Economic Research

Association

5 Wor ld Trade Center

New York, NY 10048

Martin Becker

Rensselaer Poly Tech

Nuclear Engineering Department

Troy, NY 12181

Prof. Deverle P. Harris

University of Arizona

Department of Mining and Geological

Engineering

Tucson, AZ 85721

Prof. A. S. Manne

834 Esplanada Way

Stanford, Ca 94305

Prof. J. Daniel Khazzoom

380 Kensington Way

San Francisco, CA 94127

Prof. Wayne J. Davis

University of Illinois

Dept. of General Engineering

Urbana, IL 61801

Dr. Lawrence Droutman

Westinghouse Electric Corporation

P.0. Box 158

Madison, PA 15663

Randa 11 L. Beatty

Science Applications, Inc.

800 Oak Ridge Turnpike

P.0. Box 843

Oak Ridge, TN 37830 
No. of

Copies

ONSITE

2 DOE Richland Operations Office

P. A. Craig

H. E. Ransom

70 Pacific Northwest Laboratory

R. L. Aaberg

C. H. Bloomster

A. J. Boegel

J. B. Burnham (20)

L. L. Clark

M. J. Clausen

B. M. Cole

D. E. Deonigi

R. L. Enge 1

R. M. Fle ischman

D. W. Fraley

S. Goldsmith

D. L. Hall

C. R. Hann
No. of

Copies

J. N. Hart ley

H. Harty

A. J. Haverfield

C. M. Heeb

J. C. King

R. C. Liikala

J. W. Lithchfield

J. A. Mahaffey

R. P. Marsha 11

P. J. McGoey

R. W. McKee

E. T. Merr 111

D. F. Newman

R. E. Nightingale

D. E. Olesen

P. F. Piepe 1

R. J. Sorensen

A. M. Sutey

M. K. White (10)

O. J. Wick

L. D. WiTliams

Publishing Coordination (2)

Technical Information (5) KE 